\title{
WestVirginiaUniversity
}

THE RESEARCH REPOSITORY @ WVU

Graduate Theses, Dissertations, and Problem Reports

2011

\section{Protein Surface Characterization Using an Invariant Descriptor}

\author{
Zainab Abu Deeb \\ West Virginia University
}

Follow this and additional works at: https://researchrepository.wvu.edu/etd

\section{Recommended Citation}

Abu Deeb, Zainab, "Protein Surface Characterization Using an Invariant Descriptor" (2011). Graduate Theses, Dissertations, and Problem Reports. 4681.

https://researchrepository.wvu.edu/etd/4681

This Thesis is protected by copyright and/or related rights. It has been brought to you by the The Research Repository @ WVU with permission from the rights-holder(s). You are free to use this Thesis in any way that is permitted by the copyright and related rights legislation that applies to your use. For other uses you must obtain permission from the rights-holder(s) directly, unless additional rights are indicated by a Creative Commons license in the record and/ or on the work itself. This Thesis has been accepted for inclusion in WVU Graduate Theses, Dissertations, and Problem Reports collection by an authorized administrator of The Research Repository @ WVU. For more information, please contact researchrepository@mail.wvu.edu. 


\title{
Protein Surface Characterization Using an Invariant Descriptor
}

\author{
Zainab Abu Deeb \\ Thesis submitted to the \\ College of Engineering and Mineral Resources \\ at West Virginia University \\ in partial fulfillment of the requirements for the degree of \\ Master of Science \\ in \\ Computer Science \\ Donald Adjeroh, Ph.D., Chair \\ Arun Ross, Ph.D. \\ James Mooney, Ph.D. \\ Bojan Cukic, Ph.D. \\ ' HSDW HQRRILRP SXMU6FIHQFHIDQC( GFWFDO Q IQHUD
}

Morgantown, West Virginia

2011

Keywords: Protein; Descriptor; Protein Surface; Invariant; Protein function

Copyright 2011 Zainab Abu Deeb 


\section{Abstract \\ Protein Surface Characterization Using an Invariant Descriptor}

\section{Zainab Abu Deeb}

A novel descriptor to characterize protein surfaces, and hence classify functionally similar proteins into functional families is proposed. The descriptor exploits the protein tertiary structure surface, locally and globally, to identify intra-family proteins. By using only sparse data based on the $\mathrm{C}-\alpha$ atoms on the protein surface, we characterize the surface using different invariant descriptors, namely, distance distributions, residue cooccurrences, and distance-residue co-occurrences between all atoms confined to a particular patch. Using the method, proteins with very low sequence similarity were successfully classified into their functional families with a high degree of accuracy. 


\section{Acknowledgement}

I would like to take this great opportunity to thank all whom have helped me through these two precious years of my life...

To my parents, sisters, and brothers.... Thank you for believing in me and for supporting me during this journey.

Mom, Dad, Fatima, Amal, Areej, Hussain, and Ahmad

This work is for you....

To my Grandma,

You are my reason to keep learning... Thank you so much

To my Advisor Dr.Adjeroh

Thank you for assisting me and inspiring me through my Masters study. Thank you for taking the time to teach and to guide me through the research process.

To my Committee Members:

Dr. Ross, Dr. Mooney, and Dr. Cukic

Thank you for offering me help whenever I needed it. Thank you for your critique of my work.

Dr. Ross and Dr. Mooney, I learned a lot in your courses. Dr. Cukic it would be a pleasure to learn from you in the classroom.

To my colleagues in Lab 1010 ... Marco , Rui and Chao

It was a pleasure to work with you, thank you for your help and support

\section{To SACM}

Thank you for funding me during my studies, I would not be able to write this thesis without your help. Thank you ... 


\section{Table of Contents}

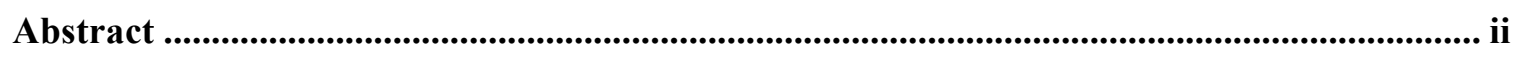

Acknowledgement ...................................................................................................................................... iii

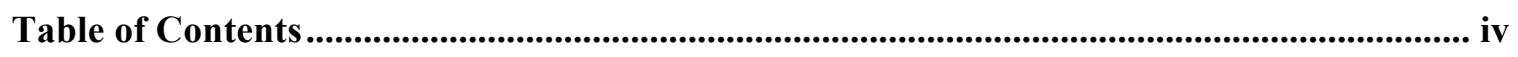

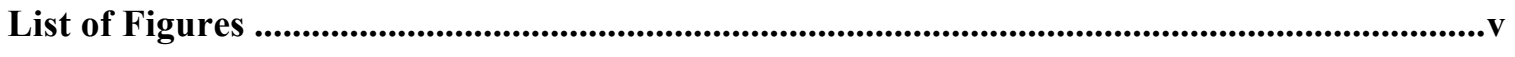

List of Tables ............................................................................................................................................ vi

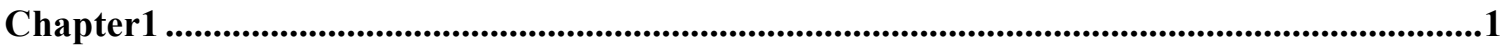

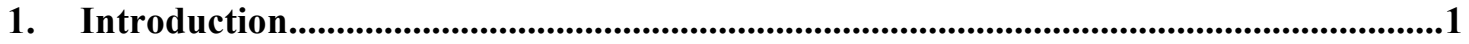

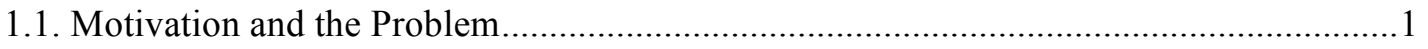

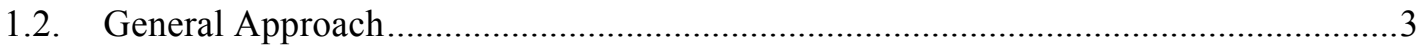

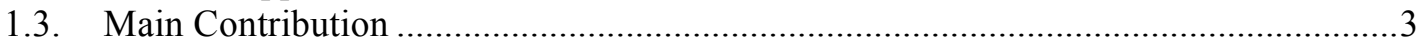

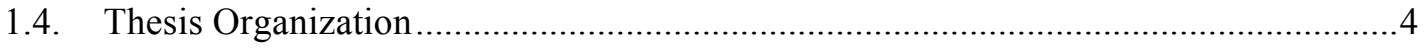

Chapter 2 ...............................................................................................................................................5

2. Background and Related Work............................................................................................5

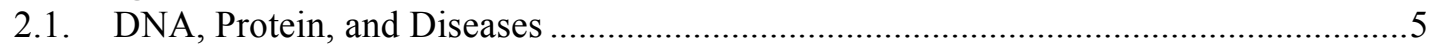

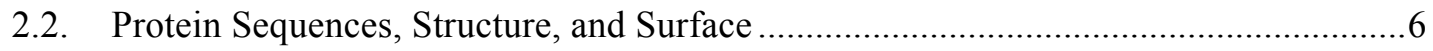

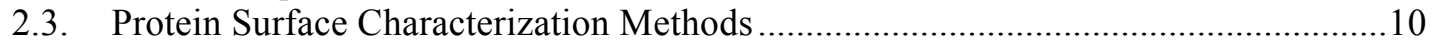

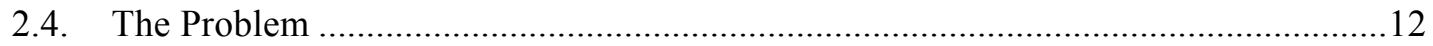

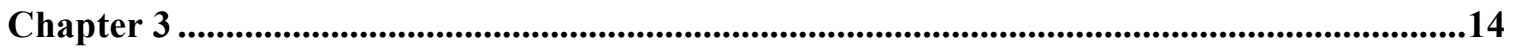

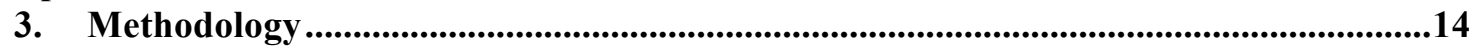

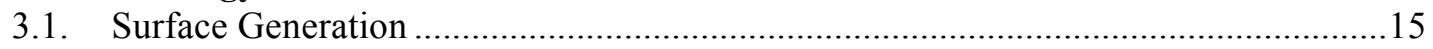

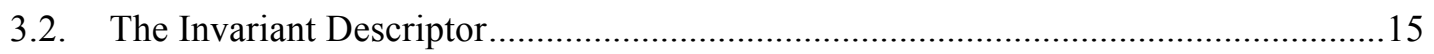

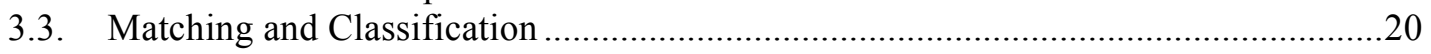

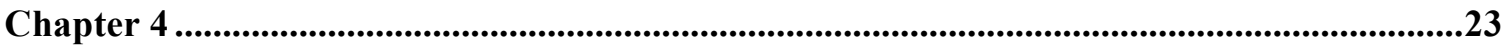

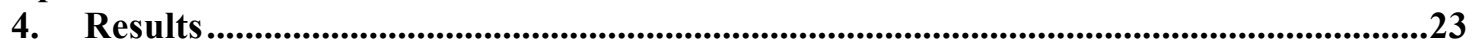

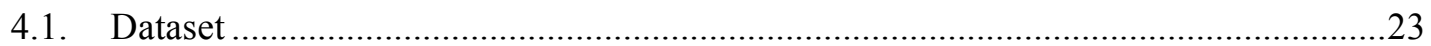

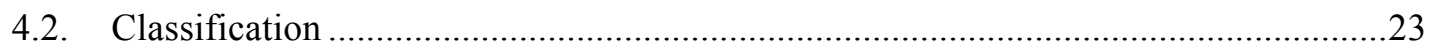

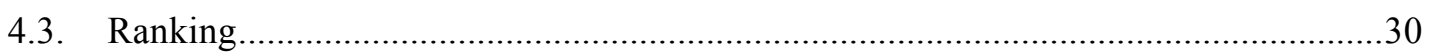

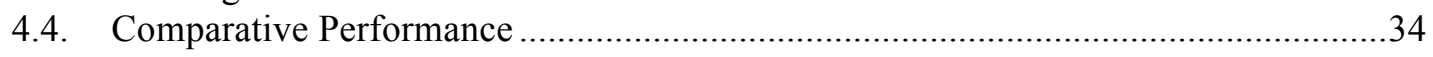

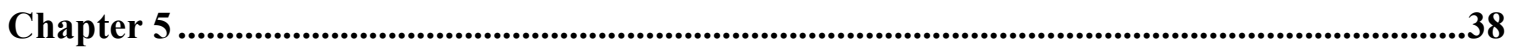

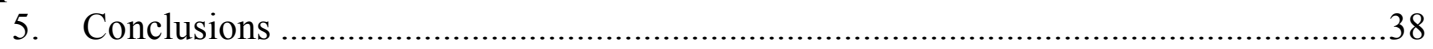

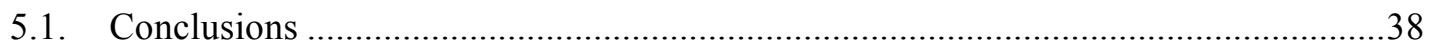

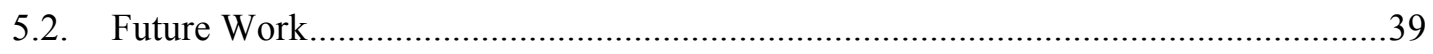

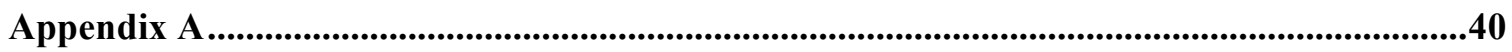

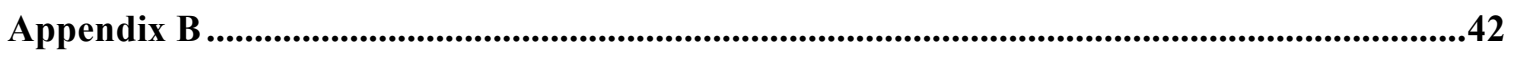

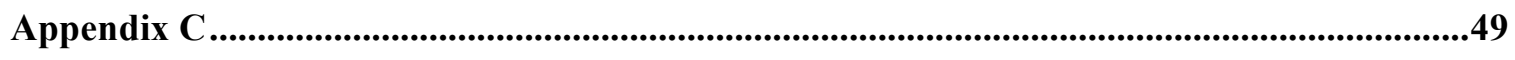

References.........................................................................................................................................................54 


\section{List of Figures}

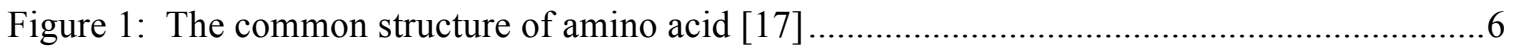

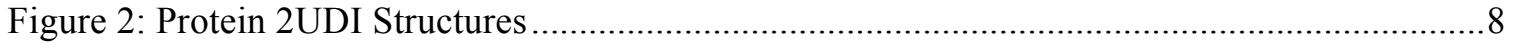

Figure 3: The secondary structure and the Tertiary structures of the sequences provided.............10

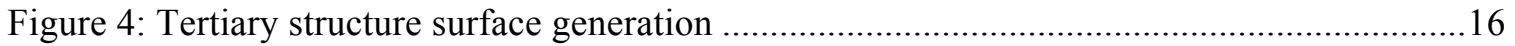

Figure 5: Schematic diagram for the methodology used in creating the local and global

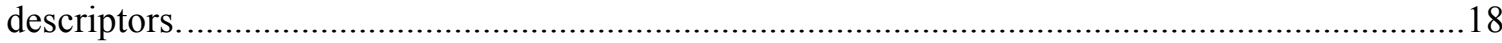

Figure 6: Variation of Classification Rate with size of training set for Naive Bayes, Simple

Logistic, and Logistic Regression on the proposed descriptors produced by DD, RC and DRC ..27

Figure 7: Variation of Classification Rate with size of testing set for Naïve Bayes, Simple

Logistic, and Logistic Regression on the proposed descriptors produced by DD, RC, and DRC .29

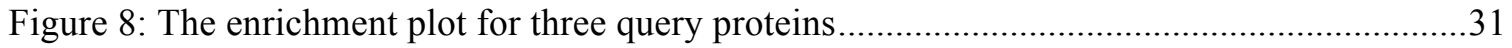

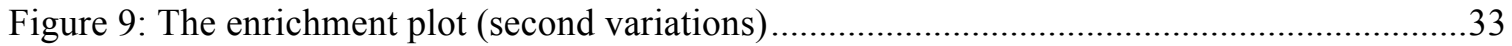

Figure 10: Variation of Classification Rate with size of training set and testing set on DD1 for

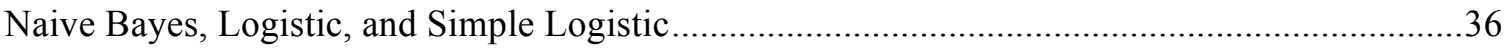

Figure 11: Enrichment plot of DD1, DD2, RC, DRC, and random indicating the retrieval performance of DD1 and the proposed method. 


\section{List of Tables}

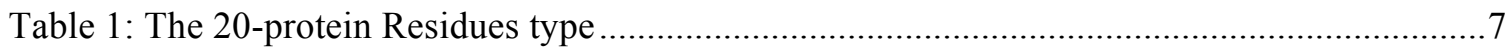

Table 2: Text Representation of the Smith-Waterman Sequence Alignment..................................

Table 3:Detailed information on the dataset used for training and testing ...................................24

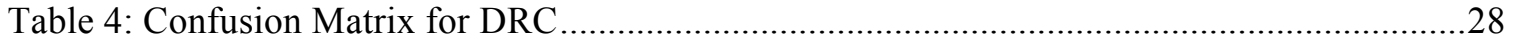

Table 5: Ranking the screened proteins according to their similarity to the query protein.............34

Table 6: Classification Rate on 300 samples training set and 100 samples testing sets.................36 


\section{Chapter1}

\section{Introduction}

The function of a given protein is largely determined by its three-dimensional structure [2]. The specific shape and orientation of proteins in 3D space are key elements that determine how a given protein interacts with its environment, and hence the function of the protein. Although related proteins often have similar functions, it is well known that studying the functional similarity between proteins based only on the amino acid sequences does not always yield expected results [1]. The reason is general sequence and fold similarity do not always translate into protein function similarity [5]. While residues on the protein surface comprise a small percentage of the total residues that make up the protein, they often represent the most conserved functional elements of the protein [4]. Therefore, analyzing protein structures using information about their 3D surfaces is essential in the quest for protein functional annotation, especially in the study of functional similarities between non-homologous proteins.

\subsection{Motivation and the Problem}

There has been a growing interest in predicting protein functions based on their global similarities by comparing protein 3D structures [1]. The capability to extract information regarding protein function from the surface structure is a critical task in the structural genomic era [6]. Indeed, finding similarities between proteins using sequence alignments had received a great attention. The sequence is used to understand the relationship between sequence-structure-function paradigms. The paradigm is used to infer unknown protein functionality from a homologous protein that shares significant sequence similarity. 
Although the one-to-one relationship rule postulates that similar sequence leads to similar structures and finally to similar functionality, this usually does not hold [15]. Some homologous proteins share significantly low sequence similarity and the sequence alignment approaches fail to identify them as homologs. This, problem can be solved using the protein structure which is more conserved over evolution than the sequence. As the number of protein structures with unknown functionality stored in the Protein Data Bank (PDB) increase rapidly, this poses a critical challenge for using the structural information to determine protein functionality.

A major difficulty in comparing protein surfaces locally is the problem of matching 3D structures, since structures need to undergo an exhaustive amount of rotation and translation in order to obtain an adequate structural alignment and to perform an accurate matching [5]. Several algorithms have been proposed to mitigate this problem, for example, Fourier Transform and Spherical Furrier Transform [20, 21]. Nevertheless, these methods are exhaustive and require a heavy computational overhead when it is been applied on large datasets, such as the PDB. The speed of any algorithm is an important factor to consider when implementing a tool to compare protein structures. Therefore, several methods make use of different descriptors to compute the profile of the protein and perform fast comparisons for local matching such as 3D Zernike and Spherical Harmonic [1,7]. Others make use of global geometric properties by capturing shape information in the form of probability distributions, thus reducing the shape-matching problem to that of histogram matching [5].

In this work we study the problem of classifying proteins into their functional families without considering the sequence similarity. This problem is a challenging one where many obstacles must be overcome. 


\subsection{General Approach}

In this work, a novel descriptor for protein tertiary structure (chains) is introduced where the complexity of comparing protein structure is reduced to a problem of comparing their descriptors. The basic idea is to create a descriptor of the protein chain that captures the co-occurrence of specific residues on the protein surface and use this descriptor determine functional similarity between proteins.

\subsection{Main Contribution}

We introduce a novel invariant global descriptor to characterize a protein surface by exploiting a sparse set of atoms (namely the C- $\alpha$ atoms) on the surface. This descriptor is extracted from local patches on the protein surface by averaging local descriptors acquired from patches with similar central residues. Applying such a method has the advantage of avoiding exhaustive alignment and transformations, and hence speeding up the process of similar protein surface retrieval. The method also avoids the time-consuming triangulation required to generate the protein surface graph, before scanning for patches. Our approach is unique in utilizing the residue co-occurrences on the surface of the protein. This way we preserve the key functional elements of the protein (the residues represented by the C- $\alpha$ atoms) and reduce the amount of information to be processed by more than half. Additionally, we avoid exhaustive matching between patches on the surface by averaging the local descriptors into one descriptor that can provide a faithful representation of the protein surface. This allowed us to perform fast classification and retrieval of functionally similar proteins based on our characterization of their surfaces. 


\subsection{Thesis Organization}

The thesis is organized into four chapters. Chapter 2 describes the background to the

problem we wish to address, and related work. Chapter 3 describes the proposed methodology used in this work. Chapter 4 provides our experimental results, while Chapter 5 concludes the thesis. 


\section{Chapter 2}

\section{Background and Related Work}

In this chapter we provide a short description of the background of the problem we address and prior work that is closely related to our approach.

\subsection{DNA, Protein, and Diseases}

DNA is an important storage device for genetic materials. The information stored in the DNA is what can transform inactive molecules into functional cells and organisms, that can regulate the chemical composition of a protein as well as the their progression and reproduction of the molecule. It is what gives us the ability to inherit several traits from our predecessors $[3,13]$.

Proteins are what alter the cell's chemistry by allowing specific chemical reaction to take place faster than it would be otherwise [13]. The process in which the sequence of genes is extracted and utilized to produce proteins is the same for all living creatures. This follows from the Central Dogma of molecular biology, in which, information from DNA is used to transcript into RNA and the information from RNA is used to translate to protein.

Proteins are the molecular kit to perform the work inside both prokaryotic and eukaryotic cells. Proteins have a huge and diverse list of functions, such as supporting bones, metabolizing food, and transporting small molecules through an organism etc. [13]. Each protein retains a specific 3D shape and is usually composed of 1000 to 50,000 atoms [14]. Indeed, proteins control our individualities in some sense, since the functional portion of any cell is determined by the amino-acid sequence of the protein. For instance, immunoglobins, which are a large group of proteins, control the functionality of our immune system, and hence, how we fight varying types of infections [14]. 


\subsection{Protein Sequences, Structure, and Surface}

Regardless of the tremendous amount of variation in functions and the $3 \mathrm{D}$ shape, all proteins share a mutual structure. Proteins are composed of 20-amino acids that are connected via peptide bounds [3]. Those amino acids are only different in the group $\mathbf{R}$ (see Figure 1), and consist of an amino group (NH) and carboxyl acid group (COOH). The constant part of the amino acid is referred to as a backbone while the group $\mathbf{R}$ is referred to as a side chain [13]. Each protein is composed of different number of the 20 amino acids organized in different order. The order of which these amino acids are connected is refered to as the Protein sequence, or the primary structure of the protein [13]. Table 1 shows the twenty amino acids.

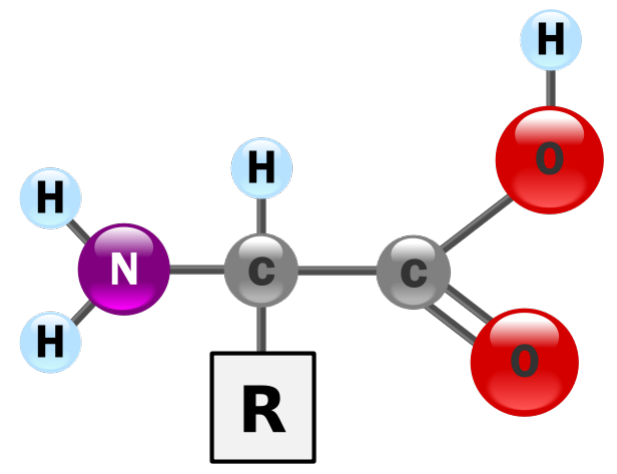

Figure 1: The common structure of amino acid [17]

The protein does not remain in a stable form of simple chain, but rather it folds and collapses into more complex structures. The order of amino acids in the protein determines the fold structure of the protein. All proteins are composed of four common structural types: primary structure, secondary structure, tertiary structure, and quaternary structure. The primary structure is simply the amino acid sequence. The secondary structure is formed by patterns of intermolecular bonding of hydrogen, and is determined primarily by the location and the directions of these patterns [13]. The overall 3D shape of the secondary structures determines the tertiary structure of the protein. When two or more 
chains combine to form a larger molecule, the whole structure is referred to as the quaternary structure. Figure 2, provides an example of the structures that comprise the protein (the sequence is not included). In order to predict the function of a protein, it is common that the function is inferred from a known homologous protein [16]. Functions of novel proteins can be determined by sequence comparisons. Nevertheless, when proteins evolve, the protein structure remains more highly conserved when compared to the sequence. Protein sequences change more easily during evolution due to residue mutations, substitution, for instance by substitution, insertion, or deletion [16]. Hence, proteins that belong to the same family (homologous proteins) may not be identified using sequences alone. Considerations of the protein structure become mandatory in such situations for further analysis of functional similarity between proteins.

Table 1: The 20-protein Residues type
\begin{tabular}{|c|c|}
\hline Residue Type & Name \\
\hline Ala & Alanine \\
\hline Arg & Arginine \\
\hline Asn & Asparagine \\
\hline Asp & Aspartic acid \\
\hline Cys & Cysteine \\
\hline Glu & Glutamic acid \\
\hline Gln & Glutamine \\
\hline Gly & Glycine \\
\hline His & Histidine \\
\hline Ile & Isoleucine \\
\hline Leu & Leucine \\
\hline Lys & Lysine \\
\hline Met & Methionine \\
\hline Phe & Phenylalanine \\
\hline Pro & Proline \\
\hline Ser & Serine \\
\hline Thr & Threonine \\
\hline Trp & Tryptophan \\
\hline Tyr & Tyrosine \\
\hline Val & Valine \\
\hline
\end{tabular}




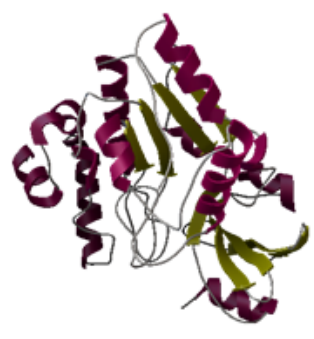

a) Secondary Structures alpha helix (Maganta) beta sheets(gold)

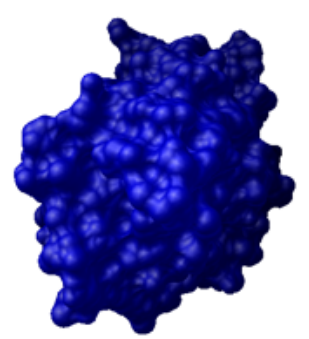

c) chain E 3D shape

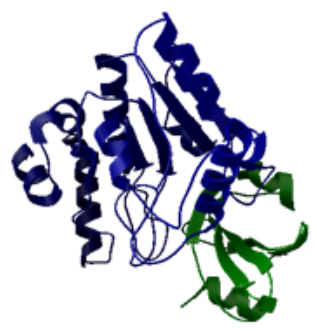

b) Chains chain E (blue) chain I (green)

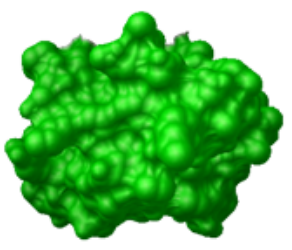

d) chain I 3D Chape

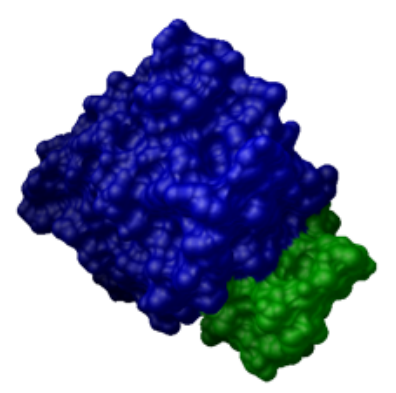

e) Protein 2UDI Qaternary Structure

Figure 2: Protein 2UDI Structures

The components of the figure are produced using PMV[11]

Using structural analysis, Orengo et al, reported that proteins related to the same family could share fewer than $15 \%$ identical residues [16]. Table 2 shows some examples of related family proteins that share a very small percentage of sequence similarity. Appendix 
$\mathrm{C}$ provides more detailed information on the sequence similarity within a functional group using Smith-Waterman alignment method.

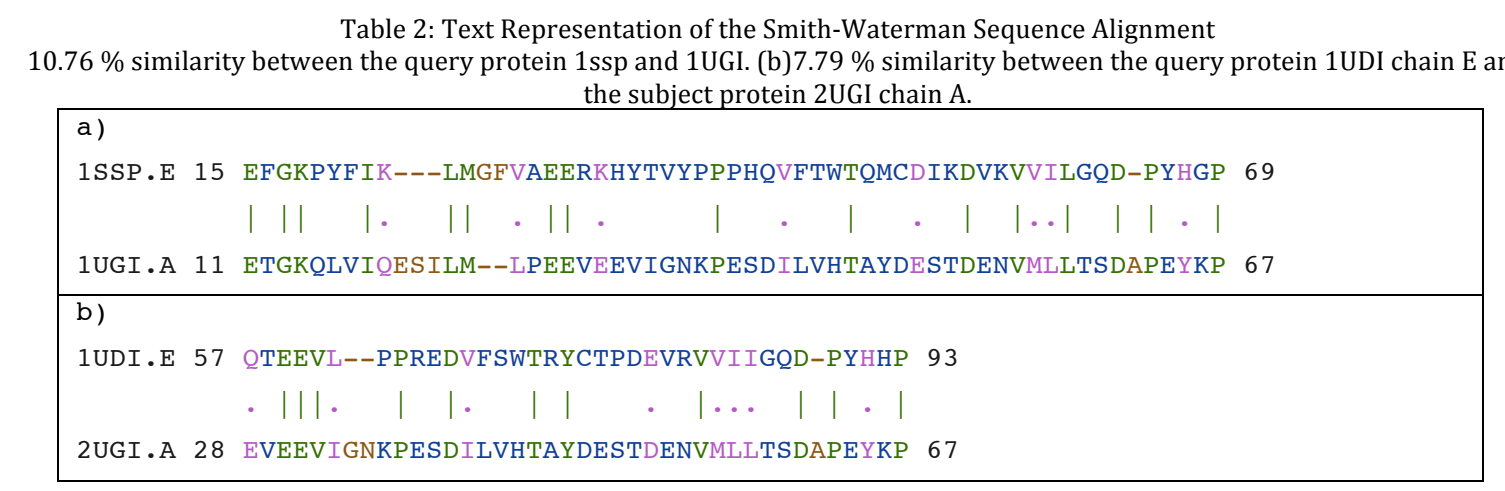

In the other hand, the protein structure retains a significant portion of similarity even between distance homologs (see Figure 3). This contributes to more than half of the interior of protein surface. In general, the degree of the structural similarity and sequences similarity substantially varies between protein families, where some families can handle more changes than others. This degree of change is called structural plasticity [15]. This change can have a considerable impact on the functionality of some proteins, yet in some other families this change does not affect the protein function. Some proteins might share similar structures, yet are not homologues. Thus similarity in structure does not necessarily imply sequence, or functional similarity. Nevertheless, this case is not addressed in this work.

Biologists follow a classical method to derive the protein function, where they start by determining the 3D protein structure before inducing its function [15]. Indeed, the protein $3 \mathrm{D}$ structures provide information about the binding site, active sites, and how proteins interact with each other, as well as providing an insight to the protein function [15]. In fact, how proteins interact with each other and with other molecules (e.g. ligands) are determined by the amino acids on the protein surface [16]. The knowledge of the amino acids on the protein surface allows us to understand what molecules are binding together 
and sometimes why they bind [16]. It also provides significant information on protein functions that cannot be detected in the absence of protein sequence similarity. Therefore, the analysis of protein surfaces is important in the study of the intermolecular interaction. This knowledge is invaluable to the design of drugs and in the fight against various diseases. Knowing the shape of proteins that are responsible of causing lethal diseases (such as cancer) could facilitate the design of the appropriate drugs, since the organism generates antibodies with specific shape (key) that can attack the lethal protein [16]. Advances in this area will surely advance the field of drug design.

(a)
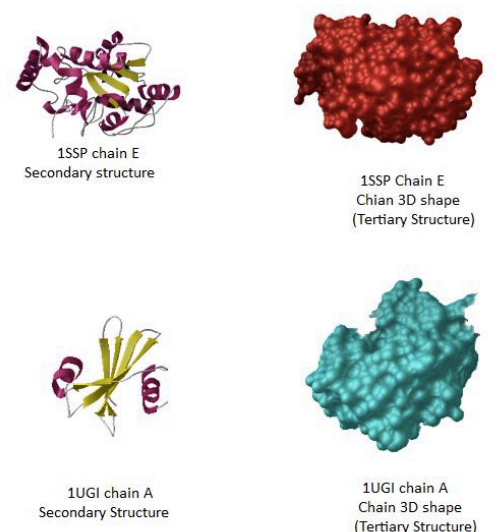

1 UGI chain A
Secondary Structure

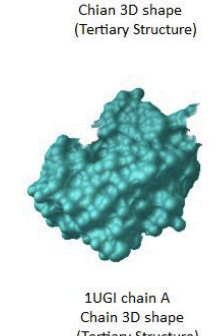

Figure 3: The secondary structure and the Tertiary structures of the sequences provided The components of the figure are produced using PMV[11]

\subsection{Protein Surface Characterization Methods}

Given the foregoing, it is not surprising that methods have been proposed to characterize the protein surface. A recent work [5] uses the idea of applying fingerprint matching on circular protein surface patches. These patches are obtained by generating the dot surface of the protein and constructing a graph to approximate the protein surface. Afterwards, the circular patches are generated as a continuous surface area from a center 
point, where the radius of the patch is within a predetermined cutoff. Indeed, the patches are created for each single point in the surface. Afterward, a fingerprint for each patch is calculated from a center vertex as a geodesic distance-dependent distribution of directional curvature. The comparison between the fingerprints was performed using the Average Fingerprint Similarity Score (AFSS) and the Direct Fingerprint Similarity Score (DFSS). Final scores are computed after an alignment procedure based on AFSS. Seal et al. [1] introduced 3D Zernike to the area of protein structural similarity matching, in which the protein 3D structure is represented as a series expansion of 3D functions. In this approach, the triangulated Connolly surface of the protein is computed (using MSROLL version 3.9.3), where the protein is placed into a 3D cubic grid and voxelized. Each voxel has a value of 0 or 1 and the internal part of the protein is left empty. The 3D Zernike function is projected into the 3D protein shape to obtain the 3D Zernike descriptors. Therefore, the 3D comparison problem is reduced to comparing two vectors representing the 3D Zernike descriptors for each protein surface. Several distances were tried such as the Euclidean distance, Manhattan distance and a correlation-based distance that is defined as the complement of the correlation coefficient between two Zernike descriptors. In more recent similar work, Sael and Kihara [22] used the Zernike descriptor to study protein surfaces in low resolution data. Venkateraman et.al [7] focused on the use of the spherical harmonic and the 3D Zernike descriptors to retrieve functionally similar proteins by representing the proteins as a unique set of numbers. Jones and Thornton [19] analyzed protein-protein interaction by exploiting surface patches. In their work they extracted six parameters of solvation potential, residue interface propensity, hydrophobicity, planarity, protrusion, and accessible surface area for each surface patch in a protein. Thy used the notations of central surface accessible residue patch, and the solvent to define a patch. The patch is constructed by using the $\mathrm{C}-\alpha$ atoms that have a predetermined accessible surface area, and adhere to the constraints on the solvent vectors. Then ranking among the patches was established using these parameters. Ferrè et. al [6] discovers locally similar structures by matching patches composed of subsets of amino acids. In their work, they reduce the dimensionality of the 
atoms space through the creation of pseudo-residue for each residue as two points composed of $\mathrm{C}-\alpha$ and the center of the side chain atoms. Then a legitimate match can be identified as the one that has decent residue similarity based on the substitution matrix and a low root mean square distance. Choi et. al. [18] identified similar protein structures through the use of finite local features from the distance matrices formed from the $\mathrm{C}-\alpha$ positions. They encoded the $\mathrm{C}-\alpha$ distance matrix for each protein by assigning its submatrices to the nearest local feature. The resulting protein structure is then represented using the frequency distribution of the local feature indices.

\subsection{The Problem}

Categorizing proteins into families could provide invaluable information about protein functions. It could also help in a deeper understanding of the evolution of proteins and of the ability of the proteins to tolerate changes in both sequence and structure [16]. Consequently, the task of classifying proteins is non-trivial, since the protein is a multistructural molecule that consists of primary, secondary, tertiary, and quaternary structures. The problem of classifying protein structure into families is different than that of protein sequence, since most of structural classification has been performed on the most evolutionary unit of the protein, which is the domain/ tertiary structure [15]. The problem of identifying protein function is a multi-faceted one. On the one hand, similar sequences could predict similar structure and similar structure can predict similar function, which is the desired outcome. On the other hand, similar protein sequences suggest similar structure, yet similar structure does not always correspond to a similar function. Additionally, similar fold may have similar functions, however, this is not always the case. Focusing on one part of the problem (for instance the surface) brings some more problems. For example, how do we represent the surface? What features to extract? Local or global? How do we define the features (e.g patch)? etc. Once that is solved, the next stage would be the computational complexity. How long would it take to extract these features? What 
searching method to use? How do we define a patch? Therefore, the main task at hand is to classify a given functionally unknown protein to its homologous 3D structural family by exploiting the proteins' 3D structural surface, and that of its individual domains. Computationally efficient methods for this task are mandatory especially given the fast pace in which structures of unknown function are being stored in the PDB [22]. 


\section{Chapter 3}

\section{Methodology}

In this work, an invariant descriptor for each circular patch on the protein surface is defined, based on the residue distances from the center of the patch. The descriptor records the distance distribution between the residues within the patch and keeps track of the number of particular pair-wise residue co-occurrences in the patch. Lastly, a global descriptor is created to represent the whole protein tertiary structure by taking the average of the similar central descriptors. This will result in a standard descriptor for each protein tertiary structure with a fixed patch size. Thus, the standard descriptor can facilitate the matching of protein chains in an efficient manner and will eliminate the need for the exhaustive alignment of the protein 3D structures. This method has been applied on three proteins families: uracil-DNA glycosylase, estrogen receptor, and cell division protein kinase 2. These are the same protein families used in a recently published work [5]. The following steps summarize the methodology used:

- Obtain the protein data from the PDB database, generate the protein chain surfaces and keep track of the $\mathrm{C}-\alpha$ atoms and their residue type.

- Generate the surface patches and the invariant descriptor for each patch.

- Perform matching and classify the proteins chains. 


\subsection{Surface Generation}

To generate the protein surface, the protein file in the .pdb format is preprocessed using Cygwin, which is a Unix like environment for windows, to execute the pdb_to_xyzr and atmtypenumbers programs. The program pdb_to_xyzr produce the $\mathrm{x}, \mathrm{y}$, and $\mathrm{z}$ coordinates from the $\mathrm{pdb}$ file where the $\mathbf{r}$ represents the radius of the atoms. The program pdb_to_xyzr depends on the program atmtypenumbers to transform the pdb atom names into Connolly numeric codes and atomic radii [10]. This step is vital to the MSMS program version 2.6.1 from the Scripps Institute [11] to generate the dot surface (.vert files/ vertices files) for a given protein since MSMS expect .xyzr file as an input. During the stage of using MSMS, the probe radius parameter of the MSMS was tuned to be 1.4 Angstrom for generating the protein surface (dot surface). Next, MATLAB Bioinformatics toolbox was used to extract the proteins chains and to generate the surface for each chain. In this step, the chains are extracted while preserving the coordinates of $\mathrm{C}-\alpha$ atoms and their type by extracting the information from the pdbs and the vertices files. Ultimately, the chains that are known to be a part of one of the families aforementioned are manually selected to create the dataset that is ready to be processed. Figure 4 shows the detailed process of surface generation.

\subsection{The Invariant Descriptor}

In order to capture protein structure similarities and to avoid the computational complexity and the time-consuming problem of aligning 3D protein structures, we propose the use of a global rotational invariant descriptor to describe overlapping circular patches on the surface. This descriptor is comprised of 20 distinct descriptors that represent each of the 20-protein residues types, which are listed in Table 1. For each residue on the surface (central residue), we consider its type and we look for all the residues within a certain distance threshold $\tau_{p}$ to obtain a circular patch. A descriptor for that patch is created by 
calculating the distribution of all distances between the central residue and all other surface residues within the patch. Additionally, the residue co-occurrences within the patch are also recorded as a part of the local descriptor and a matrix $\mathrm{D}_{\mathrm{A}}$ is created to represent this descriptor. The 2D Matrix $D_{A}$ for each local descriptor is created where the size of $D_{A}$ is $(20+1) \times(b+1)$. Here, $(20+1)$ represents the number of the rows in the matrix where the number 20 is used to represent each of the 20 distinct protein residues and the extra row is used to describe the general/ global distance distribution within the patch. The number of columns has been chosen to represent the number of bins $\mathbf{b}$ that was used to divide the distance distributions and the extra column is used to represent the residue co-occurrences.

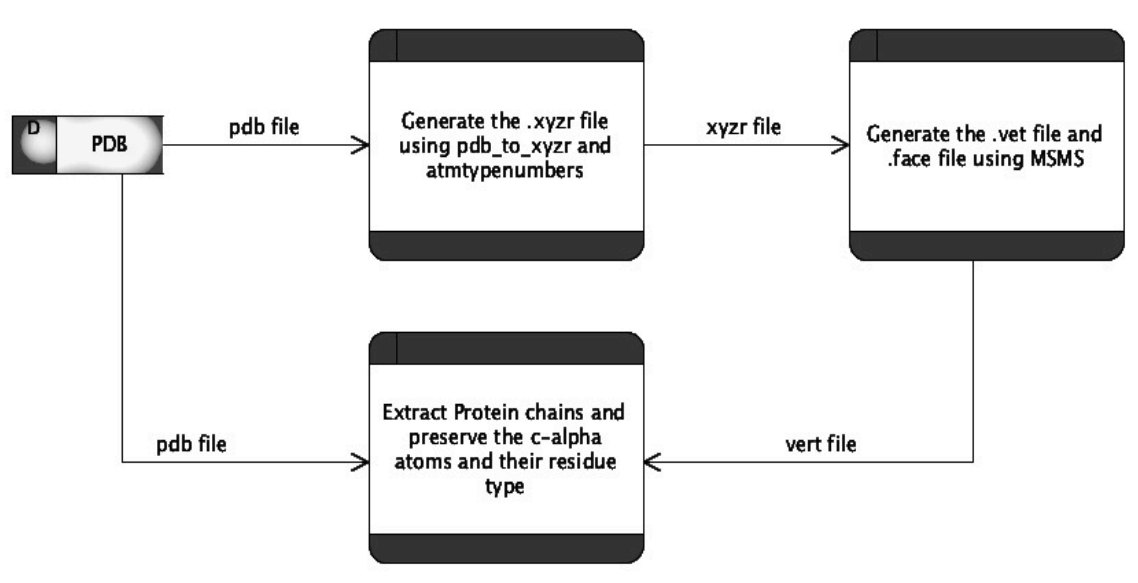

Figure 4: Tertiary structure surface generation

This process is repeated for each residue on the surface, and therefore, the number of local invariant descriptors will be equal to the number of residues that compose the chain 
surface. This number can vary from tens to hundreds and sometimes to thousands of residues that constitute one chain. However, using a huge number of local invariant descriptors for one chain to perform the matching requires an exhaustive search and would be very time-consuming. To overcome this problem, for a given chain the global rotation invariant descriptor is defined by combining the 20 distinct descriptors based on the 20 proteins residue types. Thus, all of the local descriptors for that particular chain have been reduced into one global descriptor by taking the average of all of the descriptors that belong to each given residue type and represent the result as a distinct part of the global descriptor to that chain. Figure 5 shows a schematic diagram for the procedure used in constructing the local and global descriptors.

\subsubsection{Distance Distribution (DD2)}

The basic idea of using the distance distribution is that similar functional proteins should have a similar distance distribution between the residues on their surfaces. The local patch descriptor captures the distribution in two forms. The first form is a detailed distance distribution between the central residue in the patch and each of other residues on the surface. To achieve this, a uniform distribution of the distances is assumed and the total number of bins $b$ is used to estimate the probability distribution of finding a pair of residues at one of the $b$ ranges. The second form is the global distance probability distribution. In this form we estimate the probability of observing any residue within a patch in a particular distance range from the central residue. Although the proposed descriptor captures the distance distribution in two forms, we investigate the importance of using the global distance distribution alone in identifying similar proteins surfaces and therefore protein with a similar function. Consequently, the question to be answered is, given a central residue, what is the distance distribution of the residues around the central residue? Basically, we try to find the probability of observing distance $d_{i}$ between two 
protein residues (as represented by their $\mathrm{C}-\alpha$ atoms) on similar protein surfaces. According to the aforementioned assumption, we estimate that this probability should be similar for surface patches from functionally similar proteins.
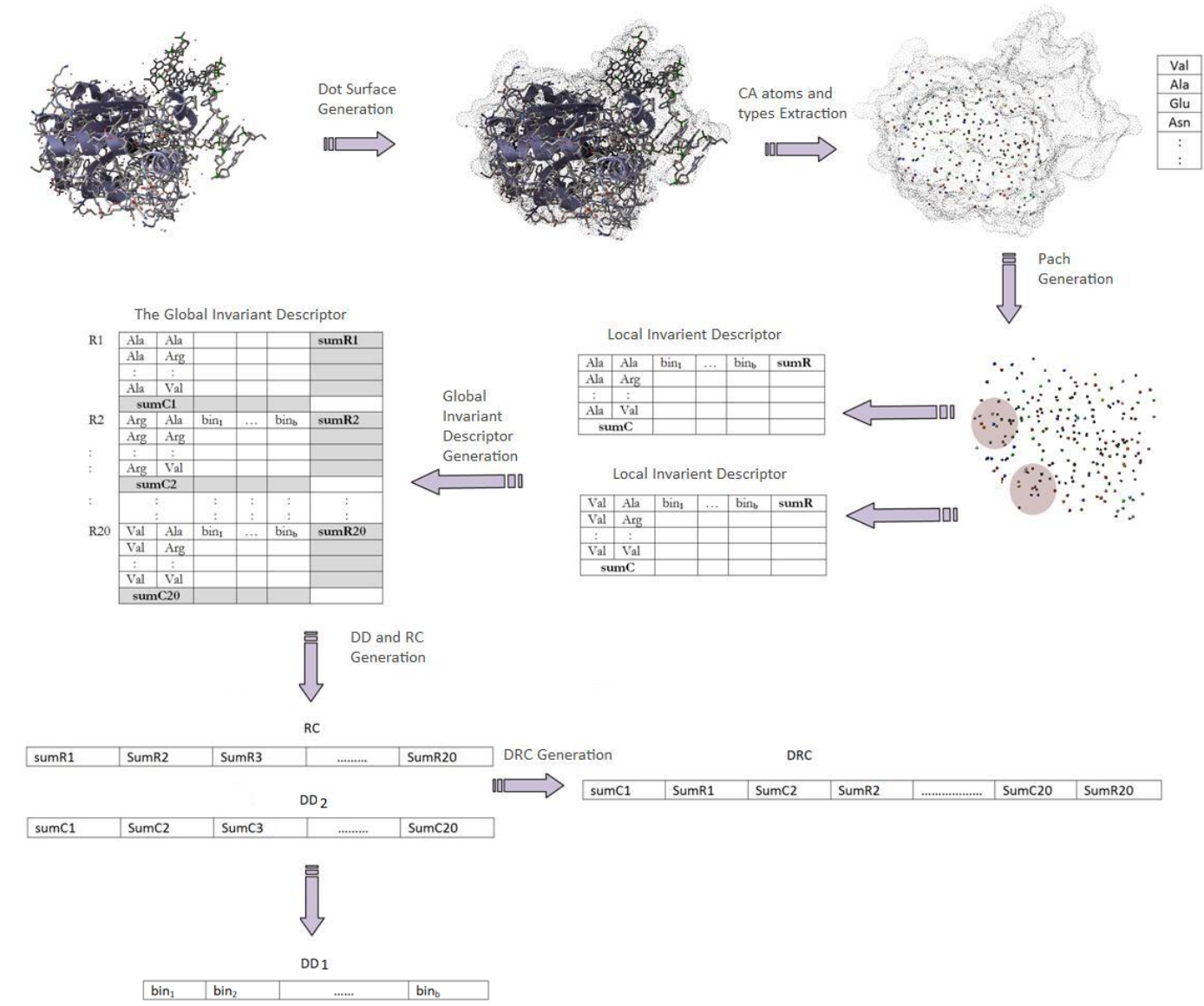

Figure 5: Schematic diagram for the methodology used in creating the local and global descriptors. Some components of the figure are produced using PMV[11] 


\subsubsection{Residue Co-occurrence $(\mathrm{RC})$}

Based on the assumption that functionally similar proteins have certain similar residues that cover their surfaces, the invariant descriptor is also designed to accommodate for residue co-occurrences on the protein surface patch. Using the distance distribution globally provide an idea of how the distances are distributed on the protein surface patch from the central residue. However, there is no constraint on or indication of which residues are involved in the formation of these distributions. The co-occurrence of given residues from the central residue is calculated by computing the number of times that residue occurs on the patch from the central residue. Thus, the main problem would be to find the probability of observing residue $R_{i}$, given a central residue $R_{c}$. Again, we expect that the probability $\mathrm{P}(\mathrm{Ri} \mid \mathrm{Rc})$ should be similar for protein surfaces from functionally similar proteins.

\subsubsection{Distance-Residue Co-occurrences (DRC)}

In this step, we investigate the significance of combining the general distance distribution (represented as a row vector sumC) and the residue co-occurrences (represented as a column vector from the global descriptor sumR) in identifying similar protein surfaces. The residue-distance co-occurrence vector $\left(\mathrm{D}_{\mathrm{RC}}\right)$ is defined as in (1).

$$
D_{R C}=\left(\operatorname{sumC}^{\circ} \operatorname{sumR}^{T}\right)
$$

where $^{\circ}$ is the concatenation operator and $x^{T}$ stands for the transpose of $x$ $R_{D C}$ is used to calculate the conditional probability $P\left(d \mid R_{i}, R_{j}\right)$, that is, the probability of observing the distance $d$ between residues $\mathrm{R}_{\mathrm{i}}$ and $\mathrm{R}_{\mathrm{j}}$ given that $\mathrm{R}_{\mathrm{i}}$ is at the center of the patch. We expect that the residue co-occurrence (sumR) should carry more distinctive 
functionally relevant information than the general distance distribution (sumC) since surface residue-co-occurrences are likely to be more conserved over evolution. By combining both vectors, we can account for both the geometry of the protein surface, and the distribution of specific residues within specific distances on the protein surface. Using both vectors brings in some biological relevance in the analysis and is likely to lead to improved performance in the identification of functionally similar protein surfaces.

\subsection{Matching and Classification}

Given two proteins, say Protein 1 and Protein 2 we represent them with their representative global descriptors, $\mathrm{D}_{\mathrm{g} 1}$ and $\mathrm{D}_{\mathrm{g} 2}$ respectively. In our work, the global descriptors could be the: Distance Distribution, Residue Co-occurrences, and DistanceResidue Co-occurrences.

\subsubsection{Distance Distribution}

For matching using the distance distribution we create a vector $\mathrm{D}_{\mathrm{g} 1 \mathrm{~d}}$ that is composed of the 20 global distance distributions represented by all sumC vectors from each descriptor where $\mathbf{D}_{\text {gld }}$ is defined as follows

$$
D_{g 1 d}=\left(D_{d 1}{ }^{\circ} D_{d 2}{ }^{\circ} \ldots^{\circ} D_{d 20}\right)
$$

where $\mathrm{D}_{\mathrm{d} 1}, \mathrm{D}_{\mathrm{d} 2}, \ldots, \mathrm{D}_{\mathrm{d} 20}$ are the distance distribution from each distinct descriptor in the global descriptor for the chain of Protein 1. Repeat the same process for Protein 2 to create $\mathrm{D}_{\mathrm{g} 2 \mathrm{~d}}$. Then we perform the matching process by taking the simple Euclidean distance. 


$$
D_{12}=\left[\sum_{i=1}^{n}\left[D_{g 1 d}(i)-D_{g 2 d}(i)\right]^{2}\right]^{\frac{1}{2}}
$$

\subsubsection{Residue Co-occurrences}

For Protein 1 we create a vector $\mathrm{D}_{\mathrm{g} 1 \mathrm{c}}$ that combines the 20 residues co-occurrence vectors that are denoted by sumR, where $\mathrm{D}_{\mathrm{glc}}$ is defined as follows

$$
D_{g 1 c}=\left(D_{c 1}^{T} \circ D_{c 2}^{T}{ }^{\circ} \ldots \circ{ }^{\circ} D_{c 20}^{T}\right)
$$

where $\mathrm{D}_{\mathrm{c} 1}{ }^{\mathrm{T}}, \mathrm{D}_{\mathrm{c} 2}{ }^{\mathrm{T}}, \ldots, \mathrm{D}_{\mathrm{c} 20}{ }^{\mathrm{T}}$ represents sumR $\mathbf{R}_{1}{ }^{\mathrm{T}}, \mathbf{S u m R}_{\mathbf{2}}{ }^{\mathrm{T}}, \mathbf{s u m R}_{\mathbf{2 0}}{ }^{\mathrm{T}}$. Similarly, we compute $\mathrm{D}_{\mathrm{g} 2 \mathrm{c}}$. Matching is performed using the Euclidean distance between $\mathrm{D}_{\mathrm{g} 2 \mathrm{c}}$ and $\mathrm{D}_{\mathrm{g} 2 \mathrm{c}}$.

\subsubsection{Distance-Residue Co-occurrences}

For matching two proteins using the Distance-Residue Co-occurrences we create a vector DRC that is comprised of all of the distance distributions as well as the residues co-occurrences. For Protein 1, we define the following

$$
D R C_{1}=\left(D_{d 1}{ }^{\circ} D_{c 1}^{T}{ }^{\circ} D_{d 2}{ }^{\circ} D_{c 2}^{T}{ }^{\circ} \ldots{ }^{\circ} D_{d 1}{ }^{\circ} D_{c 1}^{T}\right)
$$

Similarly we obtain $D R C_{2}$ for Protein 2. Again the matching can be performed using a simple Euclidean distance. Here we have used the Euclidean distance. Clearly, other distance measures could be used. 
The classification is accomplished by applying several classification methods. The ones used include simple KNN classification and simple PCA classification using KNN. We also tried other classification schemes via the WEKA environment such as Simple Logistic classification, Complement Naïve Bayes, Naïve Bayes, Naïve Bayes Multinomial, Naïve Bayes updateable and J48 classifier. 


\section{Chapter 4}

\section{Results}

This section describes detailed experimental results of applying the methodology proposed in Chapter 3, where we generate the local and global invariant descriptors.

\subsection{Dataset}

A dataset of three protein families: uracil-DNA glycosylase, cell division protein kinase 2, and estrogen receptor was created by scanning the PDB database and selecting the pdb files of those proteins that has chains belonging to one of the three families. The dataset used in the following experiments contains 416 chains that belong to 243 proteins. The dataset is distributed in the following fashion: 91 chains from 46 distinct proteins for uracil-DNA glycosylase (Group1), 186 chains from 95 distinct proteins for estrogen receptor family (Group2), and 139 chains from 102 distinct proteins from cell division protein kinase 2 (Group3). The detailed dataset is provided in Appendix A.

\subsection{Classification}

In the classification part we divide the dataset into training and testing sets and we apply different classifiers on the different descriptors proposed and show the classification rate accordingly. For the following experiments we set the patch threshold $\tau_{p}=10$. That is, we create the circular patch by searching for the nearby residues that fall within a distance threshold $10 \mathrm{~A}^{\circ}$. We also fixed the number of bins $\mathbf{b}$ for the distance distribution to 5. We used classification algorithms implemented in WEKA [23] version 3-6-4 to test the performance of our approach. 
First, we explore the impact of the size of the testing set and of the training set on the classification rate using the proposed approach.

\subsubsection{Impact of Training Set Size}

We apply the Naïve Bayes, Logistic, and Simple Logistic classifiers on the dataset produced by the global invariant descriptor. In this experiment we divide the dataset into training and testing and we vary the training set size using a fix the testing set size. Consequently, we used fixed testing sets of size 100, 200, and 300. However, the training dataset was varying in size for each fixed testing set. Table 3 provides detailed information on the number of samples each group contributed to each training set or testing set.

Table 3:Detailed information on the dataset used for training and testing

\begin{tabular}{|c|c|c|c|c|}
\hline \multicolumn{5}{|c|}{ Training $=\mathbf{3 0 0}$} \\
\hline & Group1 & Group2 & Group3 & Total \\
\hline Train & 80 & 116 & 104 & 300 \\
\hline Test1 & 11 & 20 & 19 & 50 \\
\hline Test2 & 11 & 54 & 35 & 100 \\
\hline \multicolumn{5}{|c|}{ Training $=\mathbf{2 0 0}$} \\
\hline & Group1 & Group2 & Group3 & Total \\
\hline Train & 60 & 70 & 70 & 200 \\
\hline Test1 & 12 & 20 & 18 & 50 \\
\hline Test2 & 25 & 40 & 35 & 100 \\
\hline Test3 & 31 & 69 & 50 & 150 \\
\hline Test4 & 31 & 100 & 69 & 200 \\
\hline \multicolumn{5}{|c|}{ Training $=100$} \\
\hline & Group1 & Group2 & Group3 & Total \\
\hline Train & 60 & 40 & 35 & 100 \\
\hline Test1 & 12 & 20 & 18 & 50 \\
\hline Test2 & 25 & 40 & 35 & 100 \\
\hline Test3 & 40 & 60 & 50 & 150 \\
\hline Test4 & 60 & 70 & 70 & 200 \\
\hline Test5 & 66 & 94 & 90 & 250 \\
\hline Test6 & 66 & 130 & 104 & 300 \\
\hline
\end{tabular}

Figure 6 shows the effect of changing the training size on the classification rate as recorded by applying WEKA implementation of Naïve Bayes, Simple Logistic, and Logistic classifier using the invariant descriptors proposed. 
Distance Distributions: The figure shows that applying the distance distribution (DD2) alone resulted on the lowest performance accuracy as compared to using the residue co-occurrences $(\mathrm{RC})$ or the combination of distance-residue co-occurrences (DRC). Yet, our definition of the distance distribution shows encouraging results. Classification using Naïve Bayes on DD2 alone shows a degrading classification performance when the training size increases, however, we still achieved $70 \%$ classification accuracy. Indeed, a steady performance can be obtained when applying the simple logistic as well as logistic classifiers on the DD2 alone. One can observe that we achieved around $88 \%$ performance accuracy with a training size of 200 and the testing size of 100 .

In fact, we are not unique in applying the distance information in protein structure analysis. Residue distances have been used in standard texture based analysis of 2D textures formed by the distances between residues in a protein structure [18]. Binkowski et al [4] introduced the SurfaceShapeSignature (SSS) metric, to describe protein global shape by exploiting the global shape geometrical properties to reduce the problem of matching between two 3D objects to that of a comparison of the probability distribution between the two objects. According to [4] this approach was used to perform a quick matching between complex 3D shape structures. In their approach the Euclidean distance was measured between each unique atoms pairs in the surface and then the distances were sorted before applying the Kolmogorov-Smirnov (KS) test. The use of the shape distribution has been proved to be an effective measure that is resilient to scale, rotation and mirroring. However, the key difference in our method is the use of the local patches as defined by the distance distribution between $\mathrm{C}-\propto$ atoms within each protein surface patch conditioned on the specific residue at the center of the patch and the particular residues found within the patch. The proposed method used the dot surface that was used in [5], to extract the $\mathrm{C}-\propto$ atoms that are on the surface of the protein. After that we compute the Euclidean distance distribution for each patch on the protein $\mathrm{C}-\propto$ surface by exploiting the base-1 index that holds the index of the nearest atom in the pdb file. 
Therefore, our method is unique in computing the residue-specific distance distributions for the protein surface patches using the protein's surface $C-\propto$ atoms, while the $C-\propto$ atoms of the interior protein residues are discarded.

Residue Co-occurrences on the protein surface: Because using the distance distribution of the local patches will increase the overall time complexity, we use the global distance distribution to soften the searching overhead, thus combining the ideas of using local and global protein information. This allows us to perform even faster comparison between proteins since these global descriptors will confine the local descriptors no matter how many they are to only one descriptor that represents the protein surface. We also avoided the time complexity of generating a graph representation of the surface before the surface can be scanned to generate the patches and then compute the distance distribution as in [5]. Indeed, The results shown below (see Figure 6 and Figure 7) prove that the use of surface residue co-occurrence is efficient and is resilient to model simplification according to [4].
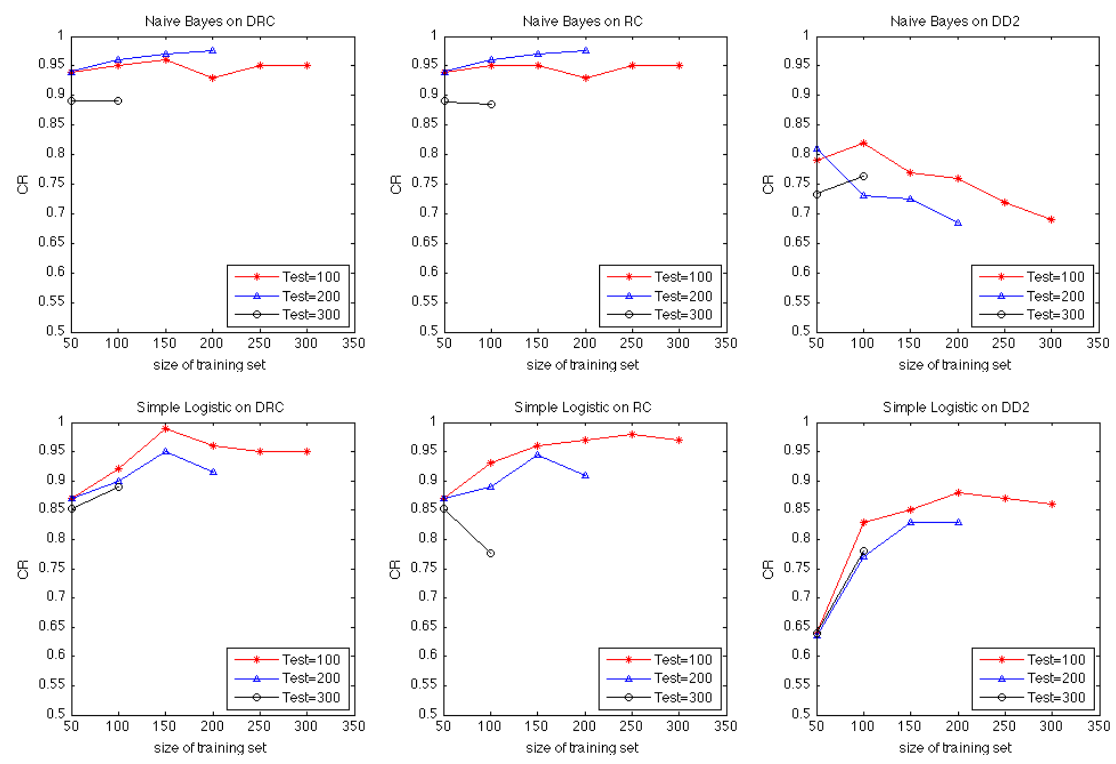

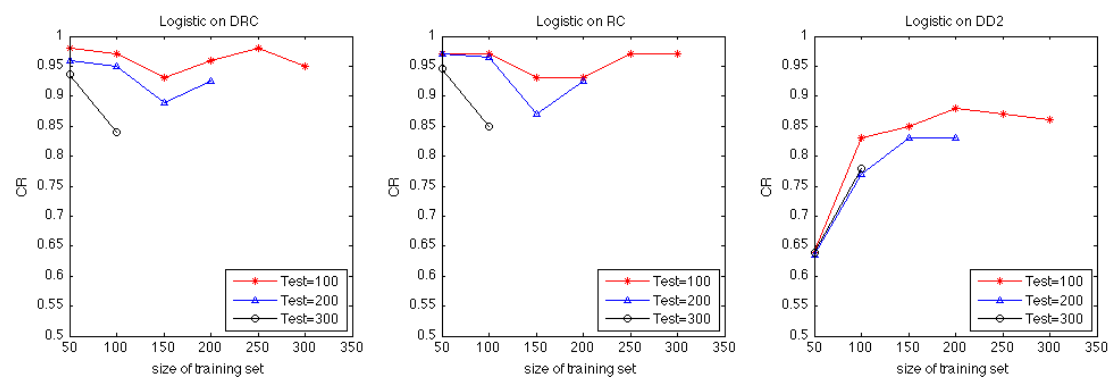

Figure 6: Variation of Classification Rate with size of training set for Naive Bayes, Simple Logistic, and Logistic Regression on the proposed descriptors produced by DD, RC and DRC

Residue Co-occurrences: The distinctiveness of our approach is the use of residue co-occurrences on the protein surface. The results of classifying proteins to their corresponding families based on the residue co-occurrences (RC) provide a significant improvement in classification accuracy using all of the classifiers aforementioned. This approach assumes that functionally similar surface proteins have similar residue cooccurrences within a small local surface region. Thus, similar proportion of all possible predefined residues (20-residues) for each protein. This approach alone improved the classification performance to $98 \%$ classification accuracy rate using Naïve Bayes classifier using a testing set of 200 protein chains and training set of 200 chains. This can be compared to the $69 \%$ accuracy rate achieved using distance distribution on the same testing. It is interesting that our method can achieve an accuracy rate of $98 \%$ using a small training set, (50 samples) and six times larger testing set (300 chains) using the Naïve Bayes classifier. This shows the robustness of the residue co-occurrences, even when using a few training samples. It is important to mention that the DD2 performance using the simple logistic and logistic as well was not as robust as the performance of the RC. The performance was around $64 \%$ using DD2 with a small training set as opposed to using a larger training set. The performance using $\mathrm{RC}$ is improved steadily as we increase the size of the training set. It stabilized at about $95 \%$ as we increased the size of the training set to 300 using the three classifiers. However a better performance of $98 \%$ was obtained by performing the simple logistic classifier using 250 training sets on a 100sample testing set. 
Distance-Residue Co-occurrence: The use of distance-residue co-occurrence presents a steadier improvement in the classification rate. Using the DRC raised the accuracy rate to $99 \%$ using the simple logistic classifier on a training set of 150 and testing set of 100. The detailed confusion matrix is provided in Table 4. One can notice how effictive this method is, that is out of 100 samples only one sample was misclassified. It is important to mention here that there is no overlap between the testing set and the training set.

Table 4: Confusion Matrix for DRC
\begin{tabular}{|c|c|c|c|c|}
\multicolumn{7}{c}{ Predicted Classes } \\
\hline \multirow{3}{*}{$\begin{array}{c}\text { Actual } \\
\text { Classes }\end{array}$} & Group1 & Group1 & Group2 & Group3 \\
\cline { 2 - 5 } & Group2 & 25 & 0 & 0 \\
\cline { 2 - 5 } & Group3 & 0 & 39 & 0 \\
\hline
\end{tabular}

\subsubsection{Impact of Testing Set Size}

Distance Distribution: Similarly to the previous experiments, we explore how the changing size of the testing set as opposed to a fixed training set size can affect the classification accuracy of the proposed method. Again, the Naïve Bayes classifier performed the worst on the training set of 200 protein chain samples when using the DD2, while the testing set changed up to 200 testing samples when the performance degrade to the lowest level of $61 \%$. However, simple logistic and logistic classifiers showed more stable classification performance. Here the accuracy rate is at least $70 \%$ and the best performance achieved on the DD2 was $89 \%$ using the simple logistic.
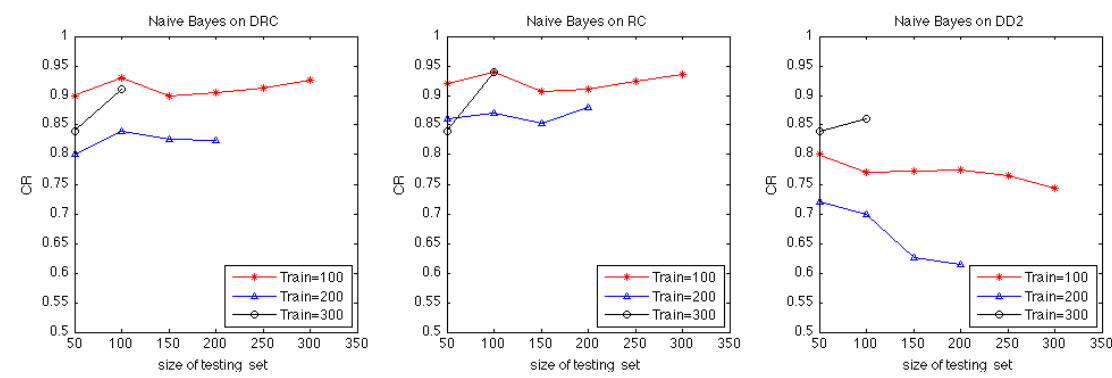

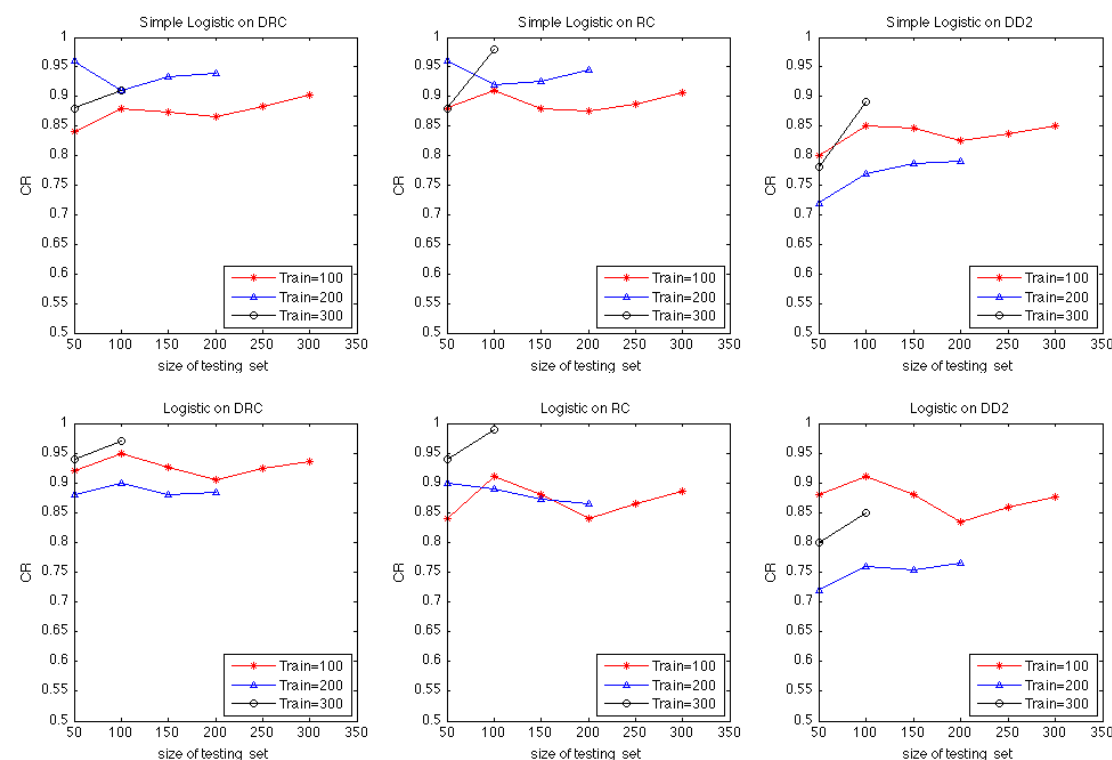

Figure 7: Variation of Classification Rate with size of testing set for Naïve Bayes, Simple Logistic, and Logistic Regression on the proposed descriptors produced by DD, RC, and DRC

Residue Co-occurrence: Better performance was achieved when the $\mathrm{RC}$ is used where the Naïve Bayes Classifier performed well on these data. The lowest performance of Naïve Bayes when applied on RC was $84 \%$ when the training set is fixed to 300 samples using 50 testing samples. As we increase the number of samples in the testing sets, we can see that the classification rate shows significant improvement to $94 \%$ using Naïve Bayes. Applying Logistic classifier shows a stunning 99\% accuracy when the training set is 300 samples and the testing set is 100. Similar classification rate on the same training and testing sets obtained when applying the simple logistic classifier where the classification rate is equal to $98 \%$. Again, there was no overlap between the testing and training data sets. This shows how powerful and intuitive the technique of using the $\mathrm{RC}$ is, since it takes into account the co-occurrence of protein residues that are the backbone to the construction of any protein.

Distance-Residue Co-occurrence: The use of the DRC showed similar to better performance e.g. the logistic classifier in the DRC data performed better than RC since we can see stable increasing in the classification rate, yet the simple logistic and Naïve Bayes showed relatively poorer in the performance. 


\subsection{Ranking}

In this section, we explore the efficacy of our approach on protein surface search and retrieval. We investigate if our approach has the robustness to retrieve most of the functionally similar protein in the top hits given a query protein. Here, a query protein from each of the three groups is used to screen the entire database (416 samples) and provide a ranking based on the similarity. In order to accomplish that, we used the $\mathbf{k}$ nearest neighbor search to find the $\mathbf{k}$ similar proteins in order of their similarity, where $\mathbf{k}$ is set to 416 . That is the most similar will be the first one retrieved and so forth. Thus, the ranking is straightforward from 1 to 416 . After that, we search over the retrieved proteins to find which rank the functionally similar proteins have achieved. We then measure the performance of our approach using the enrichment plot. We expect that most of the functionally similar proteins should be observed after a small percentage of screening. In other words, the top hits should all fit to functionally similar proteins. Figure 8 and Figure 9, shows two variations of the enrichment plot.
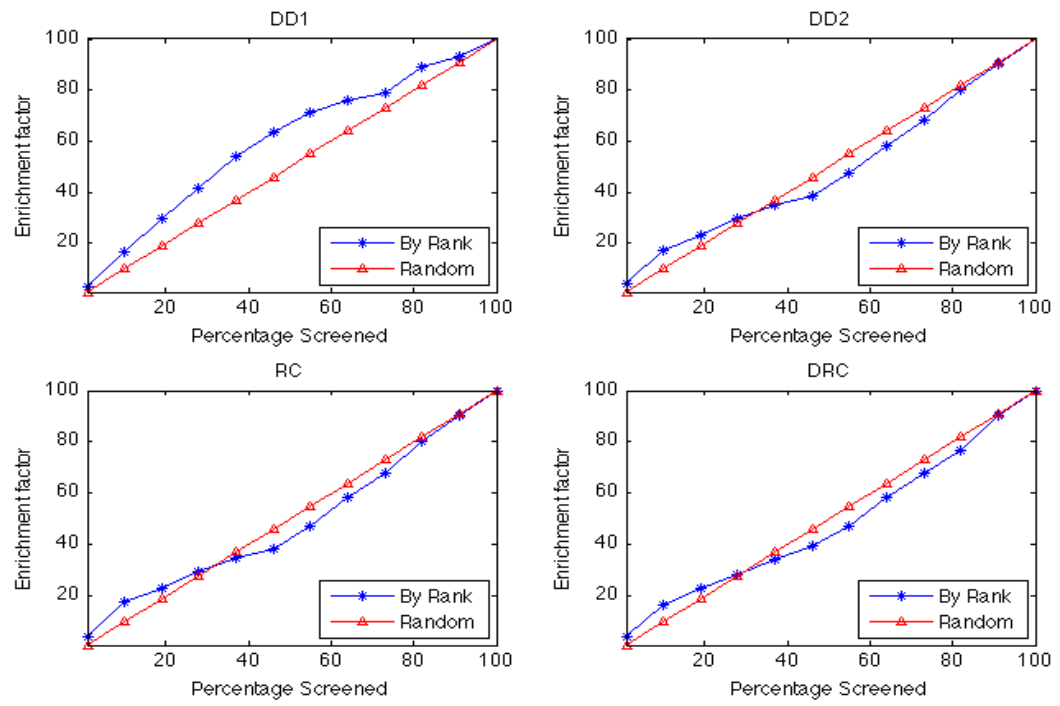

a) Query protein 1UDI chain I from Group1 

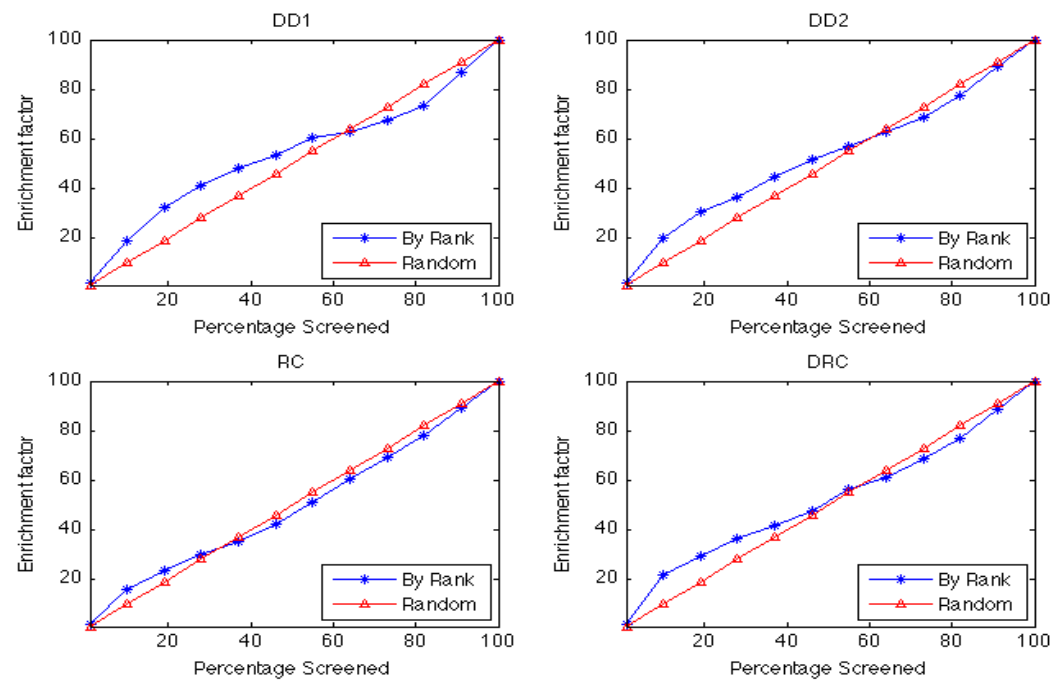

b) Query protein $1 \mathrm{QKN}$ chain A from Group2
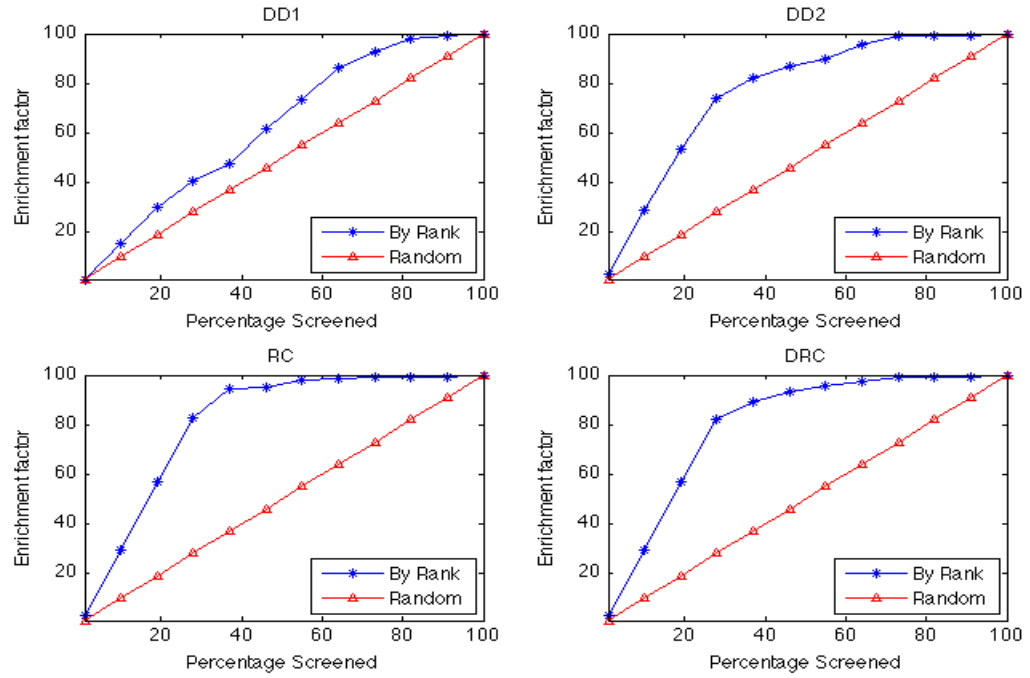

c) Query 1 YKR chain A from Group 3

Figure 8: The enrichment plot for three query proteins 

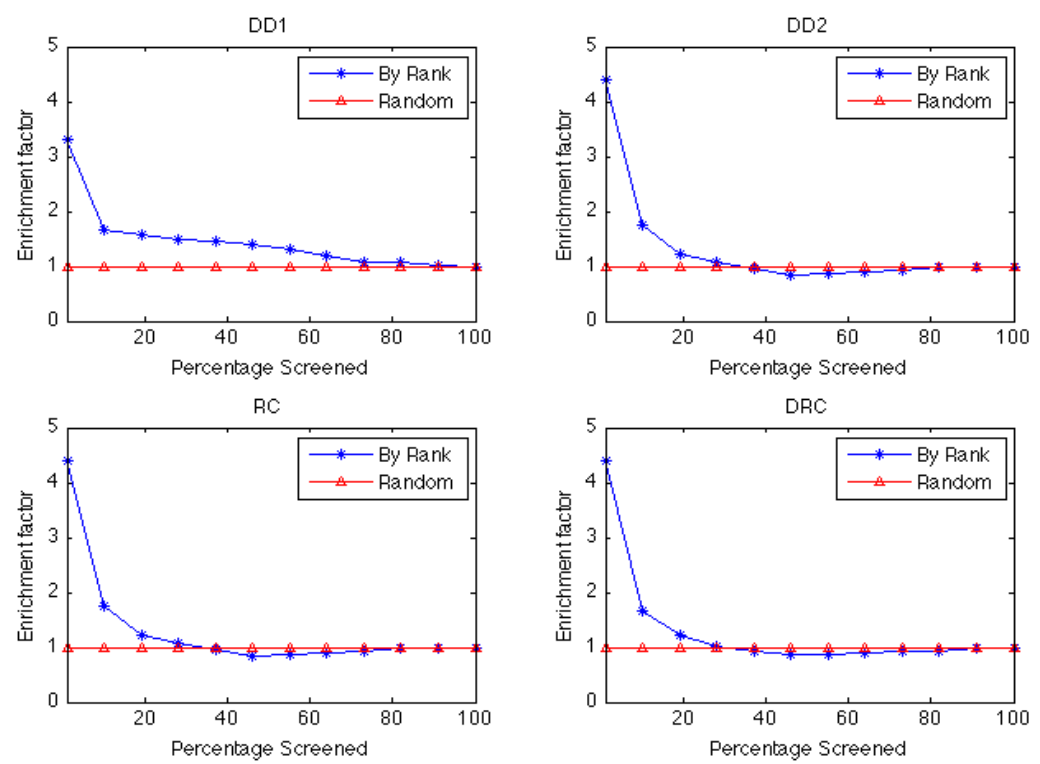

a) Query protein 1UDI chain I from Group1
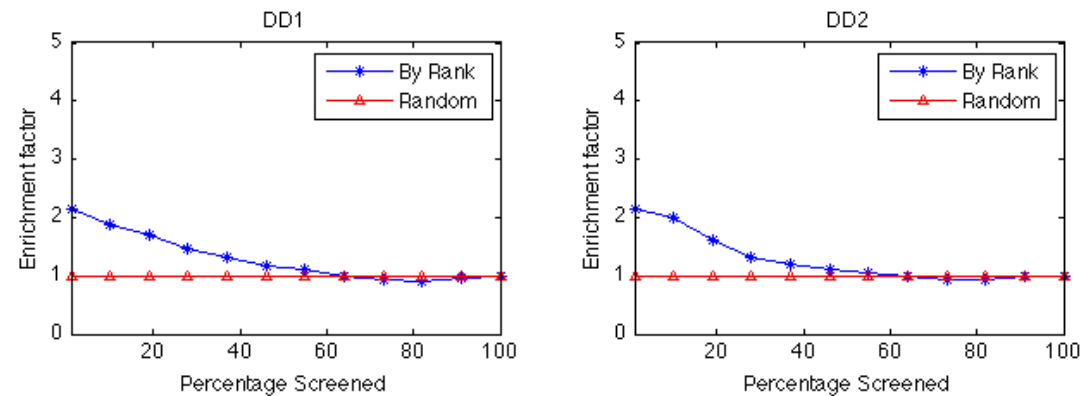

$\mathrm{RO}$
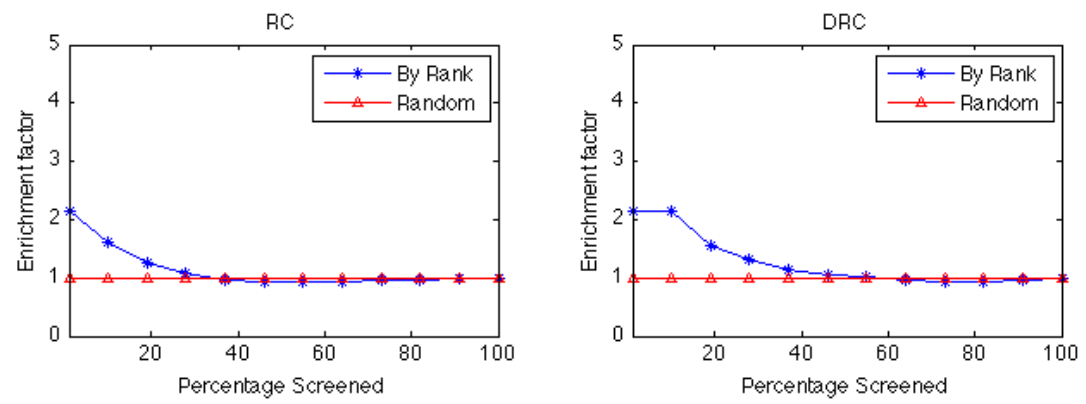

b) Query protein $1 \mathrm{QKN}$ chain A from Group2 

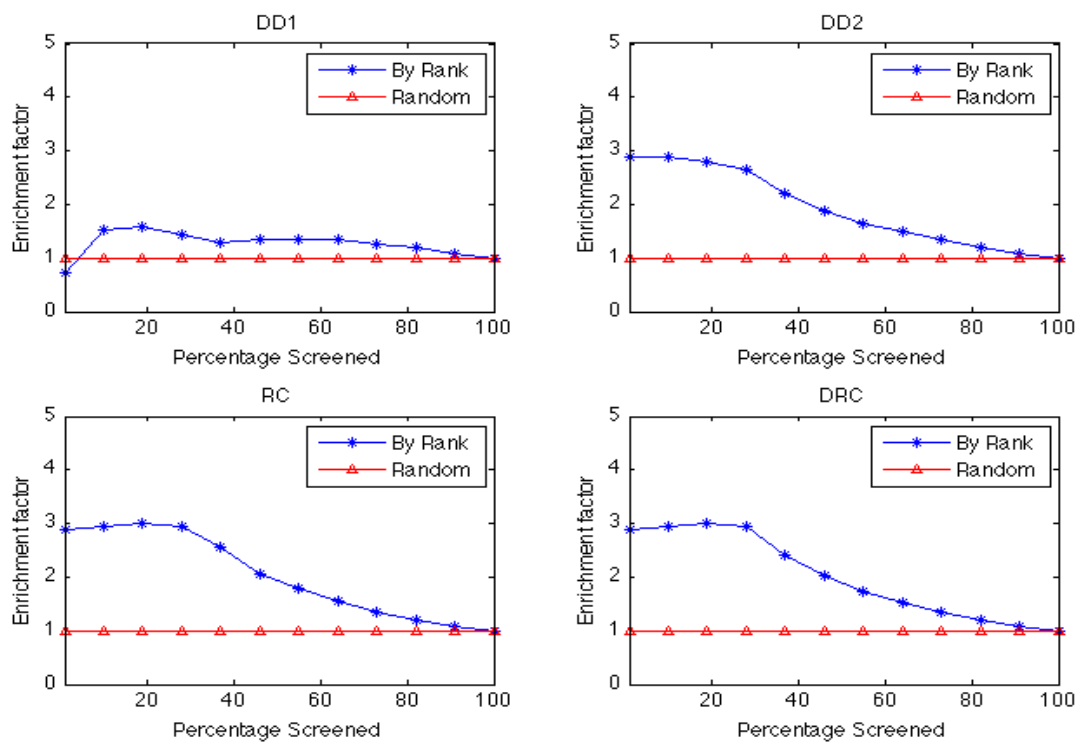

c) Query 1YKR chain A from Group 3

Figure 9: The enrichment plot (second variations)

Here, the enrichment plot shows that our proposed method provides better results as we screen the first few percentage of the dataset. In most of the cases, our method retrieved three times better than the expected random retrieval in the first $1 \%$ screened proteins for each of the 3 selected query proteins. As we increase the percent of the screening the retrieval degrades, as we are more likely to retrieve most if not all the proteins in the first few percentages of the screened dataset. Table 5, shows the rank of the retrieved proteins that belong to the same family of the query protein within the top 30 hits using DRC method. Detailed ranking using the other descriptors is provided in Appendix B.

We also provide the performance of DD1, which will be explained in the next section. 
Table 5: Ranking the screened proteins according to their similarity to the query protein

\begin{tabular}{|c|c|c|c|}
\hline $\begin{array}{c}\text { Protein } \\
\text { ID }\end{array}$ & Chain & Rank & Distance \\
\hline 1UDI & I & 1 & 0 \\
\hline $2 \mathrm{ZHX}$ & B & 2 & 2.1306 \\
\hline $1 \mathrm{LQM}$ & $\mathrm{B}$ & 3 & 2.3509 \\
\hline $1 \mathrm{LQG}$ & $\mathrm{C}$ & 4 & 2.4589 \\
\hline $2 \mathrm{UUG}$ & $\mathrm{C}$ & 5 & 2.5353 \\
\hline 1EUI & $\mathrm{C}$ & 7 & 2.5920 \\
\hline $2 \mathrm{ZHX}$ & $\mathrm{L}$ & 8 & 2.6104 \\
\hline $1 \mathrm{UGH}$ & I & 10 & 2.6349 \\
\hline 2UGI & A & 15 & 2.6809 \\
\hline 1UGI & E & 16 & 2.6872 \\
\hline $2 \mathrm{ZHX}$ & $\mathrm{H}$ & 19 & 2.6969 \\
\hline $2 \mathrm{ZHX}$ & D & 21 & 2.7006 \\
\hline $2 \mathrm{ZHX}$ & $\mathrm{N}$ & 22 & 2.7017 \\
\hline $2 \mathrm{ZHX}$ & $\mathrm{J}$ & 23 & 2.7141 \\
\hline 1UGI & G & 25 & 2.7261 \\
\hline
\end{tabular}

\begin{tabular}{|c|c|c|c|}
\hline $\begin{array}{l}\text { Protein } \\
\text { ID }\end{array}$ & $\begin{array}{c}\text { Chai } \\
\text { n }\end{array}$ & Rank & Distance \\
\hline $1 \mathrm{QKN}$ & A & 1 & 0 \\
\hline $2 \mathrm{~J} 7 \mathrm{X}$ & A & 2 & 1.3769 \\
\hline $2 \mathrm{~J} 7 \mathrm{Y}$ & A & 3 & 1.5753 \\
\hline $1 \mathrm{QKM}$ & A & 4 & 1.6793 \\
\hline 1NDE & A & 5 & 1.7368 \\
\hline $2 \mathrm{GIU}$ & $\mathrm{A}$ & 6 & 1.7371 \\
\hline 1L2I & $\mathrm{A}$ & 7 & 1.7460 \\
\hline 1U3R & B & 8 & 1.7670 \\
\hline 3ERD & A & 9 & 1.7683 \\
\hline $30 S 9$ & $\mathrm{~A}$ & 10 & 1.7715 \\
\hline $2 \mathrm{IOG}$ & A & 11 & 1.7738 \\
\hline 3LTX & $\mathrm{C}$ & 12 & 1.7742 \\
\hline 1YIM & $\mathrm{A}$ & 13 & 1.7854 \\
\hline 3ERT & $\mathrm{A}$ & 14 & 1.7966 \\
\hline $1 \mathrm{U} 3 \mathrm{Q}$ & $\mathrm{D}$ & 15 & 1.8009 \\
\hline $1 Y Y 4$ & A & 16 & 1.8090 \\
\hline $2 \mathrm{OUZ}$ & A & 17 & 1.8126 \\
\hline $1 \mathrm{YIN}$ & $\mathrm{A}$ & 18 & 1.8152 \\
\hline 1XP6 & $\mathrm{A}$ & 19 & 1.8260 \\
\hline $2 \mathrm{AYR}$ & $\mathrm{A}$ & 20 & 1.8269 \\
\hline $30 \mathrm{OS} 8$ & $\mathrm{D}$ & 21 & 1.8311 \\
\hline $2 \mathrm{QH} 6$ & $\mathrm{~A}$ & 22 & 1.8312 \\
\hline $3 \mathrm{OSA}$ & A & 23 & 1.8367 \\
\hline 1L2J & A & 24 & 1.8385 \\
\hline $2 \mathrm{JJ} 33$ & $\mathrm{~A}$ & 25 & 1.8438 \\
\hline $1 \mathrm{G} 50$ & $\mathrm{~A}$ & 26 & 1.8490 \\
\hline $30 \mathrm{OS} 8$ & $\mathrm{~A}$ & 27 & 1.8509 \\
\hline $2 \mathrm{FSZ}$ & $\mathrm{A}$ & 28 & 1.8518 \\
\hline $2 \mathrm{QGW}$ & A & 29 & 1.8604 \\
\hline $1 \mathrm{UOM}$ & A & 30 & 1.8683 \\
\hline
\end{tabular}

\begin{tabular}{|c|c|c|c|}
\hline $\begin{array}{l}\text { Protein } \\
\text { ID }\end{array}$ & Chain & Rank & Distance \\
\hline 1YKR & $\mathrm{A}$ & 1 & 0 \\
\hline $2 \mathrm{UZO}$ & A & 2 & 1.0396 \\
\hline $2 \mathrm{R} 3 \mathrm{O}$ & $\mathrm{A}$ & 3 & 1.0810 \\
\hline 3PXY & $\mathrm{A}$ & 4 & 1.0846 \\
\hline 3PY1 & $\mathrm{A}$ & 5 & 1.0940 \\
\hline 2WMA & $\mathrm{A}$ & 6 & 1.1389 \\
\hline 2IW6 & $\mathrm{A}$ & 7 & 1.1609 \\
\hline 3NS9 & $\mathrm{A}$ & 8 & 1.2043 \\
\hline 3IGG & A & 9 & 1.2141 \\
\hline 2WFY & A & 10 & 1.2179 \\
\hline $2 \mathrm{C} 5 \mathrm{Y}$ & $\mathrm{A}$ & 11 & 1.2270 \\
\hline 3DDP & $\mathrm{A}$ & 12 & 1.2280 \\
\hline $2 \mathrm{~J} 9 \mathrm{M}$ & $\mathrm{A}$ & 13 & 1.2284 \\
\hline 2R3J & $\mathrm{A}$ & 14 & 1.2374 \\
\hline $2 \mathrm{R} 3 \mathrm{~L}$ & $\mathrm{~A}$ & 15 & 1.2402 \\
\hline 3PXR & A & 16 & 1.2422 \\
\hline 2DUV & $\mathrm{A}$ & 17 & 1.2534 \\
\hline $1 \mathrm{~W} 8 \mathrm{C}$ & $\mathrm{A}$ & 18 & 1.2586 \\
\hline 3DOG & A & 19 & 1.2793 \\
\hline $2 \mathrm{~V} 22$ & $\mathrm{~A}$ & 20 & 1.2822 \\
\hline 2R3P & $\mathrm{A}$ & 21 & 1.2883 \\
\hline $2 \mathrm{~V} 22$ & $\mathrm{C}$ & 22 & 1.2963 \\
\hline 3IG7 & A & 23 & 1.3207 \\
\hline $2 \mathrm{JGZ}$ & A & 24 & 1.3275 \\
\hline 2R64 & $\mathrm{A}$ & 25 & 1.3303 \\
\hline $2 \mathrm{WHB}$ & A & 26 & 1.3381 \\
\hline $2 \mathrm{VTN}$ & $\mathrm{A}$ & 27 & 1.3458 \\
\hline 3LFN & $\mathrm{A}$ & 28 & 1.3476 \\
\hline $2 \mathrm{WIP}$ & A & 29 & 1.3514 \\
\hline $2 \mathrm{BKZ}$ & A & 30 & 1.3580 \\
\hline
\end{tabular}

\subsection{Comparative Performance}

In this section, the performance of the proposed method using the global descriptor in one of the three forms (DD2, RC, DRC) is compared with the performance of the regular definition of the distance distribution (DD1). An implementation of the DD1 based on what others have done before [18] in different contexts is used here. Here we extract DD1 by discarding any indication to residues information by collecting all the distributions DD2 and then taking the average distance as described in Figure 5 and equation (6). That is, for each bin position we compute:

$$
D D 1=\frac{\sum_{i=1}^{20} \operatorname{SumC}_{i}}{20}
$$

The resulting vector is then used for surface analysis. 
We tested the classification rate by using the three classifiers Naïve Bayes, Logistic, and Simple Logistic as we fixed the training set size and varied the testing set size. Another similar experiment is conducted as we varied the training set size and fixed the testing set size. Figure 10 shows the results.
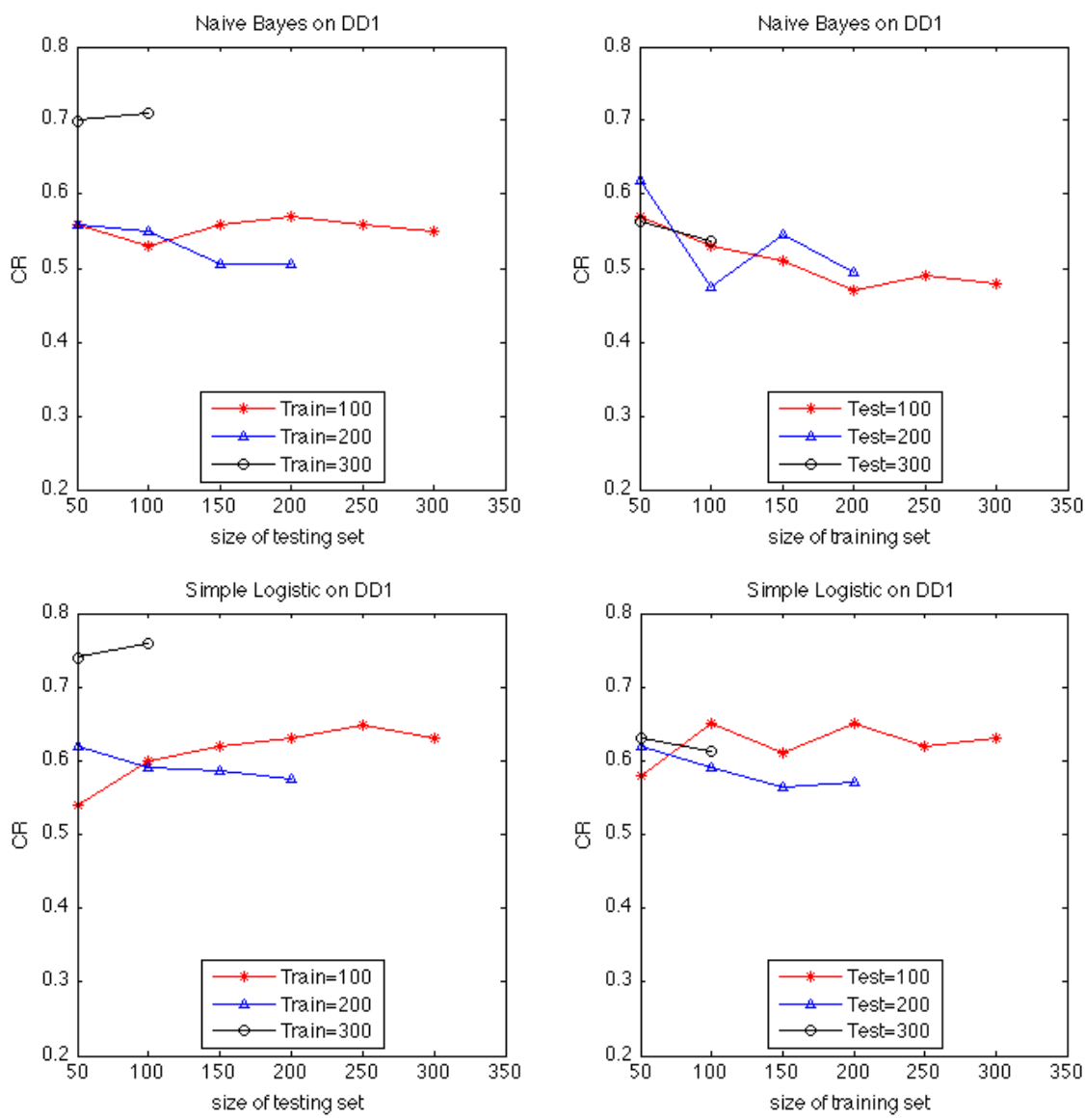

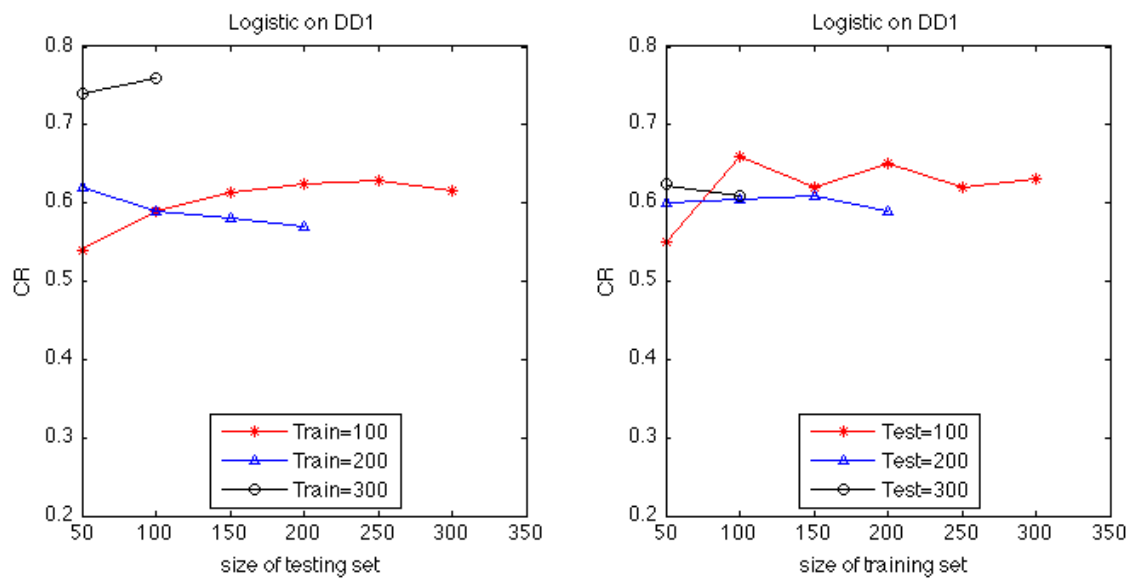

Figure 10: Variation of Classification Rate with size of training set and testing set on DD1 for Naive Bayes, Logistic, and Simple Logistic

One can notice that the highest performance of $76 \%$ is achieved when the training set is fixed to 300 and the testing set was 100 using simple logistic and logistic classifiers while Naïve Bayes achieved accuracy of $71 \%$ on the same dataset. Compared to our method by using the same training and testing sets, $89 \%$ is achieved using the simple logistic classifier, $85 \%$ using logistic, and $86 \%$ with Naïve Bayes on DD2. This shows that our definition of distance distribution DD2 is more distinctive than the regular definition of DD1. Using other forms of the descriptor (RC, and DRC) delivered further improvement on the accuracy (see Table 6)

Table 6: Classification Rate on 300 samples training set and 100 samples testing sets
\begin{tabular}{|l|c|c|c|c|}
\hline Classifier & Descriptor & DD 2 & RC & DRC \\
\hline Naïve Bayes & $71 \%$ & $86 \%$ & $94 \%$ & $91 \%$ \\
\hline Logistic & $76 \%$ & $85 \%$ & $99 \%$ & $97 \%$ \\
\hline Simple Logistic & $76 \%$ & $89 \%$ & $98 \%$ & $91 \%$ \\
\hline
\end{tabular}

To further compare the performance of DD1 with our approach, we investigated the performance of DD1 on retrieving proteins from Group 3 and we observed the ranking. In this experiments, the search is applied using five different proteins from Group 3 and the final ranking was the average ranking. The enrichment plot in Figure 11 shows the ranking results of DD1 compared to our approach. Indeed, our approach showed 
robustness in retrieving proteins two times better than DD1, and three times better than the random.

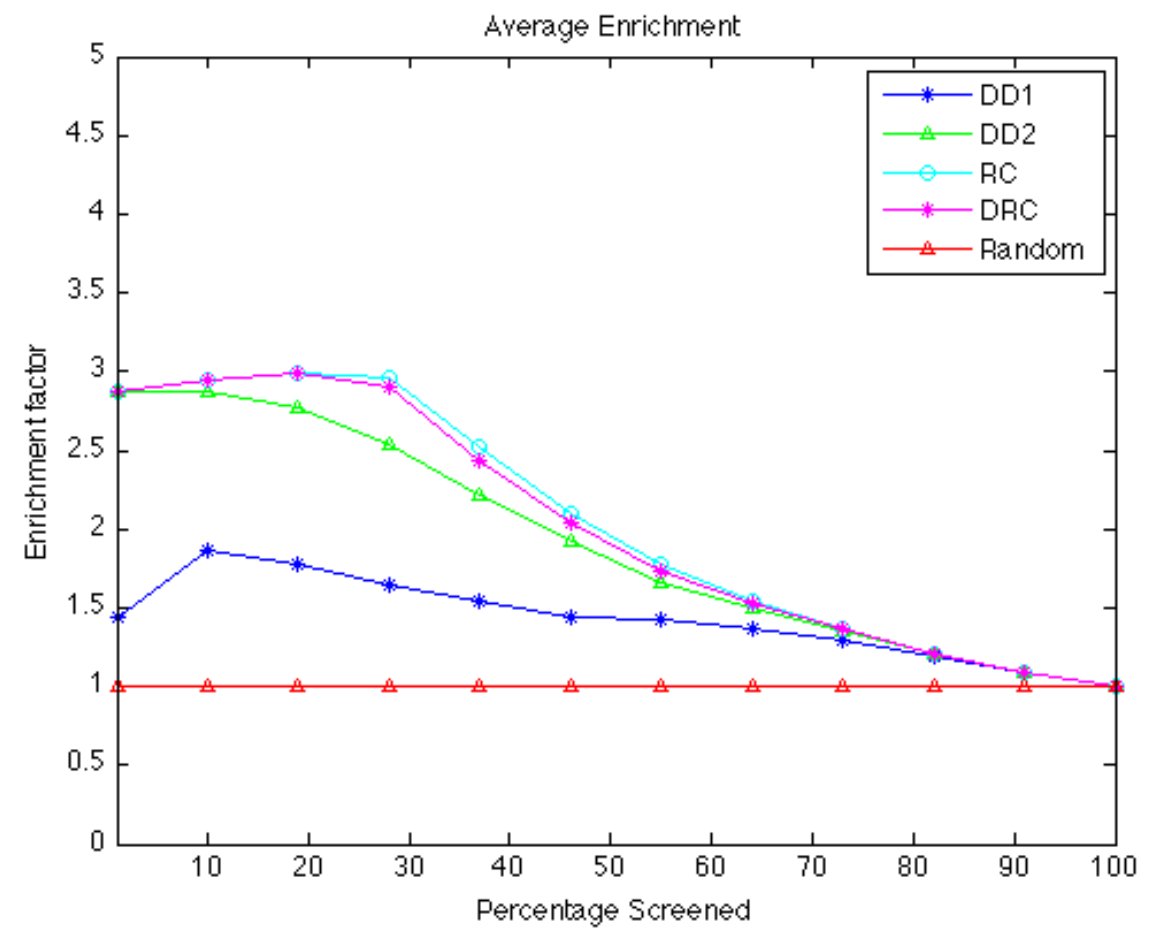

Figure 11: Enrichment plot of DD1, DD2, RC, DRC, and random indicating the retrieval performance of DD1 and the proposed method

Thus, one can see that the global descriptor is a robust identifier of the protein surface similarity as well as the functional similarity in any form used and can provide higher performance accuracy. 


\section{Chapter 5}

\section{Conclusions}

This chapter concludes the thesis by presenting some conclusions and possible future directions.

\subsection{Conclusions}

A novel approach to classify functionally similar proteins into families is introduced. This approach captures the surface structure of the protein by utilizing local patches not on the whole surface, but deliberately on the most informative, central part of the amino acid $\mathrm{C}-\alpha$, which is the main unit that comprises the protein. The novelty of this approach can be observed by the ease of handling both local and global variation on the surface (using local and global descriptors). Moving from local to global does not only reduce the complexity of the problem of matching 3D structure, it also facilitates direct comparison between proteins. By avoiding the construction of the complete 3D surface and retaining only the surface C- $\alpha$ atoms to do the analysis, the need for surface alignment of the $3 \mathrm{D}$ structure is eliminated. Further, we do not need to perform any geometrical transformation to insure reliable matching. This is very important for rapid analysis. By capturing the functionally relevant information on the surface of the protein using simple techniques, this will allow a real-time search.

We tested our approach in order to determine the impact of the testing set size and the training set size on the performance. The results are quite stunning that we achieved a stable classification rate of $95 \%$ using the simple logistic classifier on the DistanceResidue Co-occurrence. The method performed 94\% when classifying 300 samples using only 50 training samples with the logistic classifier. These results are quite encouraging and require further investigation on a larger dataset (the whole PDB for example). All the 
experimental results indicate that the global descriptor represented by either the Distance Distribution (DD2), Residue Co-occurrences (RC), or Distance-Residue Co-occurrences (DRC) is a robust descriptor that can perform excellently well in protein family classification. This new direction of avoiding the complete surface construction and using only the sparse data provided by the $\mathrm{C}-\alpha$ positions shows that for protein surface characterization, we could apply the concept of "Less is more". Perhaps more significantly, this provides an effective yet efficient method for the process of retrieving or identifying functionally similar proteins with little or no sequence similarity.

\subsection{Future Work}

Using the global surface descriptor and incorporating knowledge of the residues provides us with some biologically relevant information about the protein families. To

further investigate this issue, we plan to use more functionally relevant information into the construction of the global descriptor. We propose the use of the 7-class functional grouping to expand the idea of using the global descriptor. We therefore, can reduce the feature space significantly and hopefully improve the results further. We also plan on testing this descriptor on the whole PDB to ensure its accuracy in providing reliable large scale searching at a considerable speed. We would like to explore the possibility of creating one representative descriptor for each protein family and then we can use the idea of bag of features to predict functionally similar proteins. 


\section{Appendix A}

\section{Detailed Information of The Dataset}

Group1: Uracil -DNA Glycosylase 46 proteins, 91 chain

\begin{tabular}{|c|c|}
\hline Protein ID & chains \\
\hline 1SSP & $\mathrm{E}$ \\
\hline $2 \mathrm{SSP}$ & $\mathrm{E}$ \\
\hline 1UGI & $\mathrm{A}, \mathrm{B}, \mathrm{C}, \mathrm{D}, \mathrm{E}, \mathrm{F}, \mathrm{G}, \mathrm{H}$ \\
\hline 2UGI & $\mathrm{A}, \mathrm{B}$ \\
\hline $4 \mathrm{SKN}$ & E \\
\hline $1 \mathrm{AKZ}$ & $\mathrm{A}$ \\
\hline $1 \mathrm{LAU}$ & $E$ \\
\hline $1 \mathrm{UDH}$ & $\mathrm{A}$ \\
\hline 1UDI & $\mathrm{E}, \mathrm{I}$ \\
\hline 1UDG & $\mathrm{A}$ \\
\hline $2 \mathrm{BOO}$ & A \\
\hline $1 \mathrm{YUO}$ & $\mathrm{A}$ \\
\hline $1 \mathrm{VK} 2$ & A \\
\hline $1 \mathrm{OKB}$ & $\mathrm{A}, \mathrm{B}$ \\
\hline $1 \mathrm{Q} 3 \mathrm{~F}$ & A \\
\hline 1UI0 & $\mathrm{A}$ \\
\hline 1UI1 & $\mathrm{A}$ \\
\hline $1 \mathrm{LQJ}$ & $\mathrm{B}$ \\
\hline $1 \mathrm{LQM}$ & $\mathrm{A}, \mathrm{B}$ \\
\hline $1 \mathrm{FLZ}$ & A \\
\hline $1 \mathrm{EMH}$ & $\mathrm{A}$ \\
\hline 1EMJ & $\mathrm{A}$ \\
\hline $3 \mathrm{~A} 7 \mathrm{~N}$ & $\mathrm{~A}$ \\
\hline 2DP6 & $\mathrm{A}$ \\
\hline 2DEM & A \\
\hline 2DDG & $\mathrm{A}$ \\
\hline $2 \mathrm{HXM}$ & $\mathrm{A}$ \\
\hline 2D3Y & $\mathrm{A}$ \\
\hline $2 \mathrm{C} 53$ & $\mathrm{~A}$ \\
\hline $2 \mathrm{C} 56$ & $\mathrm{~A}$ \\
\hline $3 \mathrm{FCL}$ & $\mathrm{A}$ \\
\hline $3 \mathrm{FCI}$ & $\mathrm{A}$ \\
\hline $3 \mathrm{FCF}$ & $\mathrm{A}$ \\
\hline $3 \mathrm{CXM}$ & $\mathrm{A}$ \\
\hline $2 \mathrm{ZHX}$ & $\begin{array}{l}\text { A,B,C,D,E,F,G,H } \\
\text {,I,J,K,L,M,N }\end{array}$ \\
\hline $2 \mathrm{OYT}$ & $\mathrm{A}$ \\
\hline $2 \mathrm{OXM}$ & $\mathrm{A}$ \\
\hline 2OWR & $\mathrm{A}, \mathrm{B}, \mathrm{C}, \mathrm{D}, \mathrm{E}, \mathrm{F}, \mathrm{G}, \mathrm{H}$ \\
\hline 2OWQ & $\mathrm{A}, \mathrm{B}$ \\
\hline $2 \mathrm{JHQ}$ & $\mathrm{A}$ \\
\hline $3 \mathrm{FCK}$ & $\mathrm{B}$ \\
\hline $2 \mathrm{UUG}$ & $\mathrm{A}, \mathrm{B}, \mathrm{C}, \mathrm{D}$ \\
\hline $1 \mathrm{UGH}$ & E,I \\
\hline $1 \mathrm{LQG}$ & $\mathrm{A}, \mathrm{B}, \mathrm{C}, \mathrm{D}$ \\
\hline $2 \mathrm{~J} 8 \mathrm{X}$ & $\mathrm{A}, \mathrm{B}, \mathrm{C}, \mathrm{D}$ \\
\hline 1EUI & $\mathrm{A}, \mathrm{B}, \mathrm{C}, \mathrm{D}$ \\
\hline
\end{tabular}

Group 2: Estrogen Receptor

\begin{tabular}{|c|c|}
\hline Protein ID & Chains \\
\hline $30 \mathrm{OO}$ & $\mathrm{A}, \mathrm{B}$ \\
\hline 3OMP & $\mathrm{A}, \mathrm{B}$ \\
\hline 3OMQ & $\mathrm{A}, \mathrm{B}$ \\
\hline 3LTX & $\mathrm{A}, \mathrm{B}, \mathrm{C}, \mathrm{D}$ \\
\hline $3 \mathrm{~L} 03$ & $\mathrm{~A}, \mathrm{~B}$ \\
\hline 3OLL & $\mathrm{A}, \mathrm{B}$ \\
\hline $3 \mathrm{OLS}$ & $\mathrm{A}, \mathrm{B}$ \\
\hline $30 S 8$ & $\mathrm{~A}, \mathrm{~B}, \mathrm{C}, \mathrm{D}$ \\
\hline 3059 & $\mathrm{~A}, \mathrm{~B}, \mathrm{C}, \mathrm{D}$ \\
\hline $3 \mathrm{OSA}$ & $\mathrm{A}, \mathrm{B}, \mathrm{C}, \mathrm{D}$ \\
\hline $3 \mathrm{HLV}$ & $\mathrm{A}, \mathrm{B}$ \\
\hline 3HM1 & $\mathrm{A}, \mathrm{B}$ \\
\hline 3DT3 & $\mathrm{A}, \mathrm{B}$ \\
\hline $2 \mathrm{QXS}$ & $\mathrm{A}, \mathrm{B}$ \\
\hline $2 \mathrm{QZO}$ & $\mathrm{A}, \mathrm{B}$ \\
\hline $3 \mathrm{CBM}$ & B \\
\hline $3 \mathrm{CBO}$ & $\mathrm{B}$ \\
\hline $3 \mathrm{CBP}$ & $\mathrm{B}$ \\
\hline $2 \mathrm{R} 6 \mathrm{~W}$ & $\mathrm{~A}, \mathrm{~B}$ \\
\hline 2R6Y & $\mathrm{A}, \mathrm{B}$ \\
\hline 2QA6 & $\mathrm{A}, \mathrm{B}$ \\
\hline 2QGT & $\mathrm{A}, \mathrm{B}$ \\
\hline $2 \mathrm{QGW}$ & $\mathrm{A}, \mathrm{B}$ \\
\hline $2 \mathrm{QH} 6$ & $\mathrm{~A}, \mathrm{~B}$ \\
\hline 2QR9 & $\mathrm{A}, \mathrm{B}$ \\
\hline 2QSE & $\mathrm{A}, \mathrm{B}$ \\
\hline 2QXM & $\mathrm{A}, \mathrm{B}$ \\
\hline $2 \mathrm{OCF}$ & A \\
\hline $2 \mathrm{QTU}$ & $\mathrm{A}, \mathrm{B}$ \\
\hline $2 \mathrm{IOG}$ & A \\
\hline $2 \mathrm{IOK}$ & $\mathrm{A}, \mathrm{B}$ \\
\hline $2 \mathrm{POG}$ & $\mathrm{A}, \mathrm{B}$ \\
\hline 2QE4 & $\mathrm{A}, \mathrm{B}$ \\
\hline 2QE4 & $\mathrm{A}, \mathrm{B}$ \\
\hline $2 \mathrm{NV} 7$ & $\mathrm{~A}, \mathrm{~B}$ \\
\hline $2 \mathrm{JJ} 3$ & $\mathrm{~A}, \mathrm{~B}$ \\
\hline $2 \mathrm{Q} 70$ & $\mathrm{~A}, \mathrm{~B}$ \\
\hline $2 \mathrm{Z} 4 \mathrm{~B}$ & $\mathrm{~A}, \mathrm{~B}$ \\
\hline 2Q6J & $\mathrm{A}, \mathrm{B}$ \\
\hline $2 \mathrm{OUZ}$ & A \\
\hline $2 \mathrm{P} 15$ & $\mathrm{~A}, \mathrm{~B}$ \\
\hline $2 \mathrm{G} 5 \mathrm{O}$ & $\mathrm{A}, \mathrm{B}$ \\
\hline $2 \mathrm{JF} 9$ & $\mathrm{~A}, \mathrm{~B}, \mathrm{C}$ \\
\hline $2 \mathrm{JFA}$ & $\mathrm{A}, \mathrm{B}$ \\
\hline $2 \mathrm{G} 44$ & $\mathrm{~A}, \mathrm{~B}$ \\
\hline $2 \mathrm{~J} 7 \mathrm{X}$ & A \\
\hline $2 \mathrm{~J} 7 \mathrm{Y}$ & $\mathrm{A}$ \\
\hline $2 \mathrm{I} 0 \mathrm{G}$ & A \\
\hline $2 \mathrm{I} 0 \mathrm{~J}$ & $\mathrm{~A}, \mathrm{~B}, \mathrm{C}, \mathrm{D}$ \\
\hline $2 \mathrm{GIU}$ & A \\
\hline $2 \mathrm{~B} 1 \mathrm{Z}$ & $\mathrm{A}, \mathrm{B}$ \\
\hline $2 \mathrm{~B} 23$ & $\mathrm{~A}, \mathrm{~B}$ \\
\hline $2 \mathrm{FSZ}$ & $\mathrm{A}, \mathrm{B}$ \\
\hline $1 \mathrm{ZKY}$ & $\mathrm{A}, \mathrm{B}$ \\
\hline $2 \mathrm{~B} 1 \mathrm{~V}$ & $\mathrm{~A}, \mathrm{~B}$ \\
\hline $2 \mathrm{FAI}$ & $\mathrm{A}, \mathrm{B}$ \\
\hline $1 \mathrm{ZAF}$ & $\mathrm{A}, \mathrm{B}$ \\
\hline $1 Y Y 4$ & $\mathrm{~A}, \mathrm{~B}$ \\
\hline $1 \mathrm{YYE}$ & $\mathrm{A}, \mathrm{B}$ \\
\hline
\end{tabular}

Group 3: Cell Division Protein Kinase 2

102 proteins, 139 chains

Protein ID $\quad$ chains

3PXF

\begin{tabular}{|l|l}
\hline PPXF & A \\
\hline 3PXQ & A \\
\hline 3PXR & A \\
\hline
\end{tabular}

3PXR

3PXY

3PXZ

3PY1

$3 \mathrm{KF}$

\begin{tabular}{l|l} 
3NS9 & A \\
\hline 3NS6 & A
\end{tabular}

3LE6

\begin{tabular}{|l|l|}
\hline 2XNB & A \\
\hline
\end{tabular}

\begin{tabular}{l|l}
3 MY5 & A,C \\
\hline
\end{tabular}

\begin{tabular}{l|l}
\hline 2WMB & $\mathrm{A}, \mathrm{C}$ \\
\hline 2WMA & $\mathrm{A}, \mathrm{C}$ \\
\hline
\end{tabular}

\begin{tabular}{|l|l}
\hline WMA & $\mathrm{A}, \mathrm{C}$ \\
\hline
\end{tabular}

\begin{tabular}{|l|l|}
\hline 3LFN & A \\
\hline 3LFQ & A \\
\hline
\end{tabular}

3LFS

\begin{tabular}{|l|l}
\hline 2WPA & A,C \\
\hline
\end{tabular}

\begin{tabular}{l|l}
\hline 2WXV & A,C \\
\hline WXV & A,C \\
\hline
\end{tabular}

$2 \mathrm{X} 1 \mathrm{~N}$

$\mathrm{A}, \mathrm{C}$

\begin{tabular}{|l|l}
\hline A \\
\hline IGG
\end{tabular}

\begin{tabular}{l|l}
\hline $2 \mathrm{WIH}$ & $\mathrm{A}$ \\
\hline & $\mathrm{A}, \mathrm{C}$ \\
\hline
\end{tabular}

\begin{tabular}{l|l}
\hline WIP & A,C \\
\hline
\end{tabular}

\begin{tabular}{l|l}
\hline 2WEV & $\mathrm{A}, \mathrm{C}$ \\
\hline
\end{tabular}

2WFY $\quad A, C$

2WHB $\quad$ A,C

\begin{tabular}{|l|l|}
\hline 3FZ1 & $\mathrm{A}$ \\
\hline 3EZV & $\mathrm{A}$ \\
\hline
\end{tabular}

\begin{tabular}{|l|l}
\hline $3 \mathrm{FZ1}$ & $\mathrm{A}$ \\
\hline $3 \mathrm{EZV}$ & $\mathrm{A}$ \\
\hline $3 \mathrm{~F} 5 \mathrm{X}$
\end{tabular}

\begin{tabular}{l|l}
3 EZV & A \\
\hline 3 F5X & C \\
\hline
\end{tabular}

\begin{tabular}{|l|l}
\hline $2 \mathrm{~W} 1 \mathrm{H}$ & $\mathrm{A}$
\end{tabular}

$2 \mathrm{~W} 17$

\begin{tabular}{ll} 
3EOC & $\mathrm{A}$ \\
\hline & $\mathrm{A}, \mathrm{C}$
\end{tabular}

\begin{tabular}{|l|l}
\hline 3EID & $\mathrm{A}, \mathrm{C}$ \\
\hline
\end{tabular}

\begin{tabular}{l|l}
\hline 3EJ1 & A,C \\
\hline
\end{tabular}

2W05

\begin{tabular}{|l|l}
\hline W & A.C \\
\hline $2 \mathrm{~W} 06$ & $\mathrm{~A}$ \\
\hline
\end{tabular}

\begin{tabular}{l|l} 
2W06 & A \\
\hline 2R64 & A \\
\hline
\end{tabular}

\begin{tabular}{|l|l}
\hline 2VTA & A \\
\hline 2 A
\end{tabular}

\begin{tabular}{l|l}
\hline 2VTA & A \\
\hline $2 \mathrm{VTH}$ & $\mathrm{A}$ \\
\hline
\end{tabular}

2VTI

2VTJ

\begin{tabular}{|l|l}
\hline $\mathrm{VT}$ & $\mathrm{A}$ \\
\hline $2 \mathrm{VTM}$ & $\mathrm{A}$
\end{tabular}

2VTM

\begin{tabular}{|l|l}
$2 \mathrm{VTO}$ & $\mathrm{A}$ \\
\hline
\end{tabular}

2VTP

\begin{tabular}{|l|l|}
\hline 2VTQ & A
\end{tabular}

VVTR

2VTS

A

2VU3

2VV9

3DDP

3DDP

3DDQ

3BHT

\begin{tabular}{|l|l|}
\hline 3BHT & $\mathrm{A}, \mathrm{C}$ \\
\hline $3 \mathrm{BHU}$ & $\mathrm{C}$ \\
\hline $3 \mathrm{BHV}$ & $\mathrm{A}, \mathrm{C}$ \\
\hline
\end{tabular} 


\begin{tabular}{|l|l|}
\hline $2 \mathrm{AYR}$ & $\mathrm{A}$ \\
\hline $1 \mathrm{U} 3 \mathrm{Q}$ & $\mathrm{A}, \mathrm{B}, \mathrm{C}, \mathrm{D}$ \\
\hline $1 \mathrm{U} 3 \mathrm{R}$ & $\mathrm{A}, \mathrm{B}$ \\
\hline $1 \mathrm{U} 3 \mathrm{~S}$ & $\mathrm{~A}, \mathrm{~B}$ \\
\hline $1 \mathrm{YIM}$ & $\mathrm{A}$ \\
\hline $1 \mathrm{YIN}$ & $\mathrm{A}$ \\
\hline $1 \mathrm{U} 9 \mathrm{E}$ & $\mathrm{A}, \mathrm{B}$ \\
\hline $1 \mathrm{X} 76$ & $\mathrm{~A}, \mathrm{~B}$ \\
\hline $1 \mathrm{X} 78$ & $\mathrm{~A}, \mathrm{~B}$ \\
\hline $1 \mathrm{X} 7 \mathrm{E}$ & $\mathrm{A}, \mathrm{B}$ \\
\hline $1 \mathrm{X} 7$ & $\mathrm{~A}, \mathrm{~B}$ \\
\hline $1 \mathrm{X} 7 \mathrm{R}$ & $\mathrm{A}$ \\
\hline $2 \mathrm{BJ} 4$ & $\mathrm{~A}, \mathrm{~B}$ \\
\hline $1 \mathrm{XQC}$ & $\mathrm{A}, \mathrm{B}, \mathrm{C}, \mathrm{D}$ \\
\hline $1 \mathrm{XP1}$ & $\mathrm{A}$ \\
\hline $1 \mathrm{XP} 6$ & $\mathrm{~A}$ \\
\hline $1 \mathrm{XPC}$ & $\mathrm{A}$ \\
\hline $1 \mathrm{R} 5 \mathrm{~K}$ & $\mathrm{~A}, \mathrm{~B}, \mathrm{C}$ \\
\hline $1 \mathrm{SJ} 0$ & $\mathrm{~A}$ \\
\hline $1 \mathrm{PCG}$ & $\mathrm{A}, \mathrm{B}$ \\
\hline $1 \mathrm{UOM}$ & $\mathrm{A}$ \\
\hline $1 \mathrm{NDE}$ & $\mathrm{A}$ \\
\hline $1 \mathrm{~L} 2 \mathrm{I}$ & $\mathrm{A}, \mathrm{B}$ \\
\hline $1 \mathrm{~L} 2 \mathrm{~J}$ & $\mathrm{~A}, \mathrm{~B}$ \\
\hline $1 \mathrm{G} 50$ & $\mathrm{~A}, \mathrm{~B}, \mathrm{C}$ \\
\hline $1 \mathrm{QKT}$ & $\mathrm{A}$ \\
\hline $1 \mathrm{QKU}$ & $\mathrm{A}, \mathrm{B}, \mathrm{C}$ \\
\hline $1 \mathrm{QKM}$ & $\mathrm{A}$ \\
\hline $1 \mathrm{QKN}$ & $\mathrm{A}$ \\
\hline $3 \mathrm{ERD}$ & $\mathrm{A}, \mathrm{B}$ \\
\hline $3 \mathrm{ERT}$ & $\mathrm{A}$ \\
\hline $1 \mathrm{~A} 52$ & $\mathrm{~A}, \mathrm{~B}$ \\
\hline $1 \mathrm{ERE}$ & $\mathrm{A}, \mathrm{B}, \mathrm{C}, \mathrm{D}, \mathrm{E}, \mathrm{F}$ \\
\hline $1 \mathrm{ERR}$ & $\mathrm{A}, \mathrm{B}$ \\
\hline $1 \mathrm{HCQ}$ & $\mathrm{B}, \mathrm{E}, \mathrm{F}$ \\
\hline & \\
\hline & \\
\hline
\end{tabular}

\begin{tabular}{|c|c|}
\hline $2 \mathrm{~V} 22$ & $\mathrm{~A}, \mathrm{C}$ \\
\hline 2R3F & $\mathrm{A}$ \\
\hline $2 \mathrm{R} 3 \mathrm{G}$ & A \\
\hline $2 \mathrm{R} 3 \mathrm{H}$ & A \\
\hline 2R3I & $\mathrm{A}$ \\
\hline 2R3J & $\mathrm{A}$ \\
\hline $2 \mathrm{R} 3 \mathrm{~K}$ & A \\
\hline $2 \mathrm{R} 3 \mathrm{~L}$ & $\mathrm{~A}$ \\
\hline 2R3M & $\mathrm{A}$ \\
\hline $2 \mathrm{R} 3 \mathrm{~N}$ & $\mathrm{~A}$ \\
\hline $2 \mathrm{R} 3 \mathrm{O}$ & $\mathrm{A}$ \\
\hline 2R3P & A \\
\hline $2 \mathrm{R} 3 \mathrm{Q}$ & $\mathrm{A}$ \\
\hline $2 \mathrm{R} 3 \mathrm{R}$ & $\mathrm{A}$ \\
\hline $2 \mathrm{~J} 9 \mathrm{M}$ & A \\
\hline $2 \mathrm{UZB}$ & $\mathrm{A}, \mathrm{C}$ \\
\hline $2 \mathrm{UZD}$ & $\mathrm{A}, \mathrm{C}$ \\
\hline 2UZE & $\mathrm{C}$ \\
\hline $2 \mathrm{UZL}$ & $\mathrm{C}$ \\
\hline $2 \mathrm{UZN}$ & A \\
\hline $2 \mathrm{UZO}$ & $\mathrm{A}$ \\
\hline 2DS1 & $\mathrm{A}$ \\
\hline $2 \mathrm{JGZ}$ & $\mathrm{A}$ \\
\hline 2UUE & $\mathrm{A}, \mathrm{C}$ \\
\hline 2DUV & A \\
\hline $2 \operatorname{CLX}$ & $\mathrm{A}$ \\
\hline $2 \mathrm{FVD}$ & A \\
\hline $2 \mathrm{I} 40$ & $\mathrm{~A}, \mathrm{C}$ \\
\hline 2IW6 & $\mathrm{A}, \mathrm{C}$ \\
\hline 2IW8 & $\mathrm{A}, \mathrm{C}$ \\
\hline 2IW9 & $\mathrm{A}, \mathrm{C}$ \\
\hline $1 \mathrm{~W} 8 \mathrm{C}$ & $\mathrm{A}$ \\
\hline 2G9X & $\mathrm{A}, \mathrm{C}$ \\
\hline $2 \mathrm{CCH}$ & $\mathrm{A}, \mathrm{C}$ \\
\hline $2 \mathrm{CCI}$ & $\overline{\mathrm{A}, \mathrm{C}}$ \\
\hline $2 \mathrm{CJM}$ & $\mathrm{A}, \mathrm{C}$ \\
\hline $2 \mathrm{BKZ}$ & $\mathrm{A}, \mathrm{C}$ \\
\hline $2 \mathrm{C} 5 \mathrm{~N}$ & $\mathrm{~A}, \mathrm{C}$ \\
\hline $2 \mathrm{C} 5 \mathrm{O}$ & $\mathrm{A}, \mathrm{C}$ \\
\hline $2 \mathrm{C} 5 \mathrm{~V}$ & $\mathrm{~A}, \mathrm{C}$ \\
\hline $2 \mathrm{C} 5 \mathrm{Y}$ & $\mathrm{A}$ \\
\hline $1 \mathrm{YKR}$ & A \\
\hline $2 \mathrm{~A} 0 \mathrm{C}$ & $\mathrm{X}$ \\
\hline
\end{tabular}




\section{Appendix B}

\section{Detailed Ranking For Three Query Proteins Using DD2, RC, DRC}

Ranking 416 proteins based on their similarities to the query 1UDI chain I using the global descriptors DD2, RC, and DRC and extract the rank of the Group1 proteins

\begin{tabular}{|c|c|c|c|}
\hline \multicolumn{4}{|c|}{ DD2 } \\
\hline $\begin{array}{l}\text { Protein } \\
\text { ID }\end{array}$ & Chain & Rank & Distance \\
\hline 1UDI & I & 1 & 0 \\
\hline 2ZHX & B & 2 & 1.5742 \\
\hline $1 \mathrm{LQG}$ & $\mathrm{C}$ & 3 & 1.8300 \\
\hline 2UGI & $\mathrm{A}$ & 4 & 1.8500 \\
\hline $1 \mathrm{LQM}$ & B & 5 & 1.8600 \\
\hline 1UGI & $E$ & 6 & 1.9100 \\
\hline 2UUG & $\mathrm{C}$ & 7 & 1.9400 \\
\hline 2ZHX & $\mathrm{H}$ & 8 & 1.9575 \\
\hline $1 \mathrm{UGH}$ & I & 11 & 1.9700 \\
\hline 1EUI & $\mathrm{C}$ & 14 & 1.9765 \\
\hline $1 \mathrm{LQJ}$ & B & 18 & 1.9892 \\
\hline $2 \mathrm{ZHX}$ & $\mathrm{D}$ & 19 & 1.9938 \\
\hline 1EMJ & $\mathrm{A}$ & 22 & 1.9966 \\
\hline $2 \mathrm{BOO}$ & A & 23 & 2.0122 \\
\hline 2ZHX & $\mathrm{L}$ & 31 & 2.0123 \\
\hline $2 \mathrm{ZHX}$ & $\mathrm{N}$ & 39 & 2.0322 \\
\hline 1UGI & G & 43 & 2.0411 \\
\hline $1 \mathrm{SSP}$ & $E$ & 45 & 2.0453 \\
\hline 1UGI & $\mathrm{D}$ & 52 & 2.0525 \\
\hline 2OWR & B & 67 & 2.0561 \\
\hline 1UGI & $\mathrm{C}$ & 74 & 2.0561 \\
\hline $2 \mathrm{ZHX}$ & $\mathrm{A}$ & 80 & 2.0641 \\
\hline $3 \mathrm{CXM}$ & A & 91 & 2.0677 \\
\hline $1 \mathrm{LQG}$ & $\mathrm{D}$ & 96 & 2.0778 \\
\hline 1Q3F & $\mathrm{A}$ & 99 & 2.0929 \\
\hline $2 \mathrm{~J} 8 \mathrm{X}$ & D & 102 & 2.1000 \\
\hline $2 \mathrm{UUG}$ & $\mathrm{B}$ & 116 & 2.1002 \\
\hline $2 \mathrm{ZHX}$ & $\mathrm{J}$ & 117 & 2.1074 \\
\hline $2 \mathrm{C} 56$ & $\mathrm{~A}$ & 119 & 2.1125 \\
\hline $2 \mathrm{~J} 8 \mathrm{X}$ & C & 138 & 2.1126 \\
\hline 1UI0 & $\mathrm{A}$ & 139 & 2.1137 \\
\hline 2ZHX & C & 153 & 2.1176 \\
\hline 1EMH & $\mathrm{A}$ & 167 & 2.1219 \\
\hline $2 \mathrm{ZHX}$ & $\mathrm{F}$ & 171 & 2.1225 \\
\hline 2OWQ & $\mathrm{B}$ & 187 & 2.1300 \\
\hline $2 \mathrm{C} 53$ & $\mathrm{~A}$ & 195 & 2.1321 \\
\hline 4SKN & $\mathrm{E}$ & 197 & 2.1366 \\
\hline 2UUG & $\mathrm{D}$ & 211 & 2.1382 \\
\hline $3 \mathrm{FCF}$ & $\mathrm{A}$ & 214 & 2.1387 \\
\hline 1UDI & $E$ & 217 & 2.1413 \\
\hline $2 \mathrm{~J} 8 \mathrm{X}$ & $\mathrm{A}$ & 220 & 2.1449 \\
\hline $1 \mathrm{AKZ}$ & A & 223 & 2.1494 \\
\hline $1 \mathrm{EUI}$ & $\mathrm{D}$ & 225 & 2.1631 \\
\hline 1UDG & A & 230 & 2.1645 \\
\hline 2ZHX & $\mathrm{K}$ & 232 & 2.1648 \\
\hline 2UGI & $\mathrm{B}$ & 234 & 2.1680 \\
\hline 1UDH & A & 241 & 2.1780 \\
\hline 2OWR & $E$ & 249 & 2.1849 \\
\hline $1 \mathrm{LQG}$ & $\mathrm{B}$ & 256 & 2.1995 \\
\hline 2OWQ & $\mathrm{A}$ & 257 & 2.2008 \\
\hline 1VK2 & A & 259 & 2.2013 \\
\hline $3 \mathrm{FCK}$ & $\mathrm{B}$ & 262 & 2.2102 \\
\hline 1UGI & A & 265 & 2.2106 \\
\hline 2OWR & $\mathrm{A}$ & 267 & 2.2126 \\
\hline 2OWR & $\mathrm{F}$ & 272 & 2.2314 \\
\hline 2OWR & $\mathrm{C}$ & 275 & 2.2315 \\
\hline $1 \mathrm{FLZ}$ & $\mathrm{A}$ & 280 & 2.2462 \\
\hline 2ZHX & $\mathrm{E}$ & 285 & 2.2496 \\
\hline 1UGI & $\mathrm{F}$ & 288 & 2.2546 \\
\hline $1 \mathrm{YUO}$ & A & 297 & 2.2584 \\
\hline $1 \mathrm{OKB}$ & $\mathrm{A}$ & 301 & 2.2613 \\
\hline $3 \mathrm{~A} 7 \mathrm{~N}$ & $\mathrm{~A}$ & 302 & 2.2636 \\
\hline
\end{tabular}

\begin{tabular}{|c|c|c|c|}
\hline $\begin{array}{l}\text { Protein } \\
\text { ID }\end{array}$ & Chain & Rank & Distance \\
\hline 1UDI & I & 1 & 0 \\
\hline 2ZHX & B & 2 & 1.4359 \\
\hline $1 \mathrm{LQM}$ & B & 3 & 1.4431 \\
\hline $2 \mathrm{UUG}$ & $\mathrm{C}$ & 4 & 1.6287 \\
\hline $1 \mathrm{LQG}$ & $\mathrm{C}$ & 5 & 1.6466 \\
\hline ZZHX & $\mathrm{L}$ & 6 & 1.6629 \\
\hline 1EUI & $\mathrm{C}$ & 7 & 1.6769 \\
\hline $2 \mathrm{ZHX}$ & $\mathrm{J}$ & 8 & 1.7105 \\
\hline $1 \mathrm{UGH}$ & I & 11 & 1.7499 \\
\hline $2 \mathrm{ZHX}$ & $\mathrm{N}$ & 14 & 1.7803 \\
\hline 1UGI & $\mathrm{G}$ & 18 & 1.8072 \\
\hline 2OWR & $\mathrm{C}$ & 19 & 1.8125 \\
\hline $2 \mathrm{ZHX}$ & $\mathrm{D}$ & 22 & 1.8215 \\
\hline 1UGI & $\mathrm{A}$ & 23 & 1.8286 \\
\hline $2 \mathrm{ZHX}$ & $\mathrm{H}$ & 31 & 1.8551 \\
\hline $2 \mathrm{~J} 8 \mathrm{X}$ & $\mathrm{D}$ & 39 & 1.8715 \\
\hline 1UGI & D & 43 & 1.8852 \\
\hline 1UGI & E & 45 & 1.8876 \\
\hline 2OWR & B & 52 & 1.8935 \\
\hline $2 \mathrm{UUG}$ & $\mathrm{D}$ & 67 & 1.9107 \\
\hline $1 \mathrm{LQG}$ & $\mathrm{D}$ & 74 & 1.9160 \\
\hline $2 \mathrm{BOO}$ & A & 80 & 1.9194 \\
\hline 2OWR & D & 91 & 1.9260 \\
\hline 1EMJ & $\mathrm{A}$ & 96 & 1.9285 \\
\hline 2OWR & $\mathrm{A}$ & 99 & 1.9303 \\
\hline 2OWR & $\mathrm{E}$ & 102 & 1.9317 \\
\hline 1UI1 & $\mathrm{A}$ & 116 & 1.9388 \\
\hline 1Q3F & $\mathrm{A}$ & 117 & 1.9394 \\
\hline 2UGI & $\mathrm{A}$ & 119 & 1.9408 \\
\hline $2 \mathrm{ZHX}$ & F & 138 & 1.9540 \\
\hline 2OWR & $\mathrm{H}$ & 139 & 1.9555 \\
\hline 2OWQ & B & 153 & 1.9646 \\
\hline $2 \mathrm{OWR}$ & $F$ & 167 & 1.9785 \\
\hline $1 \mathrm{EUI}$ & $\mathrm{D}$ & 171 & 1.9818 \\
\hline $4 \mathrm{SKN}$ & $\mathrm{E}$ & 187 & 1.9932 \\
\hline $2 \mathrm{OWQ}$ & $\mathrm{A}$ & 195 & 1.9974 \\
\hline 2UGI & B & 197 & 1.9989 \\
\hline 1UDI & $\mathrm{E}$ & 211 & 2.0111 \\
\hline $2 \mathrm{ZHX}$ & $\mathrm{K}$ & 214 & 2.0129 \\
\hline $1 \mathrm{EUI}$ & $\mathrm{A}$ & 217 & 2.0157 \\
\hline 1UDH & $\mathrm{A}$ & 220 & 2.0176 \\
\hline $2 \mathrm{OXM}$ & A & 223 & 2.0195 \\
\hline 1 YUO & $\mathrm{A}$ & 225 & 2.0216 \\
\hline 1UI0 & $\mathrm{A}$ & 230 & 2.0282 \\
\hline $1 \mathrm{LQM}$ & A & 232 & 2.0299 \\
\hline $1 \mathrm{LQG}$ & $\mathrm{A}$ & 234 & 2.0350 \\
\hline $1 \mathrm{VK} 2$ & $\mathrm{~A}$ & 241 & 2.0397 \\
\hline $1 \mathrm{EMH}$ & $\mathrm{A}$ & 249 & 2.0473 \\
\hline 1FLZ & $\mathrm{A}$ & 256 & 2.0583 \\
\hline $2 \mathrm{ZHX}$ & $\mathrm{A}$ & 257 & 2.0583 \\
\hline $3 \mathrm{FCF}$ & A & 259 & 2.0607 \\
\hline 1UGI & $\mathrm{C}$ & 262 & 2.0616 \\
\hline $1 \mathrm{OKB}$ & A & 265 & 2.0640 \\
\hline $2 \mathrm{C} 53$ & $\mathrm{~A}$ & 267 & 2.0678 \\
\hline 1UDG & $\mathrm{A}$ & 272 & 2.0695 \\
\hline $1 \mathrm{SSP}$ & $\bar{E}$ & 275 & 2.0722 \\
\hline $2 \mathrm{~J} 8 \mathrm{X}$ & $\mathrm{C}$ & 280 & 2.0801 \\
\hline $2 \mathrm{SSP}$ & $\mathrm{E}$ & 285 & 2.0841 \\
\hline 2ZHX & $\mathrm{M}$ & 288 & 2.0877 \\
\hline $2 \mathrm{C} 56$ & A & 297 & 2.0989 \\
\hline 2OWR & $\mathrm{G}$ & 301 & 2.1106 \\
\hline $2 \mathrm{ZHX}$ & $\mathrm{C}$ & 302 & 2.1120 \\
\hline
\end{tabular}
$\mathrm{DRC}$

\begin{tabular}{|c|c|c|c|}
\hline $\begin{array}{l}\text { Protein } \\
\text { ID }\end{array}$ & Chain & Rank & Distance \\
\hline 1UDI & I & 1 & 0 \\
\hline 2ZHX & $\mathrm{B}$ & 2 & 2.1307 \\
\hline $1 \mathrm{LQM}$ & $\mathrm{B}$ & 3 & 2.3509 \\
\hline $1 \mathrm{LQG}$ & $\mathrm{C}$ & 4 & 2.4590 \\
\hline $2 \mathrm{UUG}$ & C & 5 & 2.5354 \\
\hline 1EUI & $\mathrm{C}$ & 7 & 2.5920 \\
\hline 2ZHX & $\mathrm{L}$ & 8 & 2.6105 \\
\hline 1UGH & $\mathrm{I}$ & 10 & 2.6350 \\
\hline 2UGI & A & 15 & 2.6809 \\
\hline $1 \mathrm{UGI}$ & $\mathrm{E}$ & 16 & 2.6873 \\
\hline $2 \mathrm{ZHX}$ & $\mathrm{H}$ & 19 & 2.6969 \\
\hline $2 \mathrm{ZHX}$ & $\mathrm{D}$ & 21 & 2.7006 \\
\hline 2ZHX & $\mathrm{N}$ & 22 & 2.7017 \\
\hline 2ZHX & $\mathrm{J}$ & 23 & 2.7142 \\
\hline 1UGI & $\mathrm{G}$ & 25 & 2.7262 \\
\hline 1EMJ & $\mathrm{A}$ & 42 & 2.7758 \\
\hline $2 \mathrm{BOO}$ & $\mathrm{A}$ & 45 & 2.7808 \\
\hline 1UGI & $\mathrm{D}$ & 47 & 2.7868 \\
\hline 2OWR & B & 50 & 2.7952 \\
\hline $2 \mathrm{~J} 8 \mathrm{X}$ & $\mathrm{D}$ & 61 & 2.8129 \\
\hline 1LQG & $\mathrm{D}$ & 70 & 2.8263 \\
\hline 1Q3F & A & 90 & 2.8533 \\
\hline 2UUG & $\mathrm{D}$ & 99 & 2.8675 \\
\hline 1UGI & A & 101 & 2.8689 \\
\hline 2OWR & $\mathrm{C}$ & 110 & 2.8749 \\
\hline $2 \mathrm{ZHX}$ & $\mathrm{F}$ & 116 & 2.8850 \\
\hline 2OWQ & B & 129 & 2.8977 \\
\hline 1SSP & $\mathrm{E}$ & 141 & 2.9115 \\
\hline 1UGI & $\mathrm{C}$ & 142 & 2.9117 \\
\hline 2ZHX & $\mathrm{A}$ & 147 & 2.9150 \\
\hline 2OWR & $\mathrm{E}$ & 151 & 2.9164 \\
\hline 4 SKN & $\mathrm{E}$ & 160 & 2.9220 \\
\hline 1UI0 & $\mathrm{A}$ & 170 & 2.9294 \\
\hline 1EUI & $\mathrm{D}$ & 179 & 2.9337 \\
\hline 2OWR & $\mathrm{A}$ & 183 & 2.9363 \\
\hline 1UDI & $\mathrm{E}$ & 184 & 2.9376 \\
\hline $1 \mathrm{EMH}$ & A & 200 & 2.9485 \\
\hline 2UGI & $\mathrm{B}$ & 201 & 2.9489 \\
\hline $2 \mathrm{ZHX}$ & $\mathrm{K}$ & 208 & 2.9560 \\
\hline $2 \mathrm{~J} 8 \mathrm{X}$ & $\mathrm{C}$ & 216 & 2.9648 \\
\hline 1UDH & $\mathrm{A}$ & 219 & 2.9689 \\
\hline $3 \mathrm{FCF}$ & $\mathrm{A}$ & 222 & 2.9699 \\
\hline $2 \mathrm{C} 53$ & $\mathrm{~A}$ & 223 & 2.9702 \\
\hline 2OWQ & A & 229 & 2.9720 \\
\hline 1LQJ & B & 231 & 2.9733 \\
\hline $3 \mathrm{CXM}$ & $\mathrm{A}$ & 232 & 2.9763 \\
\hline $2 \mathrm{C} 56$ & $\mathrm{~A}$ & 233 & 2.9779 \\
\hline 2OWR & $\mathrm{D}$ & 235 & 2.9783 \\
\hline 2OWR & $\mathrm{F}$ & 237 & 2.9823 \\
\hline $2 \mathrm{ZHX}$ & $\mathrm{C}$ & 247 & 2.9908 \\
\hline 1UDG & A & 251 & 2.9946 \\
\hline $1 \mathrm{VK} 2$ & $\mathrm{~A}$ & 255 & 3.0010 \\
\hline 2UUG & B & 264 & 3.0135 \\
\hline 1 YUO & $\mathrm{A}$ & 276 & 3.0310 \\
\hline 2OWR & $\mathrm{H}$ & 279 & 3.0353 \\
\hline 1UI1 & A & 280 & 3.0354 \\
\hline 1FLZ & A & 282 & 3.0466 \\
\hline $2 \mathrm{OXM}$ & A & 285 & 3.0515 \\
\hline $1 \mathrm{AKZ}$ & $\mathrm{A}$ & 292 & 3.0583 \\
\hline $1 \mathrm{LQG}$ & B & 296 & 3.0600 \\
\hline $1 \mathrm{OKB}$ & $\mathrm{A}$ & 299 & 3.0616 \\
\hline 1EUI & $\mathrm{A}$ & 303 & 3.0675 \\
\hline
\end{tabular}




\begin{tabular}{|l|l|l|l|}
\hline 2SSP & $\mathrm{E}$ & 306 & 2.2690 \\
\hline 1UGH & $\mathrm{E}$ & 308 & 2.2701 \\
\hline 1UGI & $\mathrm{B}$ & 311 & 2.2713 \\
\hline 2OWR & $\mathrm{D}$ & 320 & 2.2718 \\
\hline 2JHQ & $\mathrm{A}$ & 322 & 2.2819 \\
\hline 2OXM & $\mathrm{A}$ & 324 & 2.2876 \\
\hline 1EUI & $\mathrm{B}$ & 328 & 2.2885 \\
\hline 2ZHX & $\mathrm{M}$ & 329 & 2.2918 \\
\hline 1UGI & $\mathrm{H}$ & 331 & 2.2943 \\
\hline 2UUG & $\mathrm{A}$ & 336 & 2.3042 \\
\hline 1EUI & $\mathrm{A}$ & 340 & 2.3123 \\
\hline 1LAU & $\mathrm{E}$ & 345 & 2.3166 \\
\hline 2DDG & $\mathrm{A}$ & 349 & 2.3175 \\
\hline 1LQM & $\mathrm{A}$ & 350 & 2.3181 \\
\hline 2OWR & $\mathrm{H}$ & 353 & 2.3215 \\
\hline 2D3Y & $\mathrm{A}$ & 355 & 2.3234 \\
\hline 2ZHX & $\mathrm{I}$ & 357 & 2.3272 \\
\hline 2ZHX & $\mathrm{G}$ & 373 & 2.3318 \\
\hline 1LQG & $\mathrm{A}$ & 374 & 2.3334 \\
\hline 1UI1 & $\mathrm{A}$ & 377 & 2.3355 \\
\hline 2DP6 & $\mathrm{A}$ & 379 & 2.3358 \\
\hline 2OWR & $\mathrm{G}$ & 382 & 2.3484 \\
\hline 2DEM & $\mathrm{A}$ & 386 & 2.3746 \\
\hline 2HXM & $\mathrm{A}$ & 388 & 2.3847 \\
\hline 3FCL & $\mathrm{A}$ & 389 & 2.3929 \\
\hline 2J8X & $\mathrm{B}$ & 395 & 2.4235 \\
\hline 1OKB & $\mathrm{B}$ & 397 & 2.5705 \\
\hline 3FCI & $\mathrm{A}$ & 408 & 2.6351 \\
\hline 2OYT & $\mathrm{A}$ & 416 & 2.6615 \\
\hline & & & \\
\hline
\end{tabular}

\begin{tabular}{|l|l|l|l|}
\hline 2UUG & $\mathrm{A}$ & 306 & 2.1175 \\
\hline 2ZHX & $\mathrm{E}$ & 308 & 2.1210 \\
\hline 1LQG & $\mathrm{B}$ & 311 & 2.1273 \\
\hline 3CXM & $\mathrm{A}$ & 320 & 2.1408 \\
\hline 2D3Y & $\mathrm{A}$ & 322 & 2.1455 \\
\hline 1UGI & $\mathrm{H}$ & 324 & 2.1505 \\
\hline 2UUG & $\mathrm{B}$ & 328 & 2.1612 \\
\hline 1UGH & $\mathrm{E}$ & 329 & 2.1624 \\
\hline 2ZHX & $\mathrm{I}$ & 331 & 2.1647 \\
\hline 1AKZ & $\mathrm{A}$ & 336 & 2.1757 \\
\hline 2J8X & $\mathrm{B}$ & 340 & 2.1869 \\
\hline 2J8X & $\mathrm{A}$ & 345 & 2.1947 \\
\hline 1UGI & $\mathrm{B}$ & 349 & 2.2020 \\
\hline 2HXM & $\mathrm{A}$ & 350 & 2.2037 \\
\hline 2DP6 & $\mathrm{A}$ & 353 & 2.2094 \\
\hline 1LQJ & $\mathrm{B}$ & 355 & 2.2099 \\
\hline 3FCL & $\mathrm{A}$ & 357 & 2.2185 \\
\hline 2JHQ & $\mathrm{A}$ & 373 & 2.2510 \\
\hline 2ZHX & $\mathrm{G}$ & 374 & 2.2570 \\
\hline 1EUI & $\mathrm{B}$ & 377 & 2.2631 \\
\hline 1UGI & $\mathrm{F}$ & 379 & 2.2706 \\
\hline 3FCK & $\mathrm{B}$ & 382 & 2.2751 \\
\hline 3FCI & $\mathrm{A}$ & 386 & 2.3049 \\
\hline 2DDG & $\mathrm{A}$ & 388 & 2.3063 \\
\hline 3A7N & $\mathrm{A}$ & 389 & 2.3167 \\
\hline 2DEM & $\mathrm{A}$ & 395 & 2.3603 \\
\hline 1LAU & $\mathrm{E}$ & 397 & 2.3667 \\
\hline 2OYT & $\mathrm{A}$ & 408 & 2.4565 \\
\hline 1OKB & $\mathrm{B}$ & 416 & 2.6335 \\
\hline & & & \\
\hline
\end{tabular}

\begin{tabular}{|l|l|l|l|}
\hline 2J8X & A & 305 & 3.0688 \\
\hline 2SSP & E & 308 & 3.0808 \\
\hline 1LQM & A & 309 & 3.0812 \\
\hline 2ZHX & E & 317 & 3.0918 \\
\hline 1LQG & A & 319 & 3.0961 \\
\hline 2ZHX & M & 321 & 3.1001 \\
\hline 2UUG & A & 332 & 3.1294 \\
\hline 1UGH & E & 337 & 3.1351 \\
\hline 1UGI & H & 343 & 3.1446 \\
\hline 2OWR & G & 347 & 3.1574 \\
\hline 2D3Y & A & 350 & 3.1625 \\
\hline 1UGI & B & 351 & 3.1635 \\
\hline 3FCK & B & 355 & 3.1720 \\
\hline 2ZHX & I & 359 & 3.1783 \\
\hline 1UGI & F & 368 & 3.1998 \\
\hline 2JHQ & A & 370 & 3.2053 \\
\hline 2DP6 & A & 372 & 3.2152 \\
\hline 1EUI & B & 374 & 3.2185 \\
\hline 3A7N & A & 376 & 3.2390 \\
\hline 2ZHX & G & 378 & 3.2453 \\
\hline 2HXM & A & 379 & 3.2470 \\
\hline 3FCL & A & 381 & 3.2631 \\
\hline 2J8X & B & 383 & 3.2643 \\
\hline 2DDG & A & 384 & 3.2695 \\
\hline 1LAU & E & 389 & 3.3118 \\
\hline 2DEM & A & 393 & 3.3481 \\
\hline 3FCI & A & 408 & 3.5009 \\
\hline 2OYT & A & 413 & 3.6219 \\
\hline 1OKB & B & 415 & 3.6801 \\
\hline & & & \\
\hline
\end{tabular}




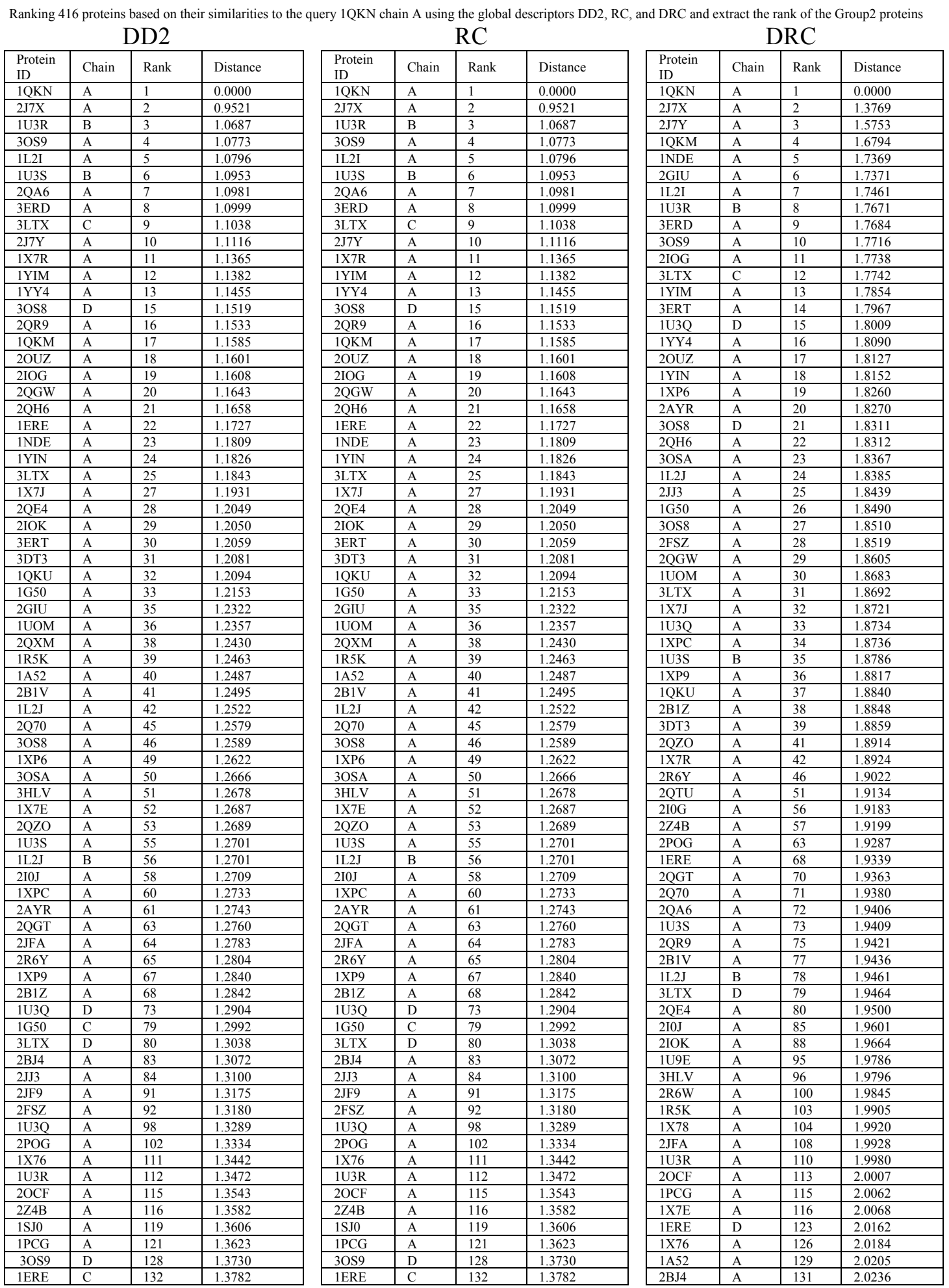




\begin{tabular}{|c|c|c|c|}
\hline $2 \mathrm{I} 0 \mathrm{G}$ & A & 133 & 1.3785 \\
\hline 1ERE & $\mathrm{F}$ & 134 & 1.3795 \\
\hline 1U9E & $\mathrm{A}$ & 139 & 1.3874 \\
\hline 3HM1 & A & 140 & 1.3875 \\
\hline $1 \times 78$ & $\mathrm{~A}$ & 141 & 1.3883 \\
\hline $2 \mathrm{QTU}$ & $\mathrm{A}$ & 142 & 1.3899 \\
\hline 1R5K & $\mathrm{C}$ & 143 & 1.3923 \\
\hline $1 \mathrm{X} 1 \mathrm{P}$ & A & 144 & 1.3954 \\
\hline 30 S & $\mathrm{C}$ & 145 & 1.3959 \\
\hline $2 \mathrm{R} 6 \mathrm{~W}$ & A & 146 & 1.3974 \\
\hline $1 \mathrm{ZAF}$ & A & 152 & 1.4049 \\
\hline 1ERE & D & 154 & 1.4061 \\
\hline 2Q6J & $\mathrm{A}$ & 160 & 1.4188 \\
\hline $2 \mathrm{JF} 9$ & $\mathrm{C}$ & 164 & 1.4228 \\
\hline 3LTX & B & 167 & 1.4273 \\
\hline 1A52 & $\mathrm{B}$ & 169 & 1.4297 \\
\hline $2 \mathrm{~B} 23$ & $\mathrm{~A}$ & 175 & 1.4424 \\
\hline $1 \mathrm{XQC}$ & $\mathrm{C}$ & 177 & 1.4444 \\
\hline 3OLS & A & 178 & 1.4451 \\
\hline $2 \mathrm{QXS}$ & $\mathrm{A}$ & 180 & 1.4456 \\
\hline $1 \mathrm{XQC}$ & $\mathrm{A}$ & 182 & 1.4469 \\
\hline 3L03 & A & 184 & 1.4514 \\
\hline 1ERE & $E$ & 186 & 1.4528 \\
\hline $1 \mathrm{X} 7 \mathrm{~B}$ & $\mathrm{~A}$ & 189 & 1.4552 \\
\hline 1R5K & B & 194 & 1.4627 \\
\hline $1 \mathrm{XQC}$ & D & 196 & 1.4642 \\
\hline 2QR9 & B & 200 & 1.4731 \\
\hline $2 \mathrm{NV} 7$ & $\mathrm{~A}$ & 201 & 1.4748 \\
\hline $2 \mathrm{G} 5 \mathrm{O}$ & A & 212 & 1.4969 \\
\hline $2 \mathrm{G} 44$ & $\mathrm{~A}$ & 213 & 1.4976 \\
\hline 2QGT & B & 214 & 1.4977 \\
\hline 1ERR & A & 217 & 1.5086 \\
\hline $1 \mathrm{ZKY}$ & A & 221 & 1.5121 \\
\hline 2QA6 & $\mathrm{B}$ & 227 & 1.5280 \\
\hline 1U3Q & C & 230 & 1.5342 \\
\hline $2 \mathrm{FSZ}$ & $\mathrm{B}$ & 239 & 1.5603 \\
\hline $3 \mathrm{OMO}$ & $\mathrm{A}$ & 240 & 1.5623 \\
\hline 1PCG & B & 244 & 1.5668 \\
\hline $2 \mathrm{~B} 23$ & B & 245 & 1.5701 \\
\hline 2FAI & B & 247 & 1.5722 \\
\hline 3DT3 & B & 248 & 1.5768 \\
\hline $2 \mathrm{FAI}$ & $\mathrm{A}$ & 249 & 1.5778 \\
\hline $1 \mathrm{YYE}$ & A & 255 & 1.5918 \\
\hline 3OSA & C & 260 & 1.5966 \\
\hline 3OSA & $\mathrm{D}$ & 266 & 1.6020 \\
\hline $2 \mathrm{Q} 6 \mathrm{~J}$ & $\mathrm{~B}$ & 270 & 1.6082 \\
\hline $2 \mathrm{QSE}$ & A & 277 & 1.6308 \\
\hline 3059 & C & 283 & 1.6394 \\
\hline 3OMP & $\mathrm{A}$ & 285 & 1.6402 \\
\hline $2 \mathrm{~B} 1 \mathrm{~V}$ & B & 286 & 1.6408 \\
\hline $2 \mathrm{G} 5 \mathrm{O}$ & $\mathrm{B}$ & 287 & 1.6482 \\
\hline $1 \mathrm{HCQ}$ & $E$ & 290 & 1.6533 \\
\hline $3 \mathrm{OSA}$ & B & 293 & 1.6643 \\
\hline $3 \mathrm{HLV}$ & B & 297 & 1.6801 \\
\hline $1 \mathrm{QKT}$ & A & 302 & 1.6924 \\
\hline 3ERD & B & 303 & 1.6928 \\
\hline $3 \mathrm{OMQ}$ & A & 304 & 1.6948 \\
\hline $2 \mathrm{QXM}$ & B & 305 & 1.6974 \\
\hline $1 \mathrm{QKU}$ & $\mathrm{C}$ & 306 & 1.7030 \\
\hline 2JFA & B & 308 & 1.7041 \\
\hline 1ERR & B & 309 & 1.7043 \\
\hline $2 \mathrm{~B} 1 \mathrm{Z}$ & B & 312 & 1.7083 \\
\hline $2 \mathrm{QTU}$ & B & 313 & 1.7102 \\
\hline $2 \mathrm{JJ} 3$ & B & 314 & 1.7105 \\
\hline $2 \mathrm{Q} 70$ & $\mathrm{~B}$ & 316 & 1.7196 \\
\hline $3 \mathrm{~L} 03$ & B & 330 & 1.7587 \\
\hline $2 \mathrm{I} 0 \mathrm{~J}$ & $\mathrm{~B}$ & 333 & 1.7704 \\
\hline 2R6Y & $\mathrm{B}$ & 334 & 1.7716 \\
\hline $2 \mathrm{QXS}$ & B & 336 & 1.7832 \\
\hline $2 \mathrm{QGW}$ & B & 338 & 1.7937 \\
\hline $2 \mathrm{IOK}$ & B & 339 & 1.7942 \\
\hline $2 \mathrm{Z4B}$ & $\mathrm{B}$ & 340 & 1.7970 \\
\hline 2QE4 & B & 344 & 1.8075 \\
\hline 1L2I & $\mathrm{B}$ & 346 & 1.8239 \\
\hline $2 \mathrm{G} 44$ & $\mathrm{~B}$ & 348 & 1.8331 \\
\hline 3HM1 & B & 351 & 1.8405 \\
\hline $1 \mathrm{G} 50$ & B & 352 & 1.8424 \\
\hline $2 \mathrm{QSE}$ & B & 353 & 1.8428 \\
\hline
\end{tabular}

\begin{tabular}{|c|c|c|c|}
\hline $2 \mathrm{I} 0 \mathrm{G}$ & $\mathrm{A}$ & 133 & 1.3785 \\
\hline 1ERE & $F$ & 134 & 1.3795 \\
\hline 1U9E & $\mathrm{A}$ & 139 & 1.3874 \\
\hline 3HM1 & A & 140 & 1.3875 \\
\hline $1 \times 78$ & $\mathrm{~A}$ & 141 & 1.3883 \\
\hline 2QTU & $\mathrm{A}$ & 142 & 1.3899 \\
\hline 1R5K & $\mathrm{C}$ & 143 & 1.3923 \\
\hline $1 \mathrm{X} 1 \mathrm{P}$ & $\mathrm{A}$ & 144 & 1.3954 \\
\hline 30 8 8 & $\mathrm{C}$ & 145 & 1.3959 \\
\hline $2 \mathrm{R} 6 \mathrm{~W}$ & $\mathrm{~A}$ & 146 & 1.3974 \\
\hline $1 \mathrm{ZAF}$ & A & 152 & 1.4049 \\
\hline 1ERE & D & 154 & 1.4061 \\
\hline 2Q6J & $\mathrm{A}$ & 160 & 1.4188 \\
\hline 2JF9 & $\mathrm{C}$ & 164 & 1.4228 \\
\hline 3LTX & B & 167 & 1.4273 \\
\hline $1 \mathrm{~A} 52$ & $\mathrm{~B}$ & 169 & 1.4297 \\
\hline $2 \mathrm{~B} 23$ & $\mathrm{~A}$ & 175 & 1.4424 \\
\hline $1 \mathrm{XQC}$ & $\mathrm{C}$ & 177 & 1.4444 \\
\hline 3OLS & A & 178 & 1.4451 \\
\hline $2 \mathrm{QXS}$ & A & 180 & 1.4456 \\
\hline $1 \mathrm{XQC}$ & $\mathrm{A}$ & 182 & 1.4469 \\
\hline $3 \mathrm{~L} 03$ & $\mathrm{~A}$ & 184 & 1.4514 \\
\hline 1ERE & E & 186 & 1.4528 \\
\hline $1 \mathrm{X7B}$ & $\mathrm{A}$ & 189 & 1.4552 \\
\hline 1R5K & B & 194 & 1.4627 \\
\hline $1 \mathrm{XQC}$ & D & 196 & 1.4642 \\
\hline 2QR9 & B & 200 & 1.4731 \\
\hline $2 \mathrm{NV7}$ & $\mathrm{A}$ & 201 & 1.4748 \\
\hline $2 \mathrm{G} 5 \mathrm{O}$ & $\mathrm{A}$ & 212 & 1.4969 \\
\hline $2 \mathrm{G} 44$ & $\mathrm{~A}$ & 213 & 1.4976 \\
\hline 2QGT & $\mathrm{B}$ & 214 & 1.4977 \\
\hline 1ERR & A & 217 & 1.5086 \\
\hline $1 \mathrm{ZKY}$ & $\mathrm{A}$ & 221 & 1.5121 \\
\hline 2QA6 & $\mathrm{B}$ & 227 & 1.5280 \\
\hline $1 \mathrm{U} 3 \mathrm{Q}$ & $\mathrm{C}$ & 230 & 1.5342 \\
\hline $2 \mathrm{FSZ}$ & $\mathrm{B}$ & 239 & 1.5603 \\
\hline $30 \mathrm{MO}$ & $\mathrm{A}$ & 240 & 1.5623 \\
\hline 1PCG & B & 244 & 1.5668 \\
\hline $2 \mathrm{~B} 23$ & B & 245 & 1.5701 \\
\hline $2 \mathrm{FAI}$ & B & 247 & 1.5722 \\
\hline 3DT3 & B & 248 & 1.5768 \\
\hline 2FAI & $\mathrm{A}$ & 249 & 1.5778 \\
\hline $1 \mathrm{YYE}$ & $\mathrm{A}$ & 255 & 1.5918 \\
\hline $30 S A$ & $\mathrm{C}$ & 260 & 1.5966 \\
\hline $3 \mathrm{OSA}$ & $\mathrm{D}$ & 266 & 1.6020 \\
\hline $2 \mathrm{Q} 6 \mathrm{~J}$ & $\mathrm{~B}$ & 270 & 1.6082 \\
\hline 2QSE & $\mathrm{A}$ & 277 & 1.6308 \\
\hline 3OS9 & $\mathrm{C}$ & 283 & 1.6394 \\
\hline 3OMP & $\mathrm{A}$ & 285 & 1.6402 \\
\hline $2 \mathrm{~B} 1 \mathrm{~V}$ & B & 286 & 1.6408 \\
\hline $2 \mathrm{G} 5 \mathrm{O}$ & $\mathrm{B}$ & 287 & 1.6482 \\
\hline $1 \mathrm{HCQ}$ & $E$ & 290 & 1.6533 \\
\hline $3 \mathrm{OSA}$ & $\mathrm{B}$ & 293 & 1.6643 \\
\hline 3HLV & B & 297 & 1.6801 \\
\hline 1QKT & A & 302 & 1.6924 \\
\hline 3ERD & B & 303 & 1.6928 \\
\hline $3 \mathrm{OMQ}$ & $\mathrm{A}$ & 304 & 1.6948 \\
\hline 2QXM & $\mathrm{B}$ & 305 & 1.6974 \\
\hline $1 \mathrm{QKU}$ & $\mathrm{C}$ & 306 & 1.7030 \\
\hline 2JFA & $\mathrm{B}$ & 308 & 1.7041 \\
\hline 1ERR & B & 309 & 1.7043 \\
\hline $2 \mathrm{~B} 1 \mathrm{Z}$ & B & 312 & 1.7083 \\
\hline $2 \mathrm{QTU}$ & B & 313 & 1.7102 \\
\hline $2 \mathrm{JJ} 3$ & B & 314 & 1.7105 \\
\hline $2 \mathrm{Q} 70$ & $\mathrm{~B}$ & 316 & 1.7196 \\
\hline $3 \mathrm{~L} 03$ & $\mathrm{~B}$ & 330 & 1.7587 \\
\hline $2 \mathrm{I} 0 \mathrm{~J}$ & $\mathrm{~B}$ & 333 & 1.7704 \\
\hline 2R6Y & $\mathrm{B}$ & 334 & 1.7716 \\
\hline 2QXS & B & 336 & 1.7832 \\
\hline $2 \mathrm{QGW}$ & B & 338 & 1.7937 \\
\hline $2 \mathrm{IOK}$ & B & 339 & 1.7942 \\
\hline $2 \mathrm{Z} 4 \mathrm{~B}$ & B & 340 & 1.7970 \\
\hline 2QE4 & B & 344 & 1.8075 \\
\hline 1L2I & B & 346 & 1.8239 \\
\hline 2G44 & B & 348 & 1.8331 \\
\hline 3HM1 & B & 351 & 1.8405 \\
\hline 1G50 & B & 352 & 1.8424 \\
\hline $2 \mathrm{QSE}$ & $\mathrm{B}$ & 353 & 1.8428 \\
\hline
\end{tabular}

\begin{tabular}{|c|c|c|c|}
\hline 3OLS & $\mathrm{A}$ & 135 & 2.0300 \\
\hline 1SJ0 & A & 136 & 2.0323 \\
\hline 2JF9 & $\mathrm{A}$ & 139 & 2.0365 \\
\hline 3HM1 & A & 142 & 2.0414 \\
\hline $2 \mathrm{QXM}$ & A & 144 & 2.0489 \\
\hline 1ZAF & A & 152 & 2.0569 \\
\hline 3LTX & B & 158 & 2.0647 \\
\hline $30 \mathrm{OS} 9$ & D & 160 & 2.0708 \\
\hline $1 \mathrm{X} 7 \mathrm{~B}$ & $\mathrm{~A}$ & 163 & 2.0771 \\
\hline 1R5K & $\mathrm{C}$ & 165 & 2.0843 \\
\hline 1X1P & A & 166 & 2.0890 \\
\hline $1 \mathrm{XQC}$ & $\mathrm{C}$ & 169 & 2.0970 \\
\hline 1ERE & E & 172 & 2.1050 \\
\hline 1ERR & $\mathrm{A}$ & 175 & 2.1084 \\
\hline $1 \mathrm{G} 50$ & $\mathrm{C}$ & 178 & 2.1118 \\
\hline $2 \mathrm{Q} 6 \mathrm{~J}$ & $\mathrm{~A}$ & 181 & 2.1182 \\
\hline $1 \mathrm{ZKY}$ & $\mathrm{A}$ & 190 & 2.1353 \\
\hline 1R5K & $\mathrm{B}$ & 194 & 2.1418 \\
\hline $2 \mathrm{FSZ}$ & B & 196 & 2.1435 \\
\hline $2 \mathrm{G} 5 \mathrm{O}$ & A & 199 & 2.1453 \\
\hline 1ERE & $\mathrm{C}$ & 203 & 2.1551 \\
\hline $1 \mathrm{XQC}$ & D & 204 & 2.1556 \\
\hline $2 \mathrm{QXS}$ & $\mathrm{A}$ & 205 & 2.1564 \\
\hline $1 \mathrm{ERE}$ & $\mathrm{F}$ & 206 & 2.1586 \\
\hline $1 \mathrm{XQC}$ & $\mathrm{A}$ & 208 & 2.1625 \\
\hline 3L03 & A & 209 & 2.1637 \\
\hline $2 \mathrm{JF} 9$ & $\mathrm{C}$ & 211 & 2.1699 \\
\hline $2 \mathrm{~B} 23$ & $\mathrm{~A}$ & 212 & 2.1701 \\
\hline $2 \mathrm{NV7}$ & $\mathrm{A}$ & 213 & 2.1702 \\
\hline $30 \mathrm{OMO}$ & $\mathrm{A}$ & 216 & 2.1718 \\
\hline $1 \mathrm{U} 3 \mathrm{Q}$ & $\mathrm{C}$ & 217 & 2.1755 \\
\hline $30 \mathrm{OS} 8$ & $\mathrm{C}$ & 218 & 2.1760 \\
\hline $3 \mathrm{OSA}$ & D & 226 & 2.1845 \\
\hline $1 \mathrm{~A} 52$ & B & 235 & 2.2051 \\
\hline $2 \mathrm{~B} 23$ & B & 249 & 2.2280 \\
\hline $2 \mathrm{G} 44$ & $\mathrm{~A}$ & 250 & 2.2286 \\
\hline 2QGT & $\mathrm{B}$ & 252 & 2.2316 \\
\hline $2 \mathrm{JJ} 3$ & B & 255 & 2.2354 \\
\hline $2 \mathrm{FAI}$ & A & 257 & 2.2377 \\
\hline $1 \mathrm{HCQ}$ & $\mathrm{E}$ & 262 & 2.2571 \\
\hline 2QA6 & B & 263 & 2.2610 \\
\hline 3OMP & $\mathrm{A}$ & 267 & 2.2707 \\
\hline 3DT3 & B & 271 & 2.2918 \\
\hline $3 \mathrm{OMQ}$ & $\mathrm{A}$ & 274 & 2.3015 \\
\hline $3 \mathrm{OSA}$ & B & 275 & 2.3077 \\
\hline 2QR9 & B & 276 & 2.3130 \\
\hline $1 \mathrm{PCG}$ & B & 277 & 2.3149 \\
\hline 1YYE & A & 280 & 2.3186 \\
\hline 2FAI & B & 283 & 2.3263 \\
\hline $2 \mathrm{QTU}$ & B & 285 & 2.3340 \\
\hline 2Q6J & B & 287 & 2.3372 \\
\hline $2 \mathrm{Z} 4 \mathrm{~B}$ & B & 289 & 2.3467 \\
\hline $3 \mathrm{OSA}$ & $\mathrm{C}$ & 290 & 2.3493 \\
\hline 1ERR & B & 291 & 2.3535 \\
\hline $2 \mathrm{G} 5 \mathrm{O}$ & B & 300 & 2.3935 \\
\hline $2 \mathrm{Q} 70$ & B & 301 & 2.4050 \\
\hline $2 \mathrm{~B} 1 \mathrm{~V}$ & B & 304 & 2.4158 \\
\hline 2QXM & $\mathrm{B}$ & 305 & 2.4201 \\
\hline 3ERD & B & 307 & 2.4237 \\
\hline $30 \mathrm{OS} 9$ & $\mathrm{C}$ & 310 & 2.4444 \\
\hline $1 \mathrm{QKT}$ & $\mathrm{A}$ & 311 & 2.4460 \\
\hline $2 \mathrm{~B} 1 \mathrm{Z}$ & B & 312 & 2.4488 \\
\hline $3 \mathrm{HLV}$ & B & 313 & 2.4524 \\
\hline $2 \mathrm{QSE}$ & $\mathrm{A}$ & 314 & 2.4536 \\
\hline $2 \mathrm{JFA}$ & B & 316 & 2.4610 \\
\hline $2 \mathrm{QXS}$ & B & 321 & 2.4813 \\
\hline 2I0J & $\mathrm{B}$ & 322 & 2.4828 \\
\hline $2 \mathrm{G} 44$ & B & 328 & 2.5098 \\
\hline 2R6Y & B & 333 & 2.5223 \\
\hline 3HM1 & B & 340 & 2.5403 \\
\hline $3 \mathrm{~L} 03$ & B & 341 & 2.5433 \\
\hline $2 \mathrm{IOK}$ & B & 342 & 2.5455 \\
\hline $2 \mathrm{QGW}$ & B & 344 & 2.5542 \\
\hline $1 \mathrm{QKU}$ & $\mathrm{C}$ & 346 & 2.5620 \\
\hline $1 \mathrm{HCQ}$ & $\mathrm{F}$ & 352 & 2.6212 \\
\hline $2 \mathrm{QSE}$ & B & 353 & 2.6232 \\
\hline 3059 & B & 354 & 2.6254 \\
\hline 3058 & B & 356 & 2.6434 \\
\hline
\end{tabular}




\begin{tabular}{|c|c|c|c|}
\hline 1ZAF & B & 354 & 1.8528 \\
\hline $1 \mathrm{HCQ}$ & $F$ & 355 & 1.8570 \\
\hline 3059 & B & 356 & 1.8571 \\
\hline $2 \mathrm{P} 15$ & A & 357 & 1.8571 \\
\hline $1 \mathrm{ERE}$ & B & 359 & 1.8592 \\
\hline 2QH6 & B & 362 & 1.8785 \\
\hline 2R6W & B & 364 & 1.8959 \\
\hline $1 \mathrm{X} 7 \mathrm{~J}$ & B & 365 & 1.9199 \\
\hline $30 \mathrm{OL}$ & $\mathrm{A}$ & 368 & 1.9297 \\
\hline 2 JF9 & B & 369 & 1.9308 \\
\hline 3058 & B & 370 & 1.9361 \\
\hline 1YY4 & B & 372 & 1.9472 \\
\hline 1X7B & B & 374 & 1.9605 \\
\hline $2 \mathrm{POG}$ & B & 376 & 1.9723 \\
\hline $30 \mathrm{OP}$ & B & 377 & 1.9734 \\
\hline $2 \mathrm{P} 15$ & B & 378 & 1.9839 \\
\hline $1 \mathrm{X} 7 \mathrm{E}$ & B & 379 & 1.9875 \\
\hline $1 \mathrm{XQC}$ & B & 383 & 2.0065 \\
\hline $3 \mathrm{OMO}$ & B & 385 & 2.0406 \\
\hline 1U9E & B & 386 & 2.0597 \\
\hline $1 \mathrm{U} 3 \mathrm{Q}$ & B & 387 & 2.0611 \\
\hline 2BJ4 & B & 389 & 2.0984 \\
\hline 1YYE & B & 391 & 2.1176 \\
\hline 3 OLS & B & 392 & 2.1290 \\
\hline 2NV7 & B & 395 & 2.1510 \\
\hline $3 \mathrm{OMQ}$ & B & 397 & 2.1746 \\
\hline $1 \mathrm{X} 76$ & B & 400 & 2.2412 \\
\hline $1 \mathrm{ZKY}$ & B & 401 & 2.2448 \\
\hline $3 \mathrm{OLL}$ & B & 403 & 2.2624 \\
\hline $1 \mathrm{HCQ}$ & B & 406 & 2.4074 \\
\hline $3 \mathrm{CBO}$ & B & 407 & 2.4074 \\
\hline $1 \mathrm{X} 78$ & B & 408 & 2.4144 \\
\hline $2 \mathrm{QZO}$ & B & 409 & 2.4212 \\
\hline $3 \mathrm{CBP}$ & B & 412 & 2.4828 \\
\hline $1 \mathrm{QKU}$ & B & 413 & 2.4839 \\
\hline $3 \mathrm{CBM}$ & B & 416 & 2.5903 \\
\hline
\end{tabular}

\begin{tabular}{|l|l|l|l|}
\hline 1ZAF & B & 354 & 1.8528 \\
\hline 1HCQ & F & 355 & 1.8570 \\
\hline 3OS9 & B & 356 & 1.8571 \\
\hline 2P15 & A & 357 & 1.8571 \\
\hline 1ERE & B & 359 & 1.8592 \\
\hline 2QH6 & B & 362 & 1.8785 \\
\hline 2R6W & B & 364 & 1.8959 \\
\hline 1X7J & B & 365 & 1.9199 \\
\hline 3OLL & A & 368 & 1.9297 \\
\hline 2JF9 & B & 369 & 1.9308 \\
\hline 3OS8 & B & 370 & 1.9361 \\
\hline 1YY4 & B & 372 & 1.9472 \\
\hline 1X7B & B & 374 & 1.9605 \\
\hline 2POG & B & 376 & 1.9723 \\
\hline 3OMP & B & 377 & 1.9734 \\
\hline 2P15 & B & 378 & 1.9839 \\
\hline 1X7E & B & 379 & 1.9875 \\
\hline 1XQC & B & 383 & 2.0065 \\
\hline 3OMO & B & 385 & 2.0406 \\
\hline 1U9E & B & 386 & 2.0597 \\
\hline 1U3Q & B & 387 & 2.0611 \\
\hline 2BJ4 & B & 389 & 2.0984 \\
\hline 1YYE & B & 391 & 2.1176 \\
\hline 3OLS & B & 392 & 2.1290 \\
\hline 2NV7 & B & 395 & 2.1510 \\
\hline 3OMQ & B & 397 & 2.1746 \\
\hline 1X76 & B & 400 & 2.2412 \\
\hline 1ZKY & B & 401 & 2.2448 \\
\hline 3OLL & B & 403 & 2.2624 \\
\hline 1HCQ & B & 406 & 2.4074 \\
\hline 3CBO & B & 407 & 2.4074 \\
\hline 1X78 & B & 408 & 2.4144 \\
\hline 2QZO & B & 409 & 2.4212 \\
\hline 3CBP & B & 412 & 2.4828 \\
\hline 1QKU & B & 413 & 2.4839 \\
\hline 3CBM & B & 416 & 2.5903 \\
\hline & & & \\
\hline
\end{tabular}

\begin{tabular}{|l|l|l|l|}
\hline 2QE4 & B & 358 & 2.6566 \\
\hline 3OLL & A & 361 & 2.6637 \\
\hline 1L2I & B & 362 & 2.6642 \\
\hline 2R6W & B & 363 & 2.6656 \\
\hline 2P15 & A & 366 & 2.6859 \\
\hline 1G50 & B & 368 & 2.6948 \\
\hline 1U3Q & B & 369 & 2.6969 \\
\hline 1YY4 & B & 370 & 2.6972 \\
\hline 1X7B & B & 371 & 2.7035 \\
\hline 3OMO & B & 372 & 2.7132 \\
\hline 1ZAF & B & 373 & 2.7193 \\
\hline 1ERE & B & 374 & 2.7293 \\
\hline 2POG & B & 376 & 2.7429 \\
\hline 2JF9 & B & 377 & 2.7700 \\
\hline 3OMP & B & 378 & 2.7792 \\
\hline 1X7J & B & 379 & 2.8011 \\
\hline 1XQC & B & 380 & 2.8102 \\
\hline 2P15 & B & 382 & 2.8267 \\
\hline 2QH6 & B & 384 & 2.8345 \\
\hline 1U9E & B & 385 & 2.8421 \\
\hline 1X7E & B & 388 & 2.8984 \\
\hline 2BJ4 & B & 389 & 2.9397 \\
\hline 3OMQ & B & 390 & 2.9535 \\
\hline 1YYE & B & 391 & 2.9604 \\
\hline 1HCQ & B & 396 & 3.0334 \\
\hline 3CBO & B & 397 & 3.0334 \\
\hline 2NV7 & B & 399 & 3.0658 \\
\hline 1ZKY & B & 402 & 3.0833 \\
\hline 3CBP & B & 403 & 3.0935 \\
\hline 3OLL & B & 404 & 3.0961 \\
\hline 3OLS & B & 405 & 3.0976 \\
\hline 1X76 & B & 406 & 3.1256 \\
\hline 3CBM & B & 410 & 3.2651 \\
\hline 2QZO & B & 412 & 3.3277 \\
\hline 1X78 & B & 413 & 3.3625 \\
\hline 1QKU & B & 414 & 3.4456 \\
\hline & & & \\
\hline
\end{tabular}


Ranking 416 proteins based on their similarities to the query 1YKR chain A using the global descriptors DD2, RC, and DRC and extract the rank of the Group3 protein

DD2

\begin{tabular}{|c|c|c|c|}
\hline $\begin{array}{l}\text { Protein } \\
\text { ID }\end{array}$ & Chain & Rank & Distance \\
\hline 1YKR & A & 1 & 0 \\
\hline 3PY1 & $\mathrm{A}$ & 2 & 0.7436 \\
\hline $2 \mathrm{R} 3 \mathrm{O}$ & $\mathrm{A}$ & 3 & 0.7449 \\
\hline 3NS9 & $\mathrm{A}$ & 4 & 0.7490 \\
\hline $2 \mathrm{C} 5 \mathrm{Y}$ & $\overline{\mathrm{A}}$ & 5 & 0.7590 \\
\hline $2 \mathrm{UZO}$ & $\mathrm{A}$ & 6 & 0.7761 \\
\hline 3PXY & $\mathrm{A}$ & 7 & 0.7896 \\
\hline 2WMA & A & 8 & 0.7996 \\
\hline 3DDP & A & 9 & 0.8082 \\
\hline $2 \mathrm{~V} 22$ & $\mathrm{C}$ & 10 & 0.8257 \\
\hline 2IW6 & $\bar{A}$ & 11 & 0.8316 \\
\hline $2 \mathrm{WFY}$ & $\mathrm{A}$ & 12 & 0.8346 \\
\hline 2R3L & $\mathrm{A}$ & 13 & 0.8554 \\
\hline 2DUV & $\mathrm{A}$ & 14 & 0.8582 \\
\hline 3LFN & A & 15 & 0.8740 \\
\hline 2R3J & A & 16 & 0.8774 \\
\hline $2 \mathrm{~J} 9 \mathrm{M}$ & $\bar{A}$ & 17 & 0.8810 \\
\hline $3 \mathrm{DOG}$ & $\mathrm{A}$ & 18 & 0.8837 \\
\hline $1 \mathrm{~W} 8 \mathrm{C}$ & $\mathrm{A}$ & 19 & 0.8839 \\
\hline 2WIP & $\overline{\mathrm{A}}$ & 20 & 0.8993 \\
\hline 2R3P & A & 21 & 0.9028 \\
\hline $2 \mathrm{R} 3 \mathrm{M}$ & A & 22 & 0.9130 \\
\hline $2 \mathrm{VTN}$ & $\mathrm{A}$ & 23 & 0.9131 \\
\hline $2 \mathrm{~W} 05$ & $\mathrm{~A}$ & 24 & 0.9140 \\
\hline 3DDP & $\mathrm{C}$ & 25 & 0.9163 \\
\hline 3PXR & $\mathrm{A}$ & 26 & 0.9226 \\
\hline $2 \mathrm{C} 5 \mathrm{~N}$ & $\mathrm{C}$ & 27 & 0.9230 \\
\hline 3EZR & $\bar{A}$ & 28 & 0.9268 \\
\hline 2R64 & A & 29 & 0.9270 \\
\hline 2VTP & $\mathrm{A}$ & 30 & 0.9378 \\
\hline 3IGG & A & 31 & 0.9389 \\
\hline $2 \mathrm{WEV}$ & $\mathrm{C}$ & 32 & 0.9407 \\
\hline 2UZD & $\mathrm{C}$ & 33 & 0.9443 \\
\hline $2 \mathrm{WXV}$ & $\mathrm{A}$ & 34 & 0.9459 \\
\hline $2 \mathrm{WIP}$ & $\mathrm{C}$ & 35 & 0.9475 \\
\hline $2 \mathrm{WIH}$ & $\mathrm{C}$ & 37 & 0.9570 \\
\hline 2JGZ & A & 38 & 0.9575 \\
\hline $2 \mathrm{~W} 06$ & $\bar{A}$ & 39 & 0.9596 \\
\hline $2 \mathrm{~V} 22$ & $\mathrm{~A}$ & 40 & 0.9625 \\
\hline $2 \mathrm{BKZ}$ & $\mathrm{C}$ & 41 & 0.9628 \\
\hline 3EID & $\mathrm{C}$ & 42 & 0.9629 \\
\hline $2 \mathrm{WXV}$ & $\mathrm{C}$ & 43 & 0.9656 \\
\hline $2 \mathrm{WHB}$ & $\mathrm{C}$ & 44 & 0.9659 \\
\hline $2 \mathrm{I} 40$ & $\mathrm{C}$ & 45 & 0.9671 \\
\hline 2UZE & $\mathrm{C}$ & 46 & 0.9680 \\
\hline $2 \mathrm{C} 5 \mathrm{~V}$ & $\mathrm{C}$ & 47 & 0.9690 \\
\hline $2 \mathrm{I} 40$ & $\mathrm{~A}$ & 49 & 0.9709 \\
\hline $2 \mathrm{C} 5 \mathrm{~V}$ & $\bar{A}$ & 50 & 0.9793 \\
\hline 2UZL & $\mathrm{C}$ & 51 & 0.9811 \\
\hline $3 \mathrm{LFQ}$ & $\mathrm{A}$ & 52 & 0.9827 \\
\hline $2 \mathrm{BKZ}$ & A & 53 & 0.9853 \\
\hline $3 \mathrm{EJ} 1$ & $\mathrm{~A}$ & 54 & 0.9876 \\
\hline 3EOC & $\mathrm{A}$ & 55 & 0.9891 \\
\hline $2 \mathrm{WHB}$ & $\mathrm{A}$ & 56 & 0.9898 \\
\hline 3IG7 & $\mathrm{A}$ & 57 & 0.9909 \\
\hline 2WPA & $\mathrm{C}$ & 58 & 0.9914 \\
\hline 3PY0 & $\mathrm{A}$ & 59 & 0.9919 \\
\hline 2UUE & $\mathrm{C}$ & 60 & 0.9930 \\
\hline $2 \mathrm{VV9}$ & $\mathrm{A}$ & 61 & 0.9931 \\
\hline $2 \mathrm{X} 1 \mathrm{~N}$ & $\mathrm{C}$ & 62 & 0.9933 \\
\hline $2 \mathrm{R} 3 \mathrm{~K}$ & $\mathrm{~A}$ & 63 & 0.9955 \\
\hline $2 \mathrm{R} 3 \mathrm{H}$ & $\mathrm{A}$ & 64 & 0.9963 \\
\hline 2VTA & $\mathrm{A}$ & 65 & 0.9979 \\
\hline $2 \mathrm{WIH}$ & $\bar{A}$ & 66 & 1.0016 \\
\hline 2IW8 & A & 67 & 1.0030 \\
\hline $3 \mathrm{EOC}$ & $\mathrm{C}$ & 68 & 1.0032 \\
\hline 2WPA & $\mathrm{A}$ & 70 & 1.0120 \\
\hline 3 F5X & $\mathrm{C}$ & 71 & 1.0137 \\
\hline 3PXZ & $\mathrm{A}$ & 72 & 1.0186 \\
\hline 2UUE & $\bar{A}$ & 75 & 1.0266 \\
\hline 3EJ1 & $\mathrm{C}$ & 76 & 1.0277 \\
\hline $2 \mathrm{CCH}$ & $\mathrm{C}$ & 77 & 1.0306 \\
\hline 2WMA & $\mathrm{C}$ & 78 & 1.0323 \\
\hline $3 \mathrm{FZ1}$ & A & 79 & 1.0327 \\
\hline
\end{tabular}

$\mathrm{RC}$

\begin{tabular}{|c|c|c|c|}
\hline $\begin{array}{c}\text { Protein } \\
\text { ID }\end{array}$ & $\begin{array}{c}\text { Chai } \\
\mathrm{n}\end{array}$ & Rank & Distance \\
\hline 1YKR & $\mathrm{A}$ & 1 & 0 \\
\hline 2UZO & $\mathrm{A}$ & 2 & 0.6917 \\
\hline 3PXY & $\mathrm{A}$ & 3 & 0.7436 \\
\hline 3IGG & $\mathrm{A}$ & 4 & 0.7699 \\
\hline 2R3O & $\mathrm{A}$ & 5 & 0.7834 \\
\hline 3PY1 & $\mathrm{A}$ & 6 & 0.8025 \\
\hline 2IW6 & $\mathrm{A}$ & 7 & 0.8101 \\
\hline 2WMA & $\mathrm{A}$ & 8 & 0.8110 \\
\hline 3PXR & $\mathrm{A}$ & 9 & 0.8318 \\
\hline 2V22 & $\mathrm{A}$ & 10 & 0.8473 \\
\hline 2J9M & $\mathrm{A}$ & 11 & 0.8561 \\
\hline 2R3 & $\mathrm{A}$ & 12 & 0.8726 \\
\hline
\end{tabular}

\begin{tabular}{|l|l|l|l|}
\hline 2R3J & A & 12 & 0.8726 \\
\hline 3IG7 & A & 13 & 0.8733 \\
\hline
\end{tabular}

\begin{tabular}{|c|c|c|c|}
\hline 2WFY & A & 14 & 0.8871 \\
\hline 1W8C & A & 15 & 0.8960 \\
\hline
\end{tabular}

\begin{tabular}{|c|c|c|c|c|}
\hline $2 \mathrm{R} 3 \mathrm{~L}$ & $\mathrm{~A}$ & 16 & 0.8980 \\
\hline $2 \mathrm{WHB}$ & $\mathrm{A}$ & 17 & 0.9005 \\
\hline
\end{tabular}

\begin{tabular}{|c|c|c|c|}
\hline $2 \mathrm{WHB}$ & $\mathrm{A}$ & 17 & 0.9005 \\
\hline $2 \mathrm{X} 1 \mathrm{~N}$ & $\mathrm{~A}$ & 18 & 0.9017 \\
\hline
\end{tabular}

\begin{tabular}{|c|c|c|c|}
\hline 2CCI & A & 19 & 0.9091 \\
\hline 2UUE & A & 20 & 0.9097 \\
\hline 2UZD & A & 21 & 0.9124 \\
\hline
\end{tabular}

\begin{tabular}{|l|c|c|c|}
\hline 2UZD & A & 21 & 0.9124 \\
\hline 2DUV & A & 22 & 0.9136 \\
\hline
\end{tabular}

\begin{tabular}{|c|c|c|c|}
\hline 2R3P & A & 23 & 0.9191 \\
\hline 2JGZ & A & 24 & 0.9196 \\
\hline
\end{tabular}

\begin{tabular}{|c|c|c|c|}
\hline 2JGZ & A & 24 & 0.9196 \\
\hline 3DDP & A & 25 & 0.9245 \\
\hline 3DOG & A & 26 & 0.9251 \\
\hline
\end{tabular}

\begin{tabular}{|c|c|c|c|}
\hline 3DOG & A & 26 & 0.9251 \\
\hline 2BKZ & A & 27 & 0.9346 \\
\hline 3PXZ & A & 28 & 0.9413 \\
\hline
\end{tabular}

\begin{tabular}{|c|c|c|c|}
\hline 3PXZ & A & 28 & 0.9413 \\
\hline 3NS9 & A & 29 & 0.9431 \\
\hline
\end{tabular}

\begin{tabular}{|c|c|c|c|}
\hline 3PY0 & A & 30 & 0.9487 \\
\hline 2WMB & A & 31 & 0.9499 \\
\hline 2VU3 & A & 32 & 0.9538 \\
\hline
\end{tabular}

\begin{tabular}{|c|c|c|c|}
\hline 2VU3 & $\mathrm{A}$ & 32 & 0.9538 \\
\hline 2R64 & $\mathrm{A}$ & 33 & 0.9542 \\
\hline
\end{tabular}

\begin{tabular}{|l|c|c|c|}
\hline $2 \mathrm{R} 3 \mathrm{~N}$ & $\mathrm{~A}$ & 33 & 0.9542 \\
\hline $2 \mathrm{C} 5 \mathrm{Y}$ & $\mathrm{A}$ & 34 & 0.9600 \\
\hline 3 & $\mathrm{~A}$ & 36 & 0.9642 \\
\hline
\end{tabular}

\begin{tabular}{|c|c|c|c|}
\hline 2C5Y & A & 35 & 0.9642 \\
\hline 3LFQ & A & 36 & 0.9655 \\
\hline 2WPA & A & 37 & 0.9690 \\
\hline
\end{tabular}

\begin{tabular}{|c|c|c|c|}
\hline 2R3K & A & 38 & 0.9704 \\
\hline 3EOC & A & 39 & 0.9718 \\
\hline
\end{tabular}

\begin{tabular}{|c|c|c|c|}
\hline 3EOC & A & 39 & 0.9718 \\
\hline 2WIH & A & 40 & 0.9732 \\
\hline 2VTT & A & 41 & 0.9865 \\
\hline
\end{tabular}

\begin{tabular}{|l|c|c|c|}
\hline 2VTT & A & 41 & 0.9865 \\
\hline 2W06 & A & 42 & 0.9878 \\
\hline
\end{tabular}

\begin{tabular}{|l|c|c|c|}
\hline 2VTN & $\mathrm{A}$ & 43 & 0.9887 \\
\hline 2VTR & $\mathrm{A}$ & 44 & 0.9892 \\
\hline
\end{tabular}

\begin{tabular}{|c|c|c|c|}
\hline 2VTR & $\mathrm{A}$ & 44 & 0.9892 \\
\hline 3EID & $\mathrm{A}$ & 45 & 0.9903 \\
\hline 2C5V & $\mathrm{A}$ & 46 & 0.9903 \\
\hline
\end{tabular}

\begin{tabular}{|c|c|c|c|}
\hline 2C5V & $\mathrm{A}$ & 46 & 0.9903 \\
\hline 3EJ1 & $\mathrm{A}$ & 47 & 0.9914 \\
\hline
\end{tabular}

\begin{tabular}{|c|c|c|c|}
\hline 3EZV & A & 48 & 0.9914 \\
\hline 3EZR & A & 49 & 0.9970 \\
\hline
\end{tabular}

\begin{tabular}{|l|c|c|c|}
\hline 3EZR & $\mathrm{A}$ & 49 & 0.9978 \\
\hline 2V22 & $\mathrm{C}$ & 50 & 0.9994 \\
\hline 2IW8 & $\mathrm{A}$ & 51 & 1.0000 \\
\hline
\end{tabular}

\begin{tabular}{|c|c|c|c|}
\hline 2IW8 & $\mathrm{A}$ & 51 & 1.0000 \\
\hline 2WXV & $\mathrm{A}$ & 52 & 1.0021 \\
\hline
\end{tabular}

\begin{tabular}{|c|c|c|c|}
\hline $2 \mathrm{I} 40$ & $\mathrm{~A}$ & 53 & 1.0021 \\
\hline $2 \mathrm{~W} 05$ & $\mathrm{~A}$ & 54 & 1.0049 \\
\hline
\end{tabular}

\begin{tabular}{|l|c|c|c}
$2 \mathrm{~W} 05$ & $\mathrm{~A}$ & 54 & 1.0067 \\
\hline 2WIP & $\mathrm{A}$ & 55 & 1.0088 \\
\hline
\end{tabular}

\begin{tabular}{|c|c|c|c|}
\hline $2 \mathrm{WIP}$ & $\mathrm{A}$ & 55 & 1.0088 \\
\hline $2 \mathrm{R} 3 \mathrm{M}$ & $\mathrm{A}$ & 56 & 1.0126 \\
\hline $3 \mathrm{EJ} 1$ & $\mathrm{C}$ & 57 & 1.0128 \\
\hline
\end{tabular}

\begin{tabular}{|c|c|c|c|}
\hline 3EJ1 & $\mathrm{C}$ & 57 & 1.0128 \\
\hline $2 \mathrm{UZN}$ & $\mathrm{A}$ & 58 & 1.0143 \\
\hline
\end{tabular}

\begin{tabular}{|c|c|c|c|}
\hline $2 \mathrm{R} 3 \mathrm{H}$ & $\mathrm{A}$ & 59 & 1.0174 \\
\hline $2 \mathrm{VTO}$ & $\mathrm{A}$ & 60 & 1.0238 \\
\hline
\end{tabular}

\begin{tabular}{|c|c|c|c|}
\hline $2 \mathrm{VTO}$ & $\mathrm{A}$ & 60 & 1.0238 \\
\hline 3EID & $\mathrm{C}$ & 61 & 1.0258 \\
\hline 3LFN & $\mathrm{A}$ & 62 & 1.0258 \\
\hline
\end{tabular}

\begin{tabular}{|c|c|c|c|}
\hline 3LFN & A & 62 & 1.0258 \\
\hline 2W1H & A & 63 & 1.0276 \\
\hline
\end{tabular}

\begin{tabular}{|c|c|c|c|}
\hline 3EOC & $\mathrm{C}$ & 64 & 1.0280 \\
\hline 3F5X & $\mathrm{C}$ & 65 & 1.0321 \\
\hline
\end{tabular}

\begin{tabular}{|c|c|c|c|}
\hline 2VTM & $\mathrm{C}$ & 65 & 1.0321 \\
\hline VTM & $\mathrm{A}$ & 66 & 1.0325 \\
\hline
\end{tabular}

\begin{tabular}{|c|c|c|c|}
\hline $2 \mathrm{VTM}$ & $\mathrm{A}$ & 66 & 1.0325 \\
\hline $2 \mathrm{WIH}$ & $\mathrm{C}$ & 67 & 1.0352 \\
\hline $3 \mathrm{FZI}$ & $\mathrm{A}$ & 68 & 1.0356 \\
\hline
\end{tabular}

\begin{tabular}{|c|c|c|c|}
\hline $3 \mathrm{FZ1}$ & $\mathrm{A}$ & 68 & 1.0356 \\
\hline 2VTP & $\mathrm{A}$ & 69 & 1.0356 \\
\hline
\end{tabular}

\begin{tabular}{|c|c|c|c|}
\hline 3LE6 & $\mathrm{A}$ & 69 & 1.0356 \\
\hline 2BKZ & $\mathrm{C}$ & 71 & 1.0361 \\
\hline & $\mathrm{C}$ & 72 & 1.0371 \\
\hline
\end{tabular}

\begin{tabular}{|c|c|c|c|}
\hline 2BKZ & $\mathrm{C}$ & 71 & 1.0371 \\
\hline 2I40 & $\mathrm{C}$ & 72 & 1.0374 \\
\hline 2W17 & $\mathrm{A}$ & 73 & 1.0388 \\
\hline 3LFS & $\mathrm{A}$ & 74 & 1.0427
\end{tabular}

DRC

\begin{tabular}{|c|c|c|c|}
\hline $\begin{array}{c}\text { Protein } \\
\text { ID }\end{array}$ & Chain & Rank & Distance \\
\hline 1YKR & A & 1 & 0 \\
\hline $2 \mathrm{UZO}$ & $\mathrm{A}$ & 2 & 1.0396 \\
\hline $2 \mathrm{R} 3 \mathrm{O}$ & $\mathrm{A}$ & 3 & 1.0810 \\
\hline 3PXY & $\mathrm{A}$ & 4 & 1.0847 \\
\hline 3PY1 & $\mathrm{A}$ & 5 & 1.0940 \\
\hline 2WMA & $\mathrm{A}$ & 6 & 1.1389 \\
\hline 2IW6 & A & 7 & 1.1610 \\
\hline 3NS9 & A & 8 & 1.2043 \\
\hline 3IGG & A & 9 & 1.2142 \\
\hline 2WFY & $\mathrm{A}$ & 10 & 1.2179 \\
\hline $2 \mathrm{C} 5 \mathrm{Y}$ & A & 11 & 1.2270 \\
\hline 3DDP & $\mathrm{A}$ & 12 & 1.2280 \\
\hline $2 \mathrm{~J} 9 \mathrm{M}$ & $\mathrm{A}$ & 13 & 1.2284 \\
\hline 2R3J & $\overline{\mathrm{A}}$ & 14 & 1.2375 \\
\hline $2 \mathrm{R} 3 \mathrm{~L}$ & A & 15 & 1.2402 \\
\hline 3PXR & A & 16 & 1.2422 \\
\hline $2 \mathrm{DUV}$ & $\mathrm{A}$ & 17 & 1.2534 \\
\hline $1 \mathrm{~W} 8 \mathrm{C}$ & A & 18 & 1.2587 \\
\hline $3 \mathrm{DOG}$ & $\mathrm{A}$ & 19 & 1.2794 \\
\hline $2 \mathrm{~V} 22$ & A & 20 & 1.2823 \\
\hline 2R3P & A & 21 & 1.2884 \\
\hline $2 \mathrm{~V} 22$ & $\mathrm{C}$ & 22 & 1.2964 \\
\hline 3IG7 & $\mathrm{A}$ & 23 & 1.3208 \\
\hline $2 \mathrm{JGZ}$ & A & 24 & 1.3276 \\
\hline 2R64 & $\mathrm{A}$ & 25 & 1.3303 \\
\hline $2 \mathrm{WHB}$ & $\mathrm{A}$ & 26 & 1.3382 \\
\hline $2 \mathrm{VTN}$ & $\mathrm{A}$ & 27 & 1.3458 \\
\hline 3LFN & $\mathrm{A}$ & 28 & 1.3476 \\
\hline 2 WIP & A & 29 & 1.3515 \\
\hline $2 \mathrm{BKZ}$ & A & 30 & 1.3580 \\
\hline 2W05 & $\mathrm{A}$ & 31 & 1.3597 \\
\hline 3EZR & $\mathrm{A}$ & 32 & 1.3619 \\
\hline $2 \mathrm{R} 3 \mathrm{M}$ & A & 33 & 1.3634 \\
\hline 2UUE & $\mathrm{A}$ & 34 & 1.3717 \\
\hline $2 \mathrm{X} 1 \mathrm{~N}$ & $\mathrm{~A}$ & 35 & 1.3720 \\
\hline 3PY0 & A & 36 & 1.3726 \\
\hline 2W06 & A & 37 & 1.3772 \\
\hline 3LFQ & $\mathrm{A}$ & 38 & 1.3777 \\
\hline $2 \mathrm{WXV}$ & $\mathrm{A}$ & 39 & 1.3780 \\
\hline 2UZD & A & 40 & 1.3799 \\
\hline $3 \mathrm{EOC}$ & $\mathrm{A}$ & 41 & 1.3866 \\
\hline 3PXZ & A & 42 & 1.3870 \\
\hline $2 \mathrm{R} 3 \mathrm{~K}$ & A & 43 & 1.3902 \\
\hline $2 \mathrm{C} 5 \mathrm{~V}$ & A & 44 & 1.3927 \\
\hline $2 \mathrm{WIH}$ & $\mathrm{A}$ & 45 & 1.3966 \\
\hline $2 \mathrm{VTP}$ & $\mathrm{A}$ & 46 & 1.3972 \\
\hline $2 \mathrm{I} 40$ & $\mathrm{~A}$ & 47 & 1.3973 \\
\hline $3 \mathrm{EJ} 1$ & $\mathrm{~A}$ & 48 & 1.3994 \\
\hline $2 \mathrm{CCI}$ & $\mathrm{A}$ & 49 & 1.4003 \\
\hline 2WPA & A & 50 & 1.4011 \\
\hline 3EID & $\mathrm{C}$ & 51 & 1.4069 \\
\hline $2 \mathrm{WIH}$ & $\mathrm{C}$ & 52 & 1.4098 \\
\hline 3DDP & $\mathrm{C}$ & 53 & 1.4115 \\
\hline $2 \mathrm{VU} 3$ & $\mathrm{~A}$ & 54 & 1.4149 \\
\hline $2 \mathrm{WEV}$ & $\mathrm{C}$ & 55 & 1.4150 \\
\hline 2BKZ & $\mathrm{C}$ & 56 & 1.4151 \\
\hline 2IW8 & $\bar{A}$ & 57 & 1.4163 \\
\hline $2 \mathrm{I} 40$ & $\mathrm{C}$ & 58 & 1.4182 \\
\hline $2 \mathrm{R} 3 \mathrm{H}$ & A & 59 & 1.4240 \\
\hline $2 \mathrm{C} 5 \mathrm{~N}$ & $\mathrm{C}$ & 60 & 1.4285 \\
\hline 2 WIP & $\mathrm{C}$ & 61 & 1.4298 \\
\hline 2UZD & $\mathrm{C}$ & 62 & 1.4306 \\
\hline $2 \mathrm{WHB}$ & $\mathrm{C}$ & 63 & 1.4329 \\
\hline $2 \mathrm{R} 3 \mathrm{~N}$ & $\mathrm{~A}$ & 64 & 1.4339 \\
\hline 2VTR & $\mathrm{A}$ & 65 & 1.4346 \\
\hline $3 \mathrm{EOC}$ & $\mathrm{C}$ & 66 & 1.4364 \\
\hline $2 \mathrm{WXV}$ & $\mathrm{C}$ & 67 & 1.4382 \\
\hline 3EID & $\mathrm{A}$ & 68 & 1.4406 \\
\hline 3EJ1 & $\mathrm{C}$ & 69 & 1.4429 \\
\hline $2 \mathrm{C} 5 \mathrm{~V}$ & $\mathrm{C}$ & 70 & 1.4456 \\
\hline $2 \mathrm{VV9}$ & $\mathrm{A}$ & 71 & 1.4459 \\
\hline 2UZE & $\mathrm{C}$ & 72 & 1.4465 \\
\hline $3 \mathrm{~F} 5 \mathrm{X}$ & $\mathrm{C}$ & 73 & 1.4467 \\
\hline 2VTT & A & 74 & 1.4495 \\
\hline
\end{tabular}




\begin{tabular}{|c|c|c|c|}
\hline $2 \mathrm{X} 1 \mathrm{~N}$ & A & 80 & 1.0340 \\
\hline 2UZD & $\mathrm{A}$ & 81 & 1.0352 \\
\hline 2FVD & $\mathrm{A}$ & 82 & 1.0352 \\
\hline 2VTR & A & 83 & 1.0390 \\
\hline $2 \mathrm{~W} 1 \mathrm{H}$ & A & 84 & 1.0400 \\
\hline 3LFS & A & 85 & 1.0410 \\
\hline 2DS1 & $\mathrm{A}$ & 86 & 1.0415 \\
\hline $2 \mathrm{UZN}$ & $\mathrm{A}$ & 87 & 1.0444 \\
\hline $2 \mathrm{VU} 3$ & $\mathrm{~A}$ & 88 & 1.0450 \\
\hline 2UZB & $\mathrm{C}$ & 89 & 1.0462 \\
\hline 3EID & A & 90 & 1.0463 \\
\hline 2VTM & A & 91 & 1.0499 \\
\hline 2VTS & $\mathrm{A}$ & 92 & 1.0508 \\
\hline $2 \mathrm{~W} 17$ & $\mathrm{~A}$ & 93 & 1.0555 \\
\hline $2 \mathrm{VTQ}$ & $\mathrm{A}$ & 94 & 1.0598 \\
\hline 2VTT & $\mathrm{A}$ & 97 & 1.0620 \\
\hline $2 \mathrm{CCI}$ & $\mathrm{A}$ & 98 & 1.0651 \\
\hline $2 \mathrm{R} 3 \mathrm{~N}$ & $\mathrm{~A}$ & 99 & 1.0652 \\
\hline 2WFY & C & 100 & 1.0697 \\
\hline 2G9X & $\mathrm{C}$ & 101 & 1.0729 \\
\hline 2VTJ & $\mathrm{A}$ & 102 & 1.0736 \\
\hline 2R3F & $\mathrm{A}$ & 103 & 1.0778 \\
\hline 2IW6 & $\mathrm{C}$ & 104 & 1.0829 \\
\hline 3LE6 & $\mathrm{A}$ & 107 & 1.1022 \\
\hline 2VTO & $\mathrm{A}$ & 110 & 1.1139 \\
\hline $2 \mathrm{WMB}$ & $\mathrm{C}$ & 111 & 1.1142 \\
\hline $2 \mathrm{WEV}$ & $\mathrm{A}$ & 112 & 1.1160 \\
\hline $2 \mathrm{CCI}$ & $\mathrm{C}$ & 113 & 1.1174 \\
\hline $3 \mathrm{EZV}$ & $\mathrm{A}$ & 115 & 1.1216 \\
\hline $3 \mathrm{DOG}$ & $\mathrm{C}$ & 121 & 1.1337 \\
\hline 2VTL & $\mathrm{A}$ & 122 & 1.1344 \\
\hline 2R3Q & A & 124 & 1.1372 \\
\hline 2VTI & A & 126 & 1.1392 \\
\hline 2UZB & $\mathrm{A}$ & 129 & 1.1520 \\
\hline $2 \mathrm{C} 5 \mathrm{O}$ & $\mathrm{C}$ & 134 & 1.1635 \\
\hline 2 CLX & $\mathrm{A}$ & 135 & 1.1650 \\
\hline 2IW8 & $\mathrm{C}$ & 138 & 1.1677 \\
\hline 2G9X & $\mathrm{A}$ & 141 & 1.1696 \\
\hline $2 \mathrm{C} 5 \mathrm{O}$ & $\mathrm{A}$ & 149 & 1.1878 \\
\hline $2 \mathrm{XNB}$ & A & 152 & 1.1905 \\
\hline 2R3R & A & 159 & 1.1985 \\
\hline 2CJM & $\mathrm{C}$ & 164 & 1.2057 \\
\hline $2 \mathrm{WMB}$ & $\mathrm{A}$ & 166 & 1.2088 \\
\hline $2 \mathrm{R} 3 \mathrm{G}$ & $\mathrm{A}$ & 168 & 1.2148 \\
\hline 2R3I & $\mathrm{A}$ & 170 & 1.2183 \\
\hline 2IW9 & $\mathrm{A}$ & 171 & 1.2197 \\
\hline $3 \mathrm{BHU}$ & $\mathrm{C}$ & 191 & 1.2548 \\
\hline 3PXF & $\mathrm{A}$ & 197 & 1.2709 \\
\hline $3 \mathrm{BHV}$ & $\mathrm{C}$ & 199 & 1.2755 \\
\hline $2 \mathrm{C} 5 \mathrm{~N}$ & $\mathrm{~A}$ & 219 & 1.3128 \\
\hline $3 \mathrm{PXQ}$ & $\mathrm{A}$ & 224 & 1.3218 \\
\hline 2IW9 & $\mathrm{C}$ & 236 & 1.3490 \\
\hline $3 \mathrm{DDQ}$ & $\mathrm{A}$ & 237 & 1.3511 \\
\hline 3 MY5 & $\mathrm{A}$ & 238 & 1.3556 \\
\hline 3BHU & A & 240 & 1.3606 \\
\hline 3DDQ & $\mathrm{C}$ & 245 & 1.3730 \\
\hline 3BHV & $\mathrm{A}$ & 251 & 1.3815 \\
\hline $2 \mathrm{VTH}$ & $\mathrm{A}$ & 260 & 1.4077 \\
\hline 3 MY5 & $\mathrm{C}$ & 265 & 1.4188 \\
\hline 3BHT & $\mathrm{C}$ & 271 & 1.4385 \\
\hline $2 \mathrm{~A} 0 \mathrm{C}$ & $\mathrm{X}$ & 276 & 1.4508 \\
\hline 3KF9 & A & 282 & 1.4648 \\
\hline 3BHT & A & 292 & 1.5033 \\
\hline 2 CJM & $\mathrm{A}$ & 300 & 1.5297 \\
\hline $2 \mathrm{CCH}$ & A & 400 & 2.1933 \\
\hline
\end{tabular}

\begin{tabular}{|c|c|c|c|}
\hline 2IW6 & $\mathrm{C}$ & 75 & 1.0427 \\
\hline 2DS1 & $\mathrm{A}$ & 76 & 1.0429 \\
\hline $2 \mathrm{FVD}$ & $\mathrm{A}$ & 77 & 1.0439 \\
\hline 2VTI & A & 78 & 1.0490 \\
\hline 2VV9 & A & 79 & 1.0509 \\
\hline 2UZB & A & 80 & 1.0532 \\
\hline $2 \mathrm{WEV}$ & $\mathrm{C}$ & 81 & 1.0570 \\
\hline $2 \mathrm{CCH}$ & $\mathrm{C}$ & 82 & 1.0580 \\
\hline $2 \mathrm{WHB}$ & $\mathrm{C}$ & 83 & 1.0585 \\
\hline 2WFY & $\mathrm{C}$ & 84 & 1.0596 \\
\hline $2 \mathrm{R} 3 \mathrm{~F}$ & A & 85 & 1.0637 \\
\hline 2VTS & A & 86 & 1.0641 \\
\hline $2 \mathrm{WXV}$ & $\mathrm{C}$ & 87 & 1.0658 \\
\hline $2 \mathrm{X} 1 \mathrm{~N}$ & $\mathrm{C}$ & 88 & 1.0682 \\
\hline $2 \mathrm{UZL}$ & $\mathrm{C}$ & 89 & 1.0702 \\
\hline $2 \mathrm{UZB}$ & $\mathrm{C}$ & 90 & 1.0706 \\
\hline $2 \mathrm{WIP}$ & $\mathrm{C}$ & 91 & 1.0708 \\
\hline $2 \mathrm{G} 9 \mathrm{X}$ & $\mathrm{A}$ & 92 & 1.0723 \\
\hline $2 \mathrm{C} 5 \mathrm{~V}$ & C & 93 & 1.0727 \\
\hline 3DDP & C & 94 & 1.0736 \\
\hline 2 UZD & $\mathrm{C}$ & 95 & 1.0746 \\
\hline 2UZE & $\mathrm{C}$ & 96 & 1.0748 \\
\hline $2 \mathrm{WEV}$ & $\mathrm{A}$ & 97 & 1.0759 \\
\hline $2 \mathrm{CCI}$ & $\mathrm{C}$ & 98 & 1.0761 \\
\hline 2R3G & A & 99 & 1.0797 \\
\hline $2 \mathrm{WPA}$ & $\mathrm{C}$ & 100 & 1.0799 \\
\hline 2UUE & $\mathrm{C}$ & 101 & 1.0811 \\
\hline $2 \mathrm{R} 3 \mathrm{Q}$ & $\mathrm{A}$ & 102 & 1.0829 \\
\hline $2 \mathrm{WMA}$ & $\mathrm{C}$ & 103 & 1.0898 \\
\hline $2 \mathrm{C} 5 \mathrm{~N}$ & $\mathrm{C}$ & 104 & 1.0903 \\
\hline $2 \mathrm{XNB}$ & A & 105 & 1.0989 \\
\hline $2 \mathrm{CJM}$ & $\mathrm{C}$ & 106 & 1.0997 \\
\hline 3PXQ & A & 107 & 1.1008 \\
\hline $2 \mathrm{VTA}$ & $\mathrm{A}$ & 108 & 1.1043 \\
\hline $2 \mathrm{VTJ}$ & $\mathrm{A}$ & 109 & 1.1131 \\
\hline $2 \mathrm{CLX}$ & $\mathrm{A}$ & 110 & 1.1198 \\
\hline $2 \mathrm{C} 5 \mathrm{O}$ & $\mathrm{A}$ & 111 & 1.1312 \\
\hline 3PXF & A & 112 & 1.1374 \\
\hline 2R3I & $\mathrm{A}$ & 113 & 1.1434 \\
\hline 2R3R & $\mathrm{A}$ & 114 & 1.1437 \\
\hline $2 \mathrm{VTQ}$ & A & 116 & 1.1553 \\
\hline $2 \mathrm{VTL}$ & $\mathrm{A}$ & 117 & 1.1555 \\
\hline 2IW9 & $\mathrm{A}$ & 118 & 1.1783 \\
\hline 2IW8 & $\mathrm{C}$ & 119 & 1.1872 \\
\hline $2 \mathrm{WMB}$ & $\mathrm{C}$ & 120 & 1.1957 \\
\hline 2G9X & $\mathrm{C}$ & 122 & 1.2144 \\
\hline 3DOG & $\mathrm{C}$ & 124 & 1.2520 \\
\hline $2 \mathrm{C} 5 \mathrm{~N}$ & $\mathrm{~A}$ & 125 & 1.2524 \\
\hline $3 \mathrm{BHU}$ & $\mathrm{C}$ & 126 & 1.2531 \\
\hline $2 \mathrm{~A} 0 \mathrm{C}$ & $\mathrm{X}$ & 127 & 1.2597 \\
\hline 3DDQ & $\mathrm{A}$ & 128 & 1.2718 \\
\hline $2 \mathrm{VTH}$ & A & 129 & 1.2803 \\
\hline 2IW9 & $\mathrm{C}$ & 130 & 1.2804 \\
\hline $3 \mathrm{MY} 5$ & A & 133 & 1.2910 \\
\hline $2 \mathrm{C} 5 \mathrm{O}$ & $\mathrm{C}$ & 134 & 1.3023 \\
\hline 3BHV & $\mathrm{A}$ & 136 & 1.3057 \\
\hline $3 \mathrm{MY} 5$ & $\mathrm{C}$ & 145 & 1.3470 \\
\hline 3BHT & $\mathrm{C}$ & 178 & 1.4156 \\
\hline $3 \mathrm{BHU}$ & $\mathrm{A}$ & 199 & 1.4560 \\
\hline 3BHV & $\mathrm{C}$ & 201 & 1.4568 \\
\hline 3DDQ & $\mathrm{C}$ & 208 & 1.4660 \\
\hline $2 \mathrm{CJM}$ & A & 218 & 1.4801 \\
\hline $3 \mathrm{BHT}$ & $\mathrm{A}$ & 251 & 1.5478 \\
\hline $3 \mathrm{KF9}$ & $\mathrm{A}$ & 288 & 1.6310 \\
\hline $2 \mathrm{CCH}$ & A & 397 & 2.0451 \\
\hline
\end{tabular}

\begin{tabular}{|c|c|c|c|}
\hline 2UZL & $\mathrm{C}$ & 75 & 1.4518 \\
\hline $2 \mathrm{UZN}$ & $\mathrm{A}$ & 76 & 1.4558 \\
\hline $2 \mathrm{X} 1 \mathrm{~N}$ & $\mathrm{C}$ & 77 & 1.4586 \\
\hline $2 \mathrm{~W} 1 \mathrm{H}$ & A & 78 & 1.4620 \\
\hline 3FZ1 & A & 79 & 1.4625 \\
\hline 2WPA & $\mathrm{C}$ & 80 & 1.4660 \\
\hline 2UUE & $\mathrm{C}$ & 81 & 1.4679 \\
\hline 2FVD & $\mathrm{A}$ & 82 & 1.4702 \\
\hline 2VTM & A & 83 & 1.4726 \\
\hline 3LFS & $\mathrm{A}$ & 84 & 1.4734 \\
\hline 2DS1 & A & 85 & 1.4738 \\
\hline $2 \mathrm{CCH}$ & $\mathrm{C}$ & 86 & 1.4770 \\
\hline $2 \mathrm{~W} 17$ & A & 87 & 1.4810 \\
\hline $2 \mathrm{VTA}$ & A & 88 & 1.4884 \\
\hline 2VTS & $\mathrm{A}$ & 89 & 1.4955 \\
\hline 2UZB & $\mathrm{C}$ & 90 & 1.4969 \\
\hline $3 \mathrm{EZV}$ & $\mathrm{A}$ & 91 & 1.5007 \\
\hline 2WMA & $\mathrm{C}$ & 92 & 1.5011 \\
\hline 2IW6 & $\mathrm{C}$ & 93 & 1.5033 \\
\hline 2WFY & $\mathrm{C}$ & 94 & 1.5057 \\
\hline 3LE6 & $\mathrm{A}$ & 95 & 1.5127 \\
\hline $2 \mathrm{VTO}$ & $\mathrm{A}$ & 96 & 1.5129 \\
\hline $2 \mathrm{R} 3 \mathrm{~F}$ & $\mathrm{~A}$ & 97 & 1.5143 \\
\hline $2 \mathrm{WMB}$ & $\mathrm{A}$ & 98 & 1.5374 \\
\hline $2 \mathrm{VTJ}$ & $\mathrm{A}$ & 99 & 1.5465 \\
\hline 2VTI & A & 100 & 1.5486 \\
\hline $2 \mathrm{WEV}$ & A & 101 & 1.5502 \\
\hline $2 \mathrm{CCI}$ & $\mathrm{C}$ & 102 & 1.5513 \\
\hline 2UZB & $\mathrm{A}$ & 103 & 1.5609 \\
\hline $2 \mathrm{VTQ}$ & A & 105 & 1.5678 \\
\hline $2 \mathrm{R} 3 \mathrm{Q}$ & A & 106 & 1.5703 \\
\hline $2 \mathrm{G} 9 \mathrm{X}$ & A & 107 & 1.5868 \\
\hline $2 \mathrm{CLX}$ & A & 108 & 1.6159 \\
\hline 2 VTL & $\mathrm{A}$ & 109 & 1.6193 \\
\hline $2 \mathrm{XNB}$ & $\mathrm{A}$ & 110 & 1.6202 \\
\hline $2 \mathrm{G} 9 \mathrm{X}$ & $\mathrm{C}$ & 111 & 1.6204 \\
\hline $2 \mathrm{R} 3 \mathrm{G}$ & A & 112 & 1.6253 \\
\hline 2CJM & $\mathrm{C}$ & 113 & 1.6318 \\
\hline $2 \mathrm{WMB}$ & $\mathrm{C}$ & 114 & 1.6343 \\
\hline $2 \mathrm{C} 5 \mathrm{O}$ & A & 115 & 1.6403 \\
\hline $2 \mathrm{R} 3 \mathrm{R}$ & A & 118 & 1.6566 \\
\hline 2IW8 & $\mathrm{C}$ & 119 & 1.6653 \\
\hline 2R3I & $\mathrm{A}$ & 121 & 1.6708 \\
\hline $3 \mathrm{DOG}$ & $\mathrm{C}$ & 123 & 1.6890 \\
\hline 2IW9 & $\mathrm{A}$ & 124 & 1.6959 \\
\hline 3PXF & $\mathrm{A}$ & 125 & 1.7056 \\
\hline $3 \mathrm{PXQ}$ & A & 127 & 1.7202 \\
\hline $2 \mathrm{C} 5 \mathrm{O}$ & $\mathrm{C}$ & 130 & 1.7463 \\
\hline $3 \mathrm{BHU}$ & $\mathrm{C}$ & 133 & 1.7734 \\
\hline $2 \mathrm{C} 5 \mathrm{~N}$ & A & 142 & 1.8144 \\
\hline $3 \mathrm{DDQ}$ & $\mathrm{A}$ & 161 & 1.8555 \\
\hline 2IW9 & $\mathrm{C}$ & 165 & 1.8599 \\
\hline $3 \mathrm{MY} 5$ & A & 172 & 1.8720 \\
\hline $3 \mathrm{BHV}$ & A & 184 & 1.9009 \\
\hline $2 \mathrm{VTH}$ & A & 186 & 1.9028 \\
\hline $2 \mathrm{~A} 0 \mathrm{C}$ & $\mathrm{X}$ & 190 & 1.9214 \\
\hline $3 \mathrm{BHV}$ & $\mathrm{C}$ & 204 & 1.9363 \\
\hline 3 MY5 & $\mathrm{C}$ & 214 & 1.9564 \\
\hline 3BHU & $\mathrm{A}$ & 225 & 1.9928 \\
\hline $3 \mathrm{DDQ}$ & $\mathrm{C}$ & 233 & 2.0086 \\
\hline 3BHT & $\mathrm{C}$ & 236 & 2.0182 \\
\hline $2 \mathrm{CJM}$ & A & 271 & 2.1286 \\
\hline 3BHT & A & 277 & 2.1576 \\
\hline 3KF9 & A & 284 & 2.1922 \\
\hline $2 \mathrm{CCH}$ & A & 398 & 2.9989 \\
\hline
\end{tabular}




\section{Appendix C}

\section{Intra-Family Sequence Similarities for randomly selected family members.}

(a) Group 1

\begin{tabular}{|c|c|c|c|c|c|}
\hline Protein 1 & Chain & Protein 2 & Chain & Identities & Similarities \\
\hline $1 \mathrm{SSP}$ & $\mathrm{E}$ & $2 \mathrm{SSP}$ & $\mathrm{E}$ & 99.55 & 99.55 \\
\hline $1 \mathrm{SSP}$ & $\mathrm{E}$ & 1UGI & A & $7.17 \%$ (query) and $19.05 \%$ (subject) & $10.76 \%$ (query) and $28.57 \%$ (subject) \\
\hline $1 \mathrm{SSP}$ & $\mathrm{E}$ & 1UGI & $\mathrm{B}$ & $7.17 \%$ (query) and $19.05 \%$ (subject) & $10.76 \%$ (query) and $28.57 \%$ (subject) \\
\hline $2 \mathrm{SSP}$ & $\mathrm{E}$ & 1UGI & A & $7.17 \%$ (query) and $19.05 \%$ (subject) & $10.76 \%$ (query) and $28.57 \%$ \\
\hline 1UGI & $\mathrm{A}$ & 2UGI & $\mathrm{A}$ & $100 \%$ & $100 \%$ \\
\hline $2 \mathrm{SSP}$ & $\mathrm{E}$ & 2UGI & A & $4.93 \%$ (query) and $5.67 \%$ (subject) & $7.62 \%$ (query) and $8.76 \%$ (subject) \\
\hline $1 \mathrm{SSP}$ & $E$ & 2UGI & $\mathrm{A}$ & $4.93 \%$ (query) and $5.67 \%$ (subject) & $7.62 \%$ (query) and $8.76 \%$ (subject) \\
\hline $1 \mathrm{SSP}$ & $E$ & $4 \mathrm{SKN}$ & $\mathrm{E}$ & 99.10 & 99.55 \\
\hline $2 \mathrm{SSP}$ & $E$ & $4 \mathrm{SKN}$ & $\mathrm{E}$ & 99.10 & 99.55 \\
\hline 1UGI & $\mathrm{E}$ & 4 SKN & $\mathrm{E}$ & $17.86 \%$ (query) and $6.73 \%$ (subject) & $28.57 \%$ (query) and $10.76 \%$ (subject) \\
\hline 2UGI & $\mathrm{E}$ & 4 SKN & E & $17.86 \%$ (query) and $6.73 \%$ (subject) & $28.57 \%$ (query) and $10.76 \%$ (subject) \\
\hline $1 \mathrm{SSP}$ & E & $1 \mathrm{AKZ}$ & A & $100 \%$ & $100 \%$ \\
\hline $2 \mathrm{SSP}$ & $\mathrm{E}$ & $1 \mathrm{AKZ}$ & A & $99.55 \%$ & $99.55 \%$ \\
\hline $1 \mathrm{UGI}$ & $\mathrm{A}$ & $1 \mathrm{AKZ}$ & A & $7.17 \%$ (query) and $19.05 \%$ (subject) & $10.76 \%$ (query) and $28.57 \%$ (subject) \\
\hline $2 \mathrm{UGI}$ & $\mathrm{A}$ & $1 \mathrm{AKZ}$ & $\mathrm{A}$ & $7.17 \%$ (query) and $19.05 \%$ (subject) & $10.76 \%$ (query) and $28.57 \%$ (subject) \\
\hline 4 SKN & $\mathrm{E}$ & $1 \mathrm{AKZ}$ & $\mathrm{A}$ & $99.10 \%$ & $99.55 \%$ \\
\hline $1 \mathrm{LAU}$ & $\mathrm{E}$ & $1 \mathrm{SSP}$ & $\mathrm{E}$ & $43.95 \%$ (query) and $40.16 \%$ (subject) & $56.95 \%$ (query) and $52.05 \%$ (subject) \\
\hline $1 \mathrm{LAU}$ & $\mathrm{E}$ & $2 \mathrm{SSP}$ & $\mathrm{E}$ & $43.50 \%$ (query) and $39.75 \%$ (subject) & $56.50 \%$ (query) and $51.64 \%$ (subject) \\
\hline $1 \mathrm{LAU}$ & $\mathrm{E}$ & 1UGI & A & $4.51 \%$ (query) and $13.10 \%$ (subject) & $7.79 \%$ (query) and $22.62 \%$ (subject) \\
\hline $1 \mathrm{LAU}$ & $\mathrm{E}$ & 2UGI & A & $4.51 \%$ (query) and $13.10 \%$ (subject) & $7.79 \%$ (query) and $22.62 \%$ (subject) \\
\hline $1 \mathrm{LAU}$ & $E$ & $4 \mathrm{SKN}$ & E & $39.34 \%$ (query) and $43.05 \%$ (subject) & $52.05 \%$ (query) and $56.95 \%$ (subject) \\
\hline $1 \mathrm{LAU}$ & $E$ & $1 \mathrm{AKZ}$ & $\mathrm{A}$ & $40.16 \%$ (query) and $43.95 \%$ (subject) & $52.46 \%$ (query) and $57.40 \%$ (subject) \\
\hline $1 \mathrm{SSP}$ & $\mathrm{E}$ & 1UDH & $\mathrm{A}$ & $43.95 \%$ (query) and $40.16 \%$ (subject) & $56.95 \%$ (query) and $52.05 \%$ (subject) \\
\hline 1UDH & $\mathrm{A}$ & $2 \mathrm{SSP}$ & $\mathrm{E}$ & $39.75 \%$ (query) and $43.50 \%$ (subject) & $52.05 \%$ (query) and $56.95 \%$ (subject) \\
\hline 1UDH & $\mathrm{A}$ & 1UGI & A & $4.51 \%$ (query) and $13.10 \%$ (subject) & $7.79 \%$ (query) and $22.62 \%$ \\
\hline 1UDH & A & 2UGI & A & $4.51 \%$ (query) and $13.10 \%$ (subject) & $7.79 \%$ (query) and $22.62 \%$ (subject) \\
\hline 1UDH & $\mathrm{A}$ & $4 \mathrm{SKN}$ & $\mathrm{E}$ & $39.34 \%$ (query) and $43.05 \%$ (subject) & $52.05 \%$ (query) and $56.95 \%$ (subject) \\
\hline 1UDH & $\mathrm{A}$ & $1 \mathrm{AKZ}$ & $\mathrm{A}$ & $40.16 \%$ (query) and $43.95 \%$ (subject) & $52.46 \%$ (query) and $57.40 \%$ (subject) \\
\hline 1UDH & $\mathrm{A}$ & $1 \mathrm{LAU}$ & $\mathrm{E}$ & $100 \%$ & $100 \%$ \\
\hline 1UDI & $\mathrm{E}$ & $1 \mathrm{SSP}$ & $\mathrm{E}$ & $40.16 \%$ (query) and $43.95 \%$ (subject) & $52.46 \%$ (query) and $57.40 \%$ (subject) \\
\hline 1UDI & $\mathrm{E}$ & $2 \mathrm{SSP}$ & $\bar{E}$ & $39.75 \%$ (query) and $43.50 \%$ (subject) & $52.05 \%$ (query) and $56.95 \%$ (subject) \\
\hline 1UDI & E & 1UGI & A & $4.51 \%$ (query) and $13.10 \%$ (subject) & $7.79 \%$ (query) and $22.62 \%$ (subject) \\
\hline 1UDI & E & 2UGI & A & $5.74 \%$ (query) and $7.22 \%$ (subject) & $9.02 \%$ (query) and $11.34 \%$ (subject) \\
\hline 1UDI & $\mathrm{E}$ & 4 SKN & $\mathrm{E}$ & $39.34 \%$ (query) and $43.05 \%$ (subject) & $52.05 \%$ (query) and $56.95 \%$ (subject) \\
\hline 1UDI & $E$ & $1 \mathrm{AKZ}$ & $\mathrm{A}$ & $40.16 \%$ (query) and $43.95 \%$ (subject) & $52.46 \%$ (query) and $57.40 \%$ (subject) \\
\hline 1UDI & $\mathrm{E}$ & $1 \mathrm{LAU}$ & $\mathrm{E}$ & $100 \%$ & $100 \%$ \\
\hline 1UDI & $\mathrm{E}$ & 1UDH & A & $100 \%$ & $100 \%$ \\
\hline 1UDG & $\mathrm{A}$ & $1 \mathrm{SSP}$ & $\bar{E}$ & $40.16 \%$ (query) and $43.95 \%$ (subject) & $52.46 \%$ (query) and $57.40 \%$ (subject) \\
\hline 1UDG & $\mathrm{A}$ & $2 \mathrm{SSP}$ & E & $39.75 \%$ (query) and $43.50 \%$ (subject) & $52.05 \%$ (query) and $56.95 \%$ (subject) \\
\hline 1UDG & A & 1UGI & A & $4.51 \%$ (query) and $13.10 \%$ (subject) & $7.79 \%$ (query) and $22.62 \%$ (subject) \\
\hline 1UDG & A & 2UGI & A & $4.51 \%$ (query) and $13.10 \%$ (subject) & $7.79 \%$ (query) and $22.62 \%$ (subject) \\
\hline 1UDG & A & $4 \mathrm{SKN}$ & E & $39.34 \%$ (query) and $43.05 \%$ (subject) & $52.05 \%$ (query) and $56.95 \%$ (subject) \\
\hline 1UDG & $\mathrm{A}$ & $1 \mathrm{AKZ}$ & $\mathrm{A}$ & $40.16 \%$ (query) and $43.95 \%$ (subject) & $52.46 \%$ (query) and $57.40 \%$ (subject) \\
\hline 1UDG & $\mathrm{A}$ & $1 \mathrm{LAU}$ & $\mathrm{E}$ & $100 \%$ & $100 \%$ \\
\hline $1 \mathrm{UDG}$ & $\mathrm{A}$ & 1UDH & $\mathrm{A}$ & $100 \%$ & $100 \%$ \\
\hline 1UDG & $\mathrm{A}$ & 1UDI & $\bar{E}$ & $100 \%$ & $100 \%$ \\
\hline
\end{tabular}


(b) Group 2

\begin{tabular}{|c|c|c|c|c|c|}
\hline Protein 1 & Chain & Protein 2 & Chain & $\begin{array}{c}\text { Identities } \\
\end{array}$ & $\begin{array}{l}\text { Similarities } \\
\end{array}$ \\
\hline $3 \mathrm{OMO}$ & $\mathrm{A}$ & 3HM1 & $\mathrm{A}$ & $60.00 \%$ (query) and $56.92 \%$ (subject) & $83.33 \%$ (query) and $79.05 \%$ (subject) \\
\hline $3 \mathrm{OMO}$ & $\mathrm{B}$ & 3DT3 & $\mathrm{B}$ & $60.42 \%$ (query) and $56.86 \%$ (subject) & $83.75 \%$ (query) and $78.82 \%$ (subject) \\
\hline $3 \mathrm{OMO}$ & $\mathrm{B}$ & $2 \mathrm{QXS}$ & $\mathrm{A}$ & $60.42 \%$ (query) and $56.20 \%$ (subject) & $83.33 \%$ (query) and $77.52 \%$ (subject) \\
\hline $3 \mathrm{OMO}$ & $\mathrm{A}$ & 2QZO & $\mathrm{A}$ & $60.00 \%$ (query) and $55.81 \%$ (subject) & $83.33 \%$ (query) and $77.52 \%$ (subject) \\
\hline $3 \mathrm{OMO}$ & $\mathrm{A}$ & 3CBM & $\mathrm{B}$ & $1.25 \%$ (query) and $30.00 \%$ (subject) & $1.67 \%$ (query) and $40.00 \%$ (subject) \\
\hline $3 \mathrm{OMO}$ & $\mathrm{A}$ & $3 \mathrm{CBO}$ & $\mathrm{B}$ & $1.25 \%$ (query) and $30.00 \%$ (subject) & $1.67 \%$ (query) and $40.00 \%$ (subject) \\
\hline $3 \mathrm{OMO}$ & $\mathrm{A}$ & $3 \mathrm{CBP}$ & $\mathrm{B}$ & $12.92 \%$ (query) and $12.11 \%$ (subject) & $22.50 \%$ (query) and $21.09 \%$ (subject) \\
\hline $3 \mathrm{OMO}$ & $\mathrm{A}$ & $2 \mathrm{R} 6 \mathrm{~W}$ & $\mathrm{~A}$ & $60.00 \%$ (query) and $58.06 \%$ (subject) & $83.33 \%$ (query) and $80.65 \%$ (subject) \\
\hline $3 \mathrm{OMO}$ & $\mathrm{A}$ & 2R6Y & $\mathrm{A}$ & $60.00 \%$ (query) and $58.06 \%$ (subject) & $83.33 \%$ (query) and $80.65 \%$ (subject) \\
\hline $3 \mathrm{OMO}$ & $\mathrm{B}$ & 2QA6 & $\mathrm{A}$ & $60.00 \%$ (query) and $55.81 \%$ (subject) & $83.33 \%$ (query) and $77.52 \%$ (subject) \\
\hline $3 \mathrm{OMO}$ & $\mathrm{B}$ & $2 \mathrm{QGT}$ & $\mathrm{A}$ & $60.00 \%$ (query) and $55.81 \%$ (subject) & $83.33 \%$ (query) and $77.52 \%$ (subject) \\
\hline $3 \mathrm{OMO}$ & $\mathrm{B}$ & 2QGW & $\mathrm{B}$ & $60.00 \%$ (query) and $55.81 \%$ (subject) & $83.33 \%$ (query) and $77.52 \%$ (subject) \\
\hline $3 \mathrm{OMO}$ & $\mathrm{A}$ & $2 \mathrm{QH} 6$ & A & $60.00 \%$ (query) and $55.81 \%$ (subject) & $83.33 \%$ (query) and $77.52 \%$ (subject) \\
\hline $3 \mathrm{OMO}$ & A & $2 \mathrm{QR} 9$ & B & $60.00 \%$ (query) and $55.81 \%$ (subject) & $83.33 \%$ (query) and $77.52 \%$ (subject) \\
\hline $3 \mathrm{OMO}$ & A & 2QSE & A & $60.00 \%$ (query) and $55.81 \%$ (subject) & $83.33 \%$ (query) and $77.52 \%$ (subject) \\
\hline $3 \mathrm{OMO}$ & $\mathrm{A}$ & 2QXM & $\mathrm{A}$ & $60.00 \%$ (query) and $55.81 \%$ (subject) & $83.33 \%$ (query) and $77.52 \%$ (subject) \\
\hline $3 \mathrm{OMO}$ & $\mathrm{B}$ & $2 \mathrm{OCF}$ & A & $60.00 \%$ (query) and $48.32 \%$ (subject) & $83.33 \%$ (query) and $67.11 \%$ (subject) \\
\hline $3 \mathrm{OMO}$ & $\mathrm{B}$ & $2 \mathrm{QTU}$ & $\mathrm{B}$ & $100.00 \%$ (query) and $93.39 \%$ (subject) & $100.00 \%$ (query) and $93.39 \%$ (subject) \\
\hline $3 \mathrm{OMO}$ & $\mathrm{B}$ & $2 \mathrm{IOG}$ & A & $60.42 \%$ (query) and $58.94 \%$ (subject) & $83.75 \%$ (query) and $81.71 \%$ (subject) \\
\hline $3 \mathrm{OMO}$ & A & $2 \mathrm{IOK}$ & A & $60.42 \%$ (query) and $57.09 \%$ (subject) & $83.75 \%$ (query) and $79.13 \%$ (subject) \\
\hline $3 \mathrm{OMO}$ & A & $2 \mathrm{POG}$ & B & $60.00 \%$ (query) and $58.06 \%$ (subject) & $83.33 \%$ (query) and $80.65 \%$ (subject) \\
\hline $3 \mathrm{OMO}$ & $\mathrm{A}$ & 2QE4 & $\mathrm{B}$ & $60.00 \%$ (query) and $58.06 \%$ (subject) & $83.33 \%$ (query) and $80.65 \%$ (subject) \\
\hline $3 \mathrm{OMO}$ & $\mathrm{B}$ & 2NV7 & $\mathrm{A}$ & $99.17 \%$ (query) and $100.00 \%$ (subject) & $99.17 \%$ (query) and $100.00 \%$ (subject) \\
\hline $3 \mathrm{OMO}$ & $\mathrm{A}$ & $2 \mathrm{JJ} 3$ & $\mathrm{~A}$ & $100.00 \%$ (query) and $93.39 \%$ (subject) & $100.00 \%$ (query) and $93.39 \%$ (subject) \\
\hline $3 \mathrm{OMO}$ & $\mathrm{A}$ & $2 \mathrm{Q} 70$ & $\mathrm{~B}$ & $60.00 \%$ (query) and $58.06 \%$ (subject) & $83.33 \%$ (query) and $80.65 \%$ (subject) \\
\hline $3 \mathrm{OMO}$ & $\mathrm{A}$ & $2 \mathrm{Z} 4 \mathrm{~B}$ & A & $100.00 \%$ (query) and $93.39 \%$ (subject) & $100.00 \%$ (query) and $93.39 \%$ (subject) \\
\hline $3 \mathrm{OMO}$ & $\mathrm{B}$ & $2 \mathrm{Q} 6 \mathrm{~J}$ & $\mathrm{~B}$ & $60.00 \%$ (query) and $55.81 \%$ (subject) & $83.33 \%$ (query) and $77.52 \%$ (subject) \\
\hline $3 \mathrm{OMO}$ & $\mathrm{B}$ & $2 \mathrm{OUZ}$ & A & $60.42 \%$ (query) and $57.31 \%$ (subject) & $83.75 \%$ (query) and $79.45 \%$ (subject) \\
\hline $3 \mathrm{OMO}$ & $\mathrm{A}$ & $2 \mathrm{P} 15$ & $\mathrm{~B}$ & $60.00 \%$ (query) and $55.81 \%$ (subject) & $83.33 \%$ (query) and $77.52 \%$ (subject) \\
\hline $3 \mathrm{OMO}$ & $\mathrm{A}$ & $2 \mathrm{G} 5 \mathrm{O}$ & $\mathrm{A}$ & $60.00 \%$ (query) and $56.03 \%$ (subject) & $83.33 \%$ (query) and $77.82 \%$ (subject) \\
\hline $3 \mathrm{OMO}$ & $\mathrm{B}$ & 2JF9 & $\mathrm{C}$ & $55.00 \%$ (query) and $52.38 \%$ (subject) & $77.50 \%$ (query) and $73.81 \%$ (subject) \\
\hline $3 \mathrm{OMO}$ & $\mathrm{A}$ & 2 JFFA & $\mathrm{B}$ & $55.00 \%$ (query) and $52.38 \%$ (subject) & $77.50 \%$ (query) and $73.81 \%$ (subject) \\
\hline $3 \mathrm{OMO}$ & $\mathrm{A}$ & $2 \mathrm{G} 44$ & A & $60.00 \%$ (query) and $56.03 \%$ (subject) & $83.33 \%$ (query) and $77.82 \%$ (subject) \\
\hline $3 \mathrm{OMO}$ & $\mathrm{B}$ & $2 \mathrm{~J} 7 \mathrm{X}$ & $\mathrm{A}$ & $92.50 \%$ (query) and $87.06 \%$ (subject) & $95.83 \%$ (query) and $90.20 \%$ (subject) \\
\hline $3 \mathrm{OMO}$ & $\mathrm{A}$ & $2 \mathrm{~J} 7 \mathrm{Y}$ & A & $92.50 \%$ (query) and $87.06 \%$ (subject) & $95.83 \%$ (query) and $90.20 \%$ (subject) \\
\hline $3 \mathrm{OMO}$ & $\mathrm{A}$ & $2 \mathrm{I} 0 \mathrm{G}$ & $\mathrm{A}$ & $100.00 \%$ (query) and $93.39 \%$ (subject) & $100.00 \%$ (query) and $93.39 \%$ (subject) \\
\hline $3 \mathrm{OMO}$ & A & $2 \mathrm{I} 0 \mathrm{~J}$ & $\mathrm{D}$ & $59.58 \%$ (query) and $58.61 \%$ (subject) & $82.92 \%$ (query) and $81.56 \%$ (subject) \\
\hline $3 \mathrm{OMO}$ & $\mathrm{B}$ & $2 \mathrm{GIU}$ & $\mathrm{A}$ & $100.00 \%$ (query) and $99.59 \%$ (subject) & $100.00 \%$ (query) and $99.59 \%$ (subject) \\
\hline $3 \mathrm{OMO}$ & $\mathrm{A}$ & $2 \mathrm{~B} 1 \mathrm{Z}$ & $\mathrm{A}$ & $60.00 \%$ (query) and $56.03 \%$ (subject) & $83.33 \%$ (query) and $77.82 \%$ (subject) \\
\hline $3 \mathrm{OMO}$ & $\mathrm{B}$ & $2 \mathrm{~B} 23$ & $\mathrm{~B}$ & $60.00 \%$ (query) and $56.03 \%$ (subject) & $83.33 \%$ (query) and $77.82 \%$ (subject) \\
\hline $3 \mathrm{OMO}$ & $\mathrm{A}$ & $2 \mathrm{FSZ}$ & $\mathrm{B}$ & $98.75 \%$ (query) and $96.34 \%$ (subject) & $98.75 \%$ (query) and $96.34 \%$ (subject) \\
\hline $3 \mathrm{OMO}$ & $\mathrm{A}$ & $1 Z K Y$ & $\mathrm{~A}$ & $60.00 \%$ (query) and $56.03 \%$ (subject) & $83.33 \%$ (query) and $77.82 \%$ (subject) \\
\hline $3 \mathrm{OMO}$ & $\mathrm{B}$ & $2 \mathrm{~B} 1 \mathrm{~V}$ & A & $60.00 \%$ (query) and $56.03 \%$ (subject) & $83.33 \%$ (query) and $77.82 \%$ (subject) \\
\hline $3 \mathrm{OMO}$ & $\mathrm{A}$ & $2 \mathrm{FAI}$ & $\mathrm{A}$ & $60.00 \%$ (query) and $56.03 \%$ (subject & $83.33 \%$ (query) and $77.82 \%$ (subject) \\
\hline $3 \mathrm{OMO}$ & $\mathrm{A}$ & $1 \mathrm{ZAF}$ & $\mathrm{B}$ & $98.75 \%$ (query) and $99.58 \%$ (subject) & $99.17 \%$ (query) and $100.00 \%$ (subject) \\
\hline $3 \mathrm{OMO}$ & $\mathrm{B}$ & $1 Y Y 4$ & $\mathrm{~A}$ & $99.17 \%$ (query) and $88.81 \%$ (subject) & $99.17 \%$ (query) and $88.81 \%$ (subject) \\
\hline $3 \mathrm{OMO}$ & $\mathrm{A}$ & $1 \mathrm{YYE}$ & $\mathrm{B}$ & $99.17 \%$ (query) and $88.81 \%$ (subject) & $99.17 \%$ (query) and $88.81 \%$ (subject) \\
\hline $3 \mathrm{OMO}$ & $\mathrm{B}$ & $2 \mathrm{AYR}$ & $\mathrm{A}$ & $60.00 \%$ (query) and $58.06 \%$ (subject) & $83.33 \%$ (query) and $80.65 \%$ (subject) \\
\hline $3 \mathrm{OMO}$ & $\mathrm{A}$ & 1U3Q & $\mathrm{C}$ & $100.00 \%$ & $100.00 \%$ \\
\hline $3 \mathrm{OMO}$ & $\mathrm{B}$ & $1 \mathrm{U} 3 \mathrm{R}$ & $\mathrm{B}$ & $100.00 \%$ (query) and $99.59 \%$ (subject) & $100.00 \%$ (query) and $99.59 \%$ (subject) \\
\hline $3 \mathrm{OMO}$ & $\mathrm{B}$ & $1 \mathrm{U} 3 \mathrm{~S}$ & $\mathrm{~B}$ & $100.00 \%$ & $100.00 \%$ \\
\hline $3 \mathrm{OMO}$ & $\mathrm{A}$ & 1YIM & A & $60.42 \%$ (query) and $58.47 \%$ (subject) & $83.75 \%$ (query) and $81.05 \%$ (subject) \\
\hline $3 \mathrm{OMO}$ & $\mathrm{A}$ & 1YIN & $\mathrm{A}$ & $60.42 \%$ (query) and $58.47 \%$ (subject) & $83.75 \%$ (query) and $81.05 \%$ (subject) \\
\hline $3 \mathrm{OMO}$ & $\mathrm{B}$ & 1U9E & $\mathrm{B}$ & $100.00 \%$ (query) and $99.59 \%$ (subject) & $100.00 \%$ (query) and $99.59 \%$ (subject) \\
\hline $3 \mathrm{OMO}$ & $\mathrm{A}$ & $1 \times 76$ & $\mathrm{~A}$ & $100.00 \%$ (query) and $99.59 \%$ (subject) & $100.00 \%$ (query) and $99.59 \%$ (subject) \\
\hline $3 \mathrm{OMO}$ & $\mathrm{A}$ & $1 \mathrm{X} 78$ & $\mathrm{~A}$ & $100.00 \%$ & $100.00 \%$ \\
\hline $3 \mathrm{OMO}$ & A & $1 \mathrm{X} 7 \mathrm{~J}$ & $\mathrm{~B}$ & $100.00 \%$ & $100.00 \%$ \\
\hline $3 \mathrm{OMO}$ & $\mathrm{B}$ & $1 \mathrm{X} 7 \mathrm{R}$ & A & $60.00 \%$ (query) and $58.78 \%$ (subject) & $83.33 \%$ (query) and $81.63 \%$ (subject) \\
\hline $3 \mathrm{OMO}$ & $\mathrm{B}$ & 2BJ4 & B & $55.00 \%$ (query) and $52.38 \%$ (subject) & $77.50 \%$ (query) and $73.81 \%$ (subject) \\
\hline $3 \mathrm{OMO}$ & $\mathrm{B}$ & $1 \mathrm{XQC}$ & $\mathrm{D}$ & $60.00 \%$ (query) and $56.69 \%$ (subject) & $83.33 \%$ (query) and $78.74 \%$ (subject) \\
\hline $3 \mathrm{OMO}$ & $\mathrm{A}$ & 1XP1 & $\mathrm{A}$ & $60.42 \%$ (query) and $58.47 \%$ (subject) & $83.75 \%$ (query) and $81.05 \%$ (subject) \\
\hline $3 \mathrm{OMO}$ & $\mathrm{A}$ & 1XP6 & $\mathrm{A}$ & $60.42 \%$ (query) and $58.47 \%$ (subject) & $83.75 \%$ (query) and $81.05 \%$ (subject) \\
\hline $3 \mathrm{OMO}$ & $\mathrm{A}$ & $1 \mathrm{XPC}$ & $\mathrm{A}$ & $60.42 \%$ (query) and $58.47 \%$ (subject) & $83.75 \%$ (query) and $81.05 \%$ (subject) \\
\hline $3 \mathrm{OMO}$ & $\mathrm{A}$ & $1 \mathrm{R} 5 \mathrm{~K}$ & $\mathrm{C}$ & $60.42 \%$ (query) and $55.56 \%$ (subject) & $83.75 \%$ (query) and $77.01 \%$ (subject) \\
\hline $3 \mathrm{OMO}$ & $\mathrm{B}$ & 1SJ0 & A & $60.42 \%$ (query) and $58.47 \%$ (subject) & $83.75 \%$ (query) and $81.05 \%$ (subject) \\
\hline $3 \mathrm{OMO}$ & A & 1PCG & $\mathrm{B}$ & $59.58 \%$ (query) and $58.61 \%$ (subject) & $82.92 \%$ (query) and $81.56 \%$ (subject) \\
\hline $3 \mathrm{OMO}$ & $\mathrm{A}$ & $1 \mathrm{UOM}$ & $\mathrm{A}$ & $60.00 \%$ (query) and $56.69 \%$ (subject) & $83.33 \%$ (query) and $78.74 \%$ (subject) \\
\hline $3 \mathrm{OMO}$ & $\mathrm{B}$ & $1 \mathrm{NDE}$ & $\mathrm{A}$ & $100.00 \%$ (query) and $94.12 \%$ (subject) & $100.00 \%$ (query) and $94.12 \%$ (subject) \\
\hline $3 \mathrm{OMO}$ & $\mathrm{A}$ & 1L2I & $\mathrm{A}$ & $60.42 \%$ (query) and $55.56 \%$ (subject) & $83.75 \%$ (query) and $77.01 \%$ (subject) \\
\hline $3 \mathrm{OMO}$ & $\mathrm{B}$ & $1 \mathrm{~L} 2 \mathrm{~J}$ & $\mathrm{~B}$ & $100.00 \%$ (query) and $88.56 \%$ (subject) & $100.00 \%$ (query) and $88.56 \%$ (subject) \\
\hline $3 \mathrm{OMO}$ & $\mathrm{B}$ & $1 \mathrm{G} 50$ & $\mathrm{C}$ & $60.42 \%$ (query) and $58.70 \%$ (subject) & $83.75 \%$ (query) and $81.38 \%$ (subject) \\
\hline $3 \mathrm{OMO}$ & $\mathrm{B}$ & 1QKT & A & $60.00 \%$ (query) and $58.06 \%$ (subject) & $83.33 \%$ (query) and $80.65 \%$ (subject) \\
\hline $3 \mathrm{OMO}$ & $\mathrm{A}$ & $1 \mathrm{QKU}$ & $\mathrm{C}$ & $60.42 \%$ (query) and $58.00 \%$ (subject) & $83.75 \%$ (query) and $80.40 \%$ (subject) \\
\hline $3 \mathrm{OMO}$ & $\mathrm{A}$ & $1 \mathrm{QKM}$ & $\mathrm{A}$ & $100.00 \%$ (query) and $94.12 \%$ (subject) & $100.00 \%$ (query) and $94.12 \%$ (subject) \\
\hline
\end{tabular}




\begin{tabular}{|c|c|c|c|c|c|}
\hline $3 \mathrm{OMO}$ & A & $1 \mathrm{QKN}$ & A & $92.08 \%$ (query) and $86.67 \%$ (subject) & $95.83 \%$ (query) and $90.20 \%$ (subject) \\
\hline $3 \mathrm{OMO}$ & A & 3ERD & $\mathrm{B}$ & $60.42 \%$ (query) and $55.56 \%$ (subject) & $83.75 \%$ (query) and $77.01 \%$ (subject) \\
\hline $3 \mathrm{OMO}$ & $\bar{A}$ & 3ERT & $\bar{A}$ & $60.42 \%$ (query) and $55.56 \%$ (subject) & $83.75 \%$ (query) and $77.01 \%$ (subject) \\
\hline $3 \mathrm{OMO}$ & B & $1 \mathrm{~A} 52$ & B & $60.42 \%$ (query) and $56.20 \%$ (subject) & $83.75 \%$ (query) and $77.91 \%$ (subject) \\
\hline $3 \mathrm{OMO}$ & B & 1ERE & $\mathrm{F}$ & $60.42 \%$ (query) and $57.31 \%$ (subject) & $83.75 \%$ (query) and $79.45 \%$ (subject) \\
\hline $3 \mathrm{OMO}$ & B & 1ERR & A & $60.42 \%$ (query) and $57.31 \%$ (subject) & $83.75 \%$ (query) and $79.45 \%$ (subject) \\
\hline $3 \mathrm{OMO}$ & A & $1 \mathrm{HCQ}$ & $\mathrm{E}$ & $2.08 \%$ (query) and $5.95 \%$ (subject) & $3.75 \%$ (query) and $10.71 \%$ (subject) \\
\hline 3OMP & A & 3OMQ & $\mathrm{A}$ & $100.00 \%$ & $100.00 \%$ \\
\hline 3OMP & $\mathrm{A}$ & 3LTX & $\mathrm{D}$ & $36.25 \%$ (query) and $35.80 \%$ (subject) & $58.33 \%$ (query) and $57.61 \%$ (subject) \\
\hline 3OMP & A & $3 \mathrm{~L} 03$ & $\mathrm{~B}$ & $60.00 \%$ (query) and $56.92 \%$ (subject) & $83.33 \%$ (query) and $79.05 \%$ (subject) \\
\hline 3OMP & B & 3OLL & A & $100.00 \%$ & $100.00 \%$ \\
\hline 3OMP & B & 3OLS & B & $100.00 \%$ & $100.00 \%$ \\
\hline 3OMP & A & $30 \mathrm{OS} 8$ & $\mathrm{C}$ & $60.00 \%$ (query) and $55.81 \%$ (subject) & $82.92 \%$ (query) and $77.13 \%$ (subject) \\
\hline 3OMP & A & 3059 & $\mathrm{D}$ & $60.00 \%$ (query) and $55.81 \%$ (subject) & $82.92 \%$ (query) and $77.13 \%$ (subject) \\
\hline 3OMP & $\mathrm{B}$ & $30 \mathrm{OSA}$ & $\mathrm{C}$ & $60.00 \%$ (query) and $55.81 \%$ (subject & $82.92 \%$ (query) and $77.13 \%$ (subject) \\
\hline 3OMP & $\mathrm{B}$ & $3 \mathrm{HLV}$ & A & $60.00 \%$ (query) and $56.92 \%$ (subject) & $83.33 \%$ (query) and $79.05 \%$ (subject) \\
\hline
\end{tabular}


c) Group 3

\begin{tabular}{|c|c|c|c|c|c|}
\hline Protein 1 & Chain & Protein 2 & Chain & Similarities & Identities \\
\hline 3PXF & $\mathrm{A}$ & $2 \mathrm{CCI}$ & $\mathrm{I}$ & $1.63 \%$ (query) and $16.67 \%$ (subject) & $1.96 \%$ (query) and $20.00 \%$ (subject) \\
\hline $3 \mathrm{PXF}$ & $\mathrm{A}$ & 2WEV & F & $0.65 \%$ (query) and $33.33 \%$ (subject) & $0.65 \%$ (query) and $33.33 \%$ (subject) \\
\hline $3 \mathrm{PXF}$ & $\mathrm{A}$ & 2WFY & E & $0.65 \%$ (query) and $33.33 \%$ (subject) & $0.65 \%$ (query) and $33.33 \%$ (subject) \\
\hline $3 \mathrm{PXF}$ & A & 3KF9 & A & $6.86 \%$ (query) and $14.09 \%$ (subject) & $12.42 \%$ (query) and $25.50 \%$ (subject) \\
\hline $3 \mathrm{PXF}$ & A & 2WPA & $\mathrm{B}$ & $10.78 \%$ (query) and $12.45 \%$ (subject) & $18.63 \%$ (query) and $21.51 \%$ (subject \\
\hline 3PXF & A & $2 \mathrm{WIH}$ & $\mathrm{D}$ & $10.78 \%$ (query) and $12.45 \%$ (subject) & $18.63 \%$ (query) and $21.51 \%$ (subject) \\
\hline $3 \mathrm{PXF}$ & $\mathrm{A}$ & $2 \mathrm{WIP}$ & $\mathrm{B}$ & $10.78 \%$ (query) and $12.45 \%$ (subject) & $18.63 \%$ (query) and $21.51 \%$ (subject) \\
\hline $3 \mathrm{PXF}$ & A & $2 \mathrm{WHB}$ & $\mathrm{D}$ & $10.78 \%$ (query) and $12.69 \%$ (subject) & $18.63 \%$ (query) and $21.92 \%$ (subject) \\
\hline 3PXF & $\mathrm{A}$ & 3EJ1 & $\mathrm{B}$ & $10.78 \%$ (query) and $12.69 \%$ (subject) & $18.63 \%$ (query) and $21.92 \%$ (subject) \\
\hline $3 \mathrm{PXF}$ & $\mathrm{A}$ & $3 \mathrm{~F} 5 \mathrm{X}$ & $\mathrm{B}$ & $10.78 \%$ (query) and $12.89 \%$ (subject) & $18.63 \%$ (query) and $22.27 \%$ (subject) \\
\hline $3 \mathrm{PXF}$ & $\mathrm{A}$ & $3 \mathrm{BHU}$ & $\mathrm{D}$ & $11.76 \%$ (query) and $13.74 \%$ (subject) & $18.95 \%$ (query) and $22.14 \%$ (subject) \\
\hline $3 \mathrm{PXF}$ & A & $2 \mathrm{CCH}$ & E & $1.63 \%$ (query) and $41.67 \%$ (subject) & $1.96 \%$ (query) and $50.00 \%$ (subject) \\
\hline 3PXF & A & 3PXQ & A & $100.00 \%$ & $100.00 \%$ \\
\hline $3 \mathrm{PXF}$ & $\mathrm{A}$ & $3 \mathrm{PXR}$ & $\mathrm{A}$ & $100.00 \%$ & $100.00 \%$ \\
\hline $3 \mathrm{PXF}$ & $\mathrm{A}$ & 3PXY & A & $100.00 \%$ & $100.00 \%$ \\
\hline $3 \mathrm{PXF}$ & $\mathrm{A}$ & $3 \mathrm{PXZ}$ & $\mathrm{A}$ & $100.00 \%$ & $100.00 \%$ \\
\hline $3 \mathrm{PXF}$ & $\mathrm{A}$ & $3 \mathrm{PY} 0$ & A & $100.00 \%$ & $100.00 \%$ \\
\hline $3 \mathrm{PXF}$ & $\mathrm{A}$ & 3PY1 & $\mathrm{A}$ & $100.00 \%$ & $100.00 \%$ \\
\hline $3 \mathrm{PXF}$ & $\mathrm{A}$ & $2 \mathrm{JGZ}$ & $\bar{A}$ & $94.12 \%$ (query) and $99.65 \%$ (subject) & $94.12 \%$ (query) and $99.65 \%$ (subject) \\
\hline 3PXF & A & $2 \mathrm{WXV}$ & A & $98.37 \%$ (query) and $97.41 \%$ (subject & $98.37 \%$ (query) and $97.41 \%$ (subject \\
\hline $3 \mathrm{PXF}$ & $\mathrm{A}$ & $2 \mathrm{BKZ}$ & $\mathrm{A}$ & $98.37 \%$ (query) and $97.41 \%$ (subject) & $98.37 \%$ (query) and $97.41 \%$ (subject) \\
\hline $3 \mathrm{PXF}$ & $\mathrm{A}$ & 2DS1 & A & $96.41 \%$ (query) and $98.99 \%$ (subject) & $96.73 \%$ (query) and $99.33 \%$ (subject) \\
\hline $3 \mathrm{PXF}$ & $\mathrm{A}$ & 3 MY5 & A & $97.39 \%$ (query) and $99.33 \%$ (subject) & $97.39 \%$ (query) and $99.33 \%$ (subject) \\
\hline $3 \mathrm{PXF}$ & $\mathrm{A}$ & $3 \mathrm{EZV}$ & $\mathrm{A}$ & $97.39 \%$ (query) and $99.33 \%$ (subject) & $97.39 \%$ (query) and $99.33 \%$ (subject) \\
\hline $3 \mathrm{PXF}$ & $\mathrm{A}$ & 3BHT & $\mathrm{C}$ & $97.39 \%$ (query) and $99.33 \%$ (subject) & $97.39 \%$ (query) and $99.33 \%$ (subject) \\
\hline $3 \mathrm{PXF}$ & $\mathrm{A}$ & 3BHV & $\mathrm{C}$ & $97.39 \%$ (query) and $99.33 \%$ (subject) & $97.39 \%$ (query) and $99.33 \%$ (subject) \\
\hline $3 \mathrm{PXF}$ & A & 2IW8 & $\mathrm{C}$ & $97.71 \%$ (query) and $99.01 \%$ (subject) & $97.71 \%$ (query) and $99.01 \%$ (subject) \\
\hline 3PXF & $\mathrm{A}$ & 3 IG7 & A & $97.39 \%$ (query) and $99.67 \%$ (subject) & $97.39 \%$ (query) and $99.67 \%$ (subject) \\
\hline 3PXF & $\mathrm{A}$ & 3IGG & $\mathrm{A}$ & $97.39 \%$ (query) and $99.67 \%$ (subject) & $97.39 \%$ (query) and $99.67 \%$ (subject) \\
\hline $3 \mathrm{PXF}$ & $\mathrm{A}$ & $2 \mathrm{~W} 17$ & $\mathrm{~A}$ & $97.39 \%$ (query) and $99.67 \%$ (subject) & $97.39 \%$ (query) and $99.67 \%$ (subject) \\
\hline $3 \mathrm{PXF}$ & $\mathrm{A}$ & $3 \mathrm{DOG}$ & $\mathrm{C}$ & $97.39 \%$ (query) and $99.67 \%$ (subject) & $97.39 \%$ (query) and $99.67 \%$ (subject) \\
\hline $3 \mathrm{PXF}$ & $\mathrm{A}$ & $2 \mathrm{~W} 06$ & A & $97.39 \%$ (query) and $99.67 \%$ (subject) & $97.39 \%$ (query) and $99.67 \%$ (subject) \\
\hline $3 \mathrm{PXF}$ & $\mathrm{A}$ & 2VV9 & $\mathrm{A}$ & $97.39 \%$ (query) and $99.67 \%$ (subject) & $97.39 \%$ (query) and $99.67 \%$ (subject) \\
\hline $3 \mathrm{PXF}$ & $\mathrm{A}$ & 3DDP & $\mathrm{C}$ & $97.39 \%$ (query) and $99.67 \%$ (subject) & $97.39 \%$ (query) and $99.67 \%$ (subject) \\
\hline $3 \mathrm{PXF}$ & $\mathrm{A}$ & 3DDQ & $\mathrm{A}$ & $97.39 \%$ (query) and $99.67 \%$ (subject) & $97.39 \%$ (query) and $99.67 \%$ (subject) \\
\hline $3 \mathrm{PXF}$ & $\mathrm{A}$ & $2 \mathrm{R} 3 \mathrm{~F}$ & $\mathrm{~A}$ & $97.39 \%$ (query) and $99.67 \%$ (subject) & $97.39 \%$ (query) and $99.67 \%$ (subject) \\
\hline 3PXF & $\mathrm{A}$ & 2R3G & $\mathrm{A}$ & $97.39 \%$ (query) and $99.67 \%$ (subject) & $97.39 \%$ (query) and $99.67 \%$ (subject) \\
\hline $3 \mathrm{PXF}$ & $\mathrm{A}$ & $2 \mathrm{R} 3 \mathrm{H}$ & $\mathrm{A}$ & $97.39 \%$ (query) and $99.67 \%$ (subject) & $97.39 \%$ (query) and $99.67 \%$ (subject) \\
\hline $3 \mathrm{PXF}$ & $\mathrm{A}$ & 2R3I & $\mathrm{A}$ & $97.39 \%$ (query) and $99.67 \%$ (subject) & $97.39 \%$ (query) and $99.67 \%$ (subject) \\
\hline $3 \mathrm{PXF}$ & $\mathrm{A}$ & 2R3J & $\mathrm{A}$ & $97.39 \%$ (query) and $99.67 \%$ (subject) & $97.39 \%$ (query) and $99.67 \%$ (subject) \\
\hline 3PXF & A & $2 \mathrm{R} 3 \mathrm{~K}$ & A & $97.39 \%$ (query) and $99.67 \%$ (subject) & $97.39 \%$ (query) and $99.67 \%$ (subject) \\
\hline $3 \mathrm{PXF}$ & $\mathrm{A}$ & $2 \mathrm{R} 3 \mathrm{~L}$ & $\mathrm{~A}$ & $97.39 \%$ (query) and $99.67 \%$ (subject) & $97.39 \%$ (query) and $99.67 \%$ (subject) \\
\hline $3 \mathrm{PXF}$ & $\mathrm{A}$ & 2R3M & A & $97.39 \%$ (query) and $99.67 \%$ (subject) & $97.39 \%$ (query) and $99.67 \%$ (subject) \\
\hline $3 \mathrm{PXF}$ & A & $2 \mathrm{R} 3 \mathrm{~N}$ & A & $97.39 \%$ (query) and $99.67 \%$ (subject) & $97.39 \%$ (query) and $99.67 \%$ (subject) \\
\hline 3PXF & $\mathrm{A}$ & $2 \mathrm{R} 3 \mathrm{O}$ & A & $97.39 \%$ (query) and $99.67 \%$ (subject & $97.39 \%$ (query) and $99.67 \%$ (subject) \\
\hline $3 \mathrm{PXF}$ & $\mathrm{A}$ & 2R3P & $\mathrm{A}$ & $97.39 \%$ (query) and $99.67 \%$ (subject) & $97.39 \%$ (query) and $99.67 \%$ (subject) \\
\hline 3PXF & $\mathrm{A}$ & 2R3R & $\mathrm{A}$ & $97.39 \%$ (query) and $99.67 \%$ (subject) & $97.39 \%$ (query) and $99.67 \%$ (subject) \\
\hline 3PXF & A & $1 \mathrm{~W} 8 \mathrm{C}$ & $\mathrm{C}$ & $97.39 \%$ (query) and $99.67 \%$ (subject) & $97.39 \%$ (query) and $99.67 \%$ (subject) \\
\hline $3 \mathrm{PXF}$ & A & 2G9X & $\mathrm{C}$ & $97.39 \%$ (query) and $99.67 \%$ (subject) & $97.39 \%$ (query) and $99.67 \%$ (subject) \\
\hline 3PXF & $\mathrm{A}$ & 3NS9 & $\mathrm{A}$ & $97.39 \%$ (query) and $100.00 \%$ (subject) & $97.39 \%$ (query) and $100.00 \%$ (subject) \\
\hline $3 \mathrm{PXF}$ & $\mathrm{A}$ & 3LE6 & $\mathrm{A}$ & $97.39 \%$ (query) and $100.00 \%$ (subject) & $97.39 \%$ (query) and $100.00 \%$ (subject) \\
\hline $3 \mathrm{PXF}$ & $\mathrm{A}$ & $2 \mathrm{XNB}$ & $\mathrm{A}$ & $97.39 \%$ (query) and $100.00 \%$ (subject) & $97.39 \%$ (query) and $100.00 \%$ (subject) \\
\hline $3 \mathrm{PXF}$ & $\mathrm{A}$ & 3LFN & $\mathrm{A}$ & $97.39 \%$ (query) and $100.00 \%$ (subject) & $97.39 \%$ (query) and $100.00 \%$ (subject) \\
\hline 3PXF & $\mathrm{A}$ & $3 \mathrm{LFQ}$ & A & $97.39 \%$ (query) and $100.00 \%$ (subject) & $97.39 \%$ (query) and $100.00 \%$ (subject) \\
\hline $3 \mathrm{PXF}$ & $\mathrm{A}$ & 3LFS & A & $97.39 \%$ (query) and $100.00 \%$ (subject) & $97.39 \%$ (query) and $100.00 \%$ (subject) \\
\hline $3 \mathrm{PXF}$ & $\mathrm{A}$ & $2 \mathrm{X} 1 \mathrm{~N}$ & $\mathrm{C}$ & $97.39 \%$ (query) and $100.00 \%$ (subject) & $97.39 \%$ (query) and $100.00 \%$ (subject) \\
\hline 3PXF & A & $3 \mathrm{FZ1}$ & A & $97.39 \%$ (query) and $100.00 \%$ (subject) & $97.39 \%$ (query) and $100.00 \%$ (subject) \\
\hline 3PXF & $\mathrm{A}$ & $2 \mathrm{~W} 1 \mathrm{H}$ & $\mathrm{A}$ & $97.39 \%$ (query) and $100.00 \%$ (subject) & $97.39 \%$ (query) and $100.00 \%$ (subject) \\
\hline $3 \mathrm{PXF}$ & $\mathrm{A}$ & $3 \mathrm{EOC}$ & $\mathrm{C}$ & $97.39 \%$ (query) and $100.00 \%$ (subject) & $97.39 \%$ (query) and $100.00 \%$ (subject) \\
\hline 3PXF & A & 3EID & $\mathrm{C}$ & $97.39 \%$ (query) and $100.00 \%$ (subject) & $97.39 \%$ (query) and $100.00 \%$ (subject) \\
\hline $3 \mathrm{PXF}$ & $\mathrm{A}$ & $2 \mathrm{~W} 05$ & A & $97.39 \%$ (query) and $100.00 \%$ (subject) & $97.39 \%$ (query) and $100.00 \%$ (subject) \\
\hline 3PXF & $\mathrm{A}$ & $2 \mathrm{R} 64$ & $\mathrm{~A}$ & $97.39 \%$ (query) and $100.00 \%$ (subject) & $97.39 \%$ (query) and $100.00 \%$ (subject) \\
\hline $3 \mathrm{PXF}$ & A & 2VTA & A & $97.39 \%$ (query) and $100.00 \%$ (subject) & $97.39 \%$ (query) and $100.00 \%$ (subject) \\
\hline 3PXF & A & $2 \mathrm{VTH}$ & A & $97.39 \%$ (query) and $100.00 \%$ (subject) & $97.39 \%$ (query) and $100.00 \%$ (subject) \\
\hline $3 \mathrm{PXF}$ & $\mathrm{A}$ & 2VTI & $\mathrm{A}$ & $97.39 \%$ (query) and $100.00 \%$ (subject) & $97.39 \%$ (query) and $100.00 \%$ (subject) \\
\hline $3 \mathrm{PXF}$ & A & 2VTJ & $\mathrm{A}$ & $97.39 \%$ (query) and $100.00 \%$ (subject) & $97.39 \%$ (query) and $100.00 \%$ (subject) \\
\hline $3 \mathrm{PXF}$ & $\mathrm{A}$ & $2 \mathrm{VT}$ & $\mathrm{A}$ & $97.39 \%$ (query) and $100.00 \%$ (subject) & $97.39 \%$ (query) and $100.00 \%$ (subject \\
\hline $3 \mathrm{PXF}$ & $\mathrm{A}$ & 2VTM & A & $97.39 \%$ (query) and $100.00 \%$ (subject) & $97.39 \%$ (query) and $100.00 \%$ (subject) \\
\hline 3PXF & $\mathrm{A}$ & 2 VTN & A & $97.39 \%$ (query) and $100.00 \%$ (subject) & $97.39 \%$ (query) and $100.00 \%$ (subject) \\
\hline 3PXF & A & $2 \mathrm{VTO}$ & A & $97.39 \%$ (query) and $100.00 \%$ (subject) & $97.39 \%$ (query) and $100.00 \%$ (subject) \\
\hline 3PXF & A & 2VTP & A & $97.39 \%$ (query) and $100.00 \%$ (subject) & $97.39 \%$ (query) and $100.00 \%$ (subject) \\
\hline
\end{tabular}




\begin{tabular}{|c|c|c|c|c|c|}
\hline 3PXF & A & 2VTQ & A & $97.39 \%$ (query) and $100.00 \%$ (subject) & $97.39 \%$ (query) and $100.00 \%$ (subject) \\
\hline 3PXF & $\mathrm{A}$ & $2 \mathrm{VTR}$ & $\mathrm{A}$ & $97.39 \%$ (query) and $100.00 \%$ (subject) & $97.39 \%$ (query) and $100.00 \%$ (subject) \\
\hline 3PXF & A & 2VTS & A & $97.39 \%$ (query) and $100.00 \%$ (subject) & $97.39 \%$ (query) and $100.00 \%$ (subject) \\
\hline $3 \mathrm{PXF}$ & A & 2VTT & A & $97.39 \%$ (query) and $100.00 \%$ (subject) & $97.39 \%$ (query) and $100.00 \%$ (subject) \\
\hline 3PXF & A & $2 \mathrm{VU} 3$ & A & $97.39 \%$ (query) and $100.00 \%$ (subject) & $97.39 \%$ (query) and $100.00 \%$ (subject) \\
\hline $3 \mathrm{PXF}$ & A & $2 \mathrm{~V} 22$ & $\mathrm{C}$ & $97.39 \%$ (query) and $100.00 \%$ (subject) & $97.39 \%$ (query) and $100.00 \%$ (subject) \\
\hline $3 \mathrm{PXF}$ & $\mathrm{A}$ & $2 \mathrm{~J} 9 \mathrm{M}$ & $\mathrm{A}$ & $97.39 \%$ (query) and $100.00 \%$ (subject) & $97.39 \%$ (query) and $100.00 \%$ (subject) \\
\hline $3 \mathrm{PXF}$ & A & $2 \mathrm{UZB}$ & $\mathrm{C}$ & $97.39 \%$ (query) and $100.00 \%$ (subject) & $97.39 \%$ (query) and $100.00 \%$ (subject) \\
\hline $3 \mathrm{PXF}$ & $\mathrm{A}$ & 2UZD & $\mathrm{A}$ & $97.39 \%$ (query) and $100.00 \%$ (subject) & $97.39 \%$ (query) and $100.00 \%$ (subject) \\
\hline $3 \mathrm{PXF}$ & A & 2UZE & $\mathrm{C}$ & $97.39 \%$ (query) and $100.00 \%$ (subject) & $97.39 \%$ (query) and $100.00 \%$ (subject) \\
\hline $3 \mathrm{PXF}$ & A & 2UZL & $\mathrm{C}$ & $97.39 \%$ (query) and $100.00 \%$ (subject) & $97.39 \%$ (query) and $100.00 \%$ (subject) \\
\hline $3 \mathrm{PXF}$ & A & $2 \mathrm{UZN}$ & A & $97.39 \%$ (query) and $100.00 \%$ (subject) & $97.39 \%$ (query) and $100.00 \%$ (subject) \\
\hline $3 \mathrm{PXF}$ & A & $2 \mathrm{UZO}$ & $\mathrm{A}$ & $97.39 \%$ (query) and $100.00 \%$ (subject) & $97.39 \%$ (query) and $100.00 \%$ (subject) \\
\hline $3 \mathrm{PXF}$ & A & 2UUE & A & $97.39 \%$ (query) and $100.00 \%$ (subject) & $97.39 \%$ (query) and $100.00 \%$ (subject) \\
\hline 3PXF & $\mathrm{A}$ & 2DUV & $\mathrm{A}$ & $97.39 \%$ (query) and $100.00 \%$ (subject) & $97.39 \%$ (query) and $100.00 \%$ (subject) \\
\hline $3 \mathrm{PXF}$ & A & $2 \mathrm{CLX}$ & A & $97.39 \%$ (query) and $100.00 \%$ (subject) & $97.39 \%$ (query) and $100.00 \%$ (subject) \\
\hline $3 \mathrm{PXF}$ & $\mathrm{A}$ & $2 \mathrm{FVD}$ & $\mathrm{A}$ & $97.39 \%$ (query) and $100.00 \%$ (subject) & $97.39 \%$ (query) and $100.00 \%$ (subject) \\
\hline 3PXF & $\mathrm{A}$ & $2 \mathrm{I} 40$ & $\mathrm{C}$ & $97.39 \%$ (query) and $100.00 \%$ (subject) & $97.39 \%$ (query) and $100.00 \%$ (subject) \\
\hline $3 \mathrm{PXF}$ & A & 2CJM & $\mathrm{C}$ & $97.39 \%$ (query) and $100.00 \%$ (subject) & $97.39 \%$ (query) and $100.00 \%$ (subject) \\
\hline $3 \mathrm{PXF}$ & A & $2 \mathrm{C} 5 \mathrm{~N}$ & $\mathrm{C}$ & $97.39 \%$ (query) and $100.00 \%$ (subject) & $97.39 \%$ (query) and $100.00 \%$ (subject) \\
\hline $3 \mathrm{PXF}$ & A & $2 \mathrm{C} 5 \mathrm{O}$ & A & $97.39 \%$ (query) and $100.00 \%$ (subject) & $97.39 \%$ (query) and $100.00 \%$ (subject) \\
\hline $3 \mathrm{PXF}$ & $\mathrm{A}$ & $2 \mathrm{C} 5 \mathrm{~V}$ & $\mathrm{~A}$ & $97.39 \%$ (query) and $100.00 \%$ (subject) & $97.39 \%$ (query) and $100.00 \%$ (subject) \\
\hline 3PXF & $\mathrm{A}$ & $2 \mathrm{C} 5 \mathrm{Y}$ & $\mathrm{A}$ & $97.39 \%$ (query) and $100.00 \%$ (subject) & $97.39 \%$ (query) and $100.00 \%$ (subject) \\
\hline 3PXF & $\mathrm{A}$ & $1 \mathrm{YKR}$ & $\mathrm{A}$ & $97.39 \%$ (query) and $100.00 \%$ (subject) & $97.39 \%$ (query) and $100.00 \%$ (subject) \\
\hline $3 \mathrm{PXF}$ & A & $2 \mathrm{~A} 0 \mathrm{C}$ & $\mathrm{X}$ & $97.39 \%$ (query) and $100.00 \%$ (subject) & $97.39 \%$ (query) and $100.00 \%$ (subject) \\
\hline $3 \mathrm{PXF}$ & A & 2IW6 & $\mathrm{C}$ & $98.37 \%$ (query) and $99.67 \%$ (subject) & $98.37 \%$ (query) and $99.67 \%$ (subject) \\
\hline $3 \mathrm{PXF}$ & A & 2IW9 & $\mathrm{C}$ & $98.37 \%$ (query) and $99.67 \%$ (subject) & $98.37 \%$ (query) and $99.67 \%$ (subject) \\
\hline $3 \mathrm{PXF}$ & $\mathrm{A}$ & $2 \mathrm{WMB}$ & $\mathrm{A}$ & $99.02 \%$ (query) and $100.00 \%$ (subject) & $99.02 \%$ (query) and $100.00 \%$ (subject) \\
\hline 3PXF & $\mathrm{A}$ & 2WMA & $\mathrm{A}$ & $99.02 \%$ (query) and $100.00 \%$ (subject) & $99.02 \%$ (query) and $100.00 \%$ (subject) \\
\hline
\end{tabular}




\section{References}

1. Sael, 1., Li, B., La, D., Fang, Y., \& Ramani, K. (2008). Fast protein tertiary structure retrieval based on global shape similarity. Proteins, 72, 1259-1273.

2. Gront, D., Kolinski, A., \& Hansmann, U. H. (2005). Protein Structure Prediction by Tempering Spatial Constraints. Journal of Computer-Aided Molecular Design, 19(8), 603-608.

3. Buehler, L. K., \& Rashidi, H. H. (2005). Bioinformatics basics: applications in biological science and medicine., AL: CRC Press.

4. Binkowski, T., \& Joachimiak, A. (2008). , Protein Functional Surfaces:Global Shape Matching and Local Spatial Alignments of Ligand Binding Sites. BMC Struct Biol, 8(45), 1-23.

5. Yin, S., Proctor, E. A., Lugovskoy, A. A., \& Dokholyan, N. V. (2009, August 17). Fast screening of protein surfaces using geometric invariant fingerprint. PNAS, 106(39), 1662-16626.

6. FerreÁ, F., Ausiello, G., Zanzoni, A., \& Helmer-Citterich, M. V. (2004). SURFACE: a database of protein surface regions for functional annotation. Nucleic Acids Research, 23, D240-D244.

7. Venkatraman, V., Sael, L., \& Kihara, D. (2009, June 14). Potential for Protein Surface Shape Analysis Using Spherical Harmonics and 3D Zernike Descriptors. Cell Biochem Biophys, 54, 23-32.

8. Stahl, M., Taroni, C., \& Schneider, G. (2000). Mapping of protein surface cavities and prediction of enzyme class by self-organizing neural network. Protein Engineering, 13(2), 83-88

9. Sanner, M. F. (1999). Python: A Programming Language for Software Integration and Development. J. Mol. Graphics Mod. Protein Engineering, 17, 57-61.

10. Smith, J. (2009, January 30). Computing a triangulated surface with MSMS. In Vanderbilt University Center for Structural Biology. Retrieved April 29, 2011, from http://structbio.vanderbilt.edu/comp/soft/msms/tutorial.php

11. Sanner, M. F., \& Olson, A. J. (1996). Reduced surface: An efficient way to compute molecular surfaces. Biopolymers, 38(3), 305-320.

12. Kimball, J. W. (1996). Amino Acids. In Amino Acids. Retrieved April 29, 2011, from http://users.rcn.com/jkimball.ma.ultranet/BiologyPages/A/AminoAcids.html

13. Krane, D. E., \& Raymer, M. L. (2003). Fundamental Concepts of Bioinformatics (pp. 2-13). , AL: Pearson Education.

14. Fogel, G., \& Corne, D. (2003). Evolutionary computation in Bioinformatics Elsevier., AL: Elsevier

15. Orengo, C., Jones, D., \& Thornton, J. (2003). Bioinformatics Genes, Proteins, and Computers. New York, AL: Oxford: BIOS Scientific. 
16. Gibas, C., \& Jambeck, P. (2001). Developing Bioinformatics Computer Skills. , AL: O'Reilly Media.

17. Mrabet, Y. (2001). In File:AminoAcidball.svg. Retrieved April 29, 2011, from http://en.wikipedia.org/wiki/File:AminoAcidball.svg

18. Choi, I., Kwon, J., \& Kim, S. (2004, March 16). Local Feature frequencey profile: A method to measure structural similarity in proteins. PNAS, 101(11), 3797-3802.

19. Jones, S., \& Thornton, J. M. (1997, September 12). Analysis of protein-protein interaction sites using surface patches. Journal of Molecular Biology, 272(1), 121-132.

20. Katchalski-katzirt, E., Shariv, I., Eisenstein, M., Friesem, A. A., Aflalo, C., \& Vakser, I. A. (1992, March). Molecular surface recognition: Determination of geometric fit between proteins and their ligands by correlation techniques. Biophysics, 89(1), 2195-2199.

21. Morris, R. J., Najmanovich, R. J., Kahraman, A. \& Thornton, J. M. (2005). Real spherical harmonic expansion coefficients as 3D shape descriptors for protein binding pocket and ligand comparisons. Bioinformatics 21, 2347-2355.

22. Sael, L., \& Kihara, D. (2010). Improved protein surface comparison and application to low-resolution protein structure data. BMC Bioinformatics, 11(11), 1-12.

23. Hall, M., Frank, E., Holmes, G., pfahringer, B., Reutemann, P., \& Witten, I. H. (2009). The WEKA Data Mining Software: An Update. SIGKDD Explorations, 11(1). 